
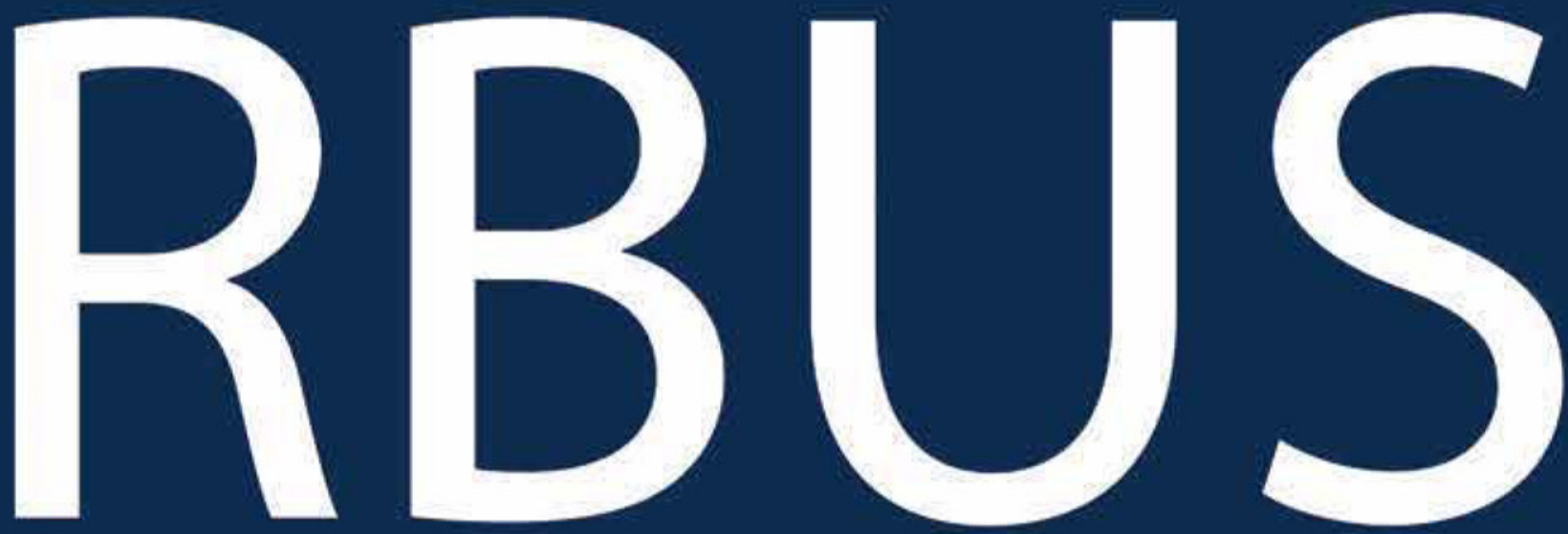

REVISTA BRASILEIRA DE ULTRASSONOGRAFIA

ISSN - 2675-4800 
》〉

ABRACE

CADA MOMENTO DA

VIDA COM LIBERDADE

E SEGURANÇA.

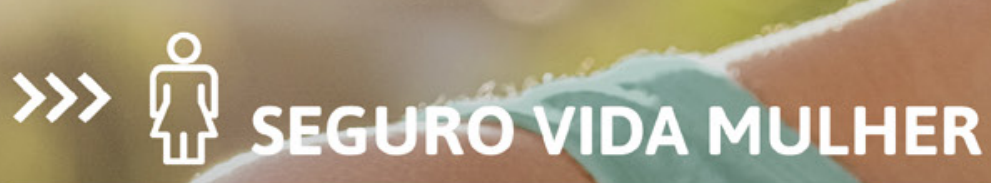

O Seguro Vida Mulher do Sicoob foi criado especialmente para proteger você e quem você ama. Além de oferecer as coberturas tradicionais por morte e invalidez, que resguardam o conforto de sua familia, o Seguro Vida Mulher do Sicoob oferece proteção financeira para você em vida, em casos de doenças graves. Confira alguns benefícios:

- Indenização em caso de invalidez permanente.

- Indenização em caso de morte natural ou acidental.

- Indenização em caso de doenças graves.

- Assistência funeral.

Central de Relacionamento:

Centro-Oeste e Norte: (62) 3221-2000

Sudeste: 08007771136

[3] 잉 sicoobunicentrobrasileira

Somos feitos de valores.

sicoob.com.br

\section{$\checkmark$ SICOOB}


Copyright (C) 2020 by: RBUS - Revista Brasileira de Ultrassonografia

Editora : DED Comunicação Ltda

CIP - Brasil - Catalogação na Fonte

Dartony Diocen T. Santos CRB-1 ( $1^{\circ}$ Região $) 3294$

R454 RBUS - Revista Brasileira de Ultrassonografia / Sociedade Brasileira de Ultrassonografia. V.28, n. 28. - Goiânia:. DED Comunicação

Ltda,2020.

52p. : il. ( Publicação semestral)

1. Revista. 2. Ultrassonografia. 3. Citologia. 4. Ginecologia.

I.Título.

CDU: 616.62(52)

Impresso no Brasil

Índice para catalogo sistemático:

Printed in Brazil - 2020

CDU: 616.62(52)

\section{DIRETORIA DA SBUS | 2018-2021}

\section{PRESIDENTE}

Rui Gilberto Ferreira

VICE PRESIDENTE

Adilson Cunha Ferreira

SECRETÁRIO GERAL

Maurício Saito

$1{ }^{\circ}$ SECRETÁRIO

Pedro Pires Ferreira Neto

TESOUREIRO GERAL

Waldemar Naves do Amaral

$1^{\circ}$ TESOUREIRO

Fernando Marum Mauad

DIRETOR CIENTÍFICO E CULTURAL

Sang Choon Cha

DIRETOR DE DEFESA PROFISSIONAL

Carlos Stéfano Holffmann Britto

DIRETOR SOCIAL E COMUNICAÇÃO

Jorge Alberto Bianchi Telles
CONSELHO FISCAL

Dra. Rejane Maria Ferlin

Dr. Washington Luiz Ferreira Rios

Dra. Maithe Vendas Galhardo

\section{SUPLENTES}

Dr. Monres José Gomes

Dr. Manoel Chaves Filho

CONSULTIVO

Dra. Lucy Kerr

Dr. Sang Choon Cha

Dr. Waldemar Naves do Amaral

\section{EDITOR-CHEFE}

Antonio Gadelha da Costa

Heverton Pettersen (MG)

Waldemar Naves do Amaral
EDITORES ADJUNTOS

Sang Choon Cha (SP)

Roberto A. D. Cardoso (SP)

CONSELHO EDITORIAL

Ademar Yamanaka

Adilson Cunha Ferreira

Antonio Gadelha da Costa

Carlos Stéfano Hoffmann Britto

Francisco Mauad Filho

Jorge Fonte de Rezende Filho

Jose Carlos Gaspar Junior

Lucy Kerr

Luiz Augusto Antonio Batista

Luiz Eduardo Machado

Marcos Faria

Marcello Viggiano

Milton Bricola Filho

Monres Jose Gomes
Patricia Spara Gadelha

Rosemeire Fernandes Garcia

Rui Gilberto Ferreira

Sebastiao Marques Zanforlin Filho

Sergio Luiz Simoes

Viviane Almeida De Alcantara Lopes

Walter Pereira Borges

CONSELHO EDITORIAL INTERNACIONAL

Kypros Nicolaides - INGLATERRA

Rodrigo Ruano - ESTADOS UNIDOS

Jader Cruz - PORTUGAL

Afonso Cohen - PORTUGAL

Nicola Volpe - ITÁLIA

Baskaran Thilaganathan - INGLATERRA

Waldo Sepulveda - CHILE

Fernando Bonilla - ESPANHA

Anna Bianchi - URUGUAY

Pran Pandya - INGLATERRA
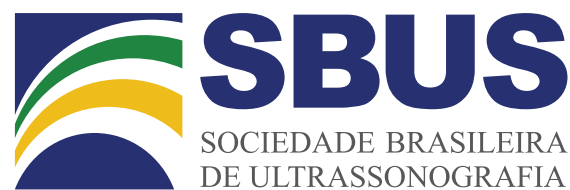

SOCIEDADE BRASILEIRA DE ULTRASSONOGRAFIA
Rua Teodoro Sampaio, 352 - Conj. 53/54

Pinheiros CEP: 05406-000 - São Paulo - SP

Fones: (11) 3081-6049 | (11) 3081-6736

Site:www.sbus.org.br |E-mail:sbus@sbus.org.br

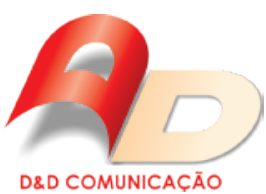

D\&D COMUNICAÇÃO

RUA 27-A No 142 - SETOR AEROPORTO

FONE: (62) 3941-7676

JORNALISTA RESPONSÁVEL:DÁRIOÁLVARES

DIAGRAMAÇÃO: LETHICIA SERRANO

TIRAGEM: 1.000 
A revista aceitará material original para publicação no campo relacionado à ultrassonografia. A revista publicará:

1. Artigos originais completos sejam prospectivos, experimentais ou retrospectivos.

2. Relatos de casos de grande interesse desde que bem documentados clínica e laboratorialmente.

3. Números especiais com anais, coletâneas de trabalhos apresentados nos congressos brasileiros patrocinados pela SBUS e suplementos com trabalhos versando sobre tema de grande interesse.

4. Artigos de revisão, inclusive meta-análises e comentários editoriais, a convite, quando solicitados a membros do conselho editorial.

\section{PROCESSAMENTO}

Todo material enviado será analisado pelo Corpo Editorial da revista composto pelo: editores da revista e do jornal, conselho editorial, editor associados, colaboradores e adjuntos; sendo vetado a identificação aos revisores dos autores ou do serviço onde os trabalhos foram desenvolvidos, assim como os revisores não serão identificados pelos autores, exceto quando solicitados por aqueles.

Ao recebimento os artigos serão datados e codificados sendo seus autores comunicados do recebimento. Os artigos que não preencherem as normas editoriais serão rejeitados neste estágio. Aqueles que estiverem de acordo serão enviados a dois revisores indicados pelo Editor. Os autores serão informados sobre a aceitação e das modificações eventualmente sugeridas pelo Corpo Editorial. Quando modificações forem solicitadas os autores deverão retornar o trabalho corrigido dentro de 15 dias, devendo justificar se alguma sugestão não for aceita.

\section{DIREITOS AUTORAIS (COPYRIGHT)}

É uma condição de publicação em que os autores transferem os direitos autorais de seus artigos a Sociedade Brasileira de Ultrassonografia (SBUS). A transferência dos direitos autorais à revista não afeta os direitos de patente ou acordos relacionado aos autores. As figuras, fotos ou tabelas de outras publicações podem ser reproduzidas, desde que autorizadas pelo proprietário. $\mathrm{O}$ material publicado passa a ser propriedade da SBUS, podendo ser reproduzido com sua anuência.

\section{ASPECTOS ÉTICOS}

O Corpo Editorial segue os princípios da Declaração de Helsinki e recomendamos que os autores dos artigos enviados obedeçam a comissão ética e preencham os requerimentos reguladores e legais para experiências em seres humanos com drogas, incluindo consentimento informado, de acordo com os procedimentos necessários em sua instituição ou país. Toda informação do paciente deve ser anônima, em particular, checar se o número de identificação e o nome da paciente foram retirados das fotos de ultrassom. Para maiores detalhes acessar o site da comissão de ética e pesquisa (http://www.datasus. gov.br/conselho/comissões/ética/conep.htm).

\section{AUTORIDADE E RESPONSABILIDADE}

O conteúdo intelectual dos trabalhos é de total responsabilidade de seus autores. O Corpo Editorial não assumirá qualquer responsabilidade sobre as opiniões ou afirmações dos autores. Todo esforço será feito pelo Corpo Editorial para evitar dados incorretos ou imprecisos. O número de autores deve ser limitado em seis.

\section{SUBMISSÃO DOS ARTIGOS}

Os autores enviarão cópias juntamente com jogos de figuras, fotos ou tabelas e manter uma cópia para referência. O texto deve identificar um autor como correspondente para onde serão enviadas as notificações da revista. Deverá conter o endereço completo, telefone e e-mail desta pessoa. Os trabalhos devem ser enviados para o e-mail sbus@sbus.org.br ou clinicaorigen@gmail.com

\section{APRESENTAÇÃO}

Os artigos devem ser digitados em espaço duplo e devem conter os seguin- tes tópicos: Título (português e inglês), resumo (português e inglês), in- trodução, métodos, resultados, discussão, agradecimentos e referências. Cada tópico deve ser iniciado em uma nova página. Os relatos de casos devem ser estruturados em: introdução, relato de caso, discussão e referências. A pri- meira página deve incluir: título, primeiro e último nome dos autores e sua filiação, títulos (não mais que 20 letras), palavras chaves (5-8) e o endereço de email. A segunda página deve conter o título do manuscrito no cabeçalho e cuidado deve ser tomado no restante do texto para que o serviço ou os autores não possa ser identificado (suprimi-los).

\section{RESUMO}

O resumo dos artigos originais deve ser dividido em seções contendo informações que permita ao leitor ter uma ideia geral do artigo, sendo divididos nos seguintes tópicos: objetivos, métodos, resultados e conclusões. Não deve exceder 250 palavras. O resumo dos relatos de casos deve ser em um único parágrafo. Uma versão em inglês do resumo e das palavras chaves deve ser fornecido.

\section{ESTILO}

As abreviaturas devem ser em letras maiúsculas e não utilizar ponto após as letras, ex: US e não U.S.. As análises estatísticas devem ser pormenorizadas no tópico referente aos métodos. $\mathrm{O}$ uso de rodapé não será permitido, exceto em tabelas. O Corpo Editorial reserva o direito de alterar os manuscritos sempre que necessário para adaptá-los ao estilo bibliográfico da revista.

\section{LITERATURA CITADA}

As referências devem ser numeradas consecutivamente à medida que aparecem no texto e depois nas figuras e tabelas se necessárias, citadas em numeral sobrescrito, ex: "Trabalho recente sobre o efeito do ultrassom ${ }^{22}$ mostra que..... Todas as referências devem ser citadas no fim do artigo seguindo as informações abaixo:

1. et al. não é usado. Todos os autores do artigo devem ser citados.

2. As abreviações dos jornais médicos devem seguir o formato do Index Meddicus.

3. Trabalhos não publicados, artigos em preparação ou comunicações pessoais não devem ser usadas como referências Quando absolutamente necessárias, somente citá-las no texto.

4. Não usar artigos de acesso difícil ou restrito aos leitores, selecionando os mais relevantes ou recentes. Nos artigos originais o número de referência deve ser limitado em 25 e os relatos de casos e cartas em 10.

5. A exatidão dos dados da referência é de responsabilidade dos autores.

As referências devem seguir o estilo Vancouver como nos exemplos abaixo:

Artigos de jornais: Cook CM, Ellwood DA. A longitudinal study of the cervix in pregnancy using transvaginal ultrasound. Br J Obstet Gynaecol 1966; 103:16-8

In press: Wyon DP. Thermal comfort during surgical operations. J Hyg Camb 20-;in press (colocar o ano atual).

Artigo em livro editado: Speroff L, Glass RH, Kase NG. In Mitchell C, ed. Clinical Gynecologic

Endocrinology and Infertility. Baltimore, USA: Williams \& Wilkins, 1994:1-967.

\section{AGRADECIMENTOS}

Dirigidos às contribuições científicas ou materiais de outros que não justificam co-autoria.

\section{ILUSTRAÇÕES}

Todas as ilustrações devem ser identificadas com o nome do autor principal e número da figura. Todas as ilustrações devem ser citadas no texto e numeradas de acordo com aparecimento, ex: figura 3. 
LEONARDO PIBER, CARLA FREITAS, THIAGO TEIXEIRA, ARTHUR BEZERRA, MAYRA FERNANDES, REGINA YOSHIASSU

ULTRASSONOGRAFIA PARA MEDIDA DA TRANSLUCÊNCIA NUCAL E O RASTREIO GENÉTICO PRÉ NATAL . .13

LORHAYNE AFONSO SIQUEIRA, TÁRIK KASSEM SAIDAH, PATRÍCIA GONÇALVES EVANGELISTA, WALDEMAR NAVES DO AMARAL

PREVALÊNCIA DE LESÕES NEUROLÓGICAS DIAGNOSTICADAS POR ULTRASSONOGRAFIA TRANSFONTANELA EM RN TERMO

LORENA CABRAL DE CASTRO LOURENZO, MIDIÃ FONSECA LIMA, SIMONE CARRIJO SANTOS, PATRÍCIA GONÇALVES EVANGELISTA

A ULTRASSONOGRAFIA NO DIAGNÓSTICO DE OBSTRUÇÃO INTESTINAL FETAL - UM RELATO DE CASO .........21

VALDIVINA ETERNA FALONE, WALDEMAR NAVES DO AMARAL FILHO, TARIK KASSEM SAIDAH, PATRÍCIA MENDONÇA LEITE, THAYNARA DE MORAES PACHECO, LORENA TASSARA QUIRINO VIEIRA, ANTÔNIO DE MORAIS JÚNIOR, WALDEMAR NAVES DO AMARAL

ASPECTO ULTRASSONOGRÁFICO DO DISPOSITIVO ANTICONCEPCIONAL FEMININO PERMANENTE ESSURE ${ }^{\circledR}$ RELATO DE CASO

LEONARDO DE SOUZA PIBER, CAIO VINÍCIUS DA FONSECA SILVA, GEORGIA DE SÁ CAVALCANTE TEIXEIRA, GABRIELA RAMOS REZENDE DEL CASTILHO, MATHEUS FLORENTINO DOS SANTOS, REBECA GUIMARÃES RIBEIRO DE ALMEIDA, MARIA TERESA NATEL DE ALMEIDA, MARIA ELENA GUIMARÃES RIBEIRO DE ALMEIDA

LINFOMA NA GRAVIDEZ COM FETO VIVO: RELATO DE CASO .28

VALDIVINA ETERNA FALONE, WALDEMAR NAVES DO AMARAL FILHO, TARIK KASSEM SAIDAH, ADRIELLY JOICE MENDES SANTANA BRANDÃO, THAYNARA DE MORAES PACHECO, LORENA TASSARA QUIRINO VIEIRA, MATHEUS FERREIRA GONÇALVES, WALDEMAR NAVES DO AMARAL

FASCIÍTE NODULAR: UM CASO SIMULANDO PATOLOGIA SUSPEITA À ULTRASSONOGRAFIA

ANA CAROLINA SILVA, LUIZA CAIXETA, GABRIEL TOFANI, LAIO RASPANTE, ELIZABETH DE AYUB, LETICIA AZEREDO, LEONARDO PEREIRA,

CARLOS HENRIQUE SILVA

DIAGNÓSTICO PRENATAL DE ESQUIZENCEFALIA COM EVOLUÇÃO PROGRESSIVA UNILATERAL PARA BILATE-

RAL - RELATO DE CASO

RENATO MURTA, MARCOS FARIA, LUCCA PENNA FARIA, BRUNO PENNA FARIA, HEVERTON PETTERSEN

SINOVITE VILONODULAR PIGMENTADA: RELATO DE CASO

JORGE GARCIA, ANA CLAUDIA PEREIRA LIMA, PROCÓPIO DE FREITAS, AUGUSTO CESAR SAAB BENEDETI, FERNANDO MARUM MAUAD,

FRANCISCO MAUAD FILHO

ULTRASSONOGRAFIA COM DOPPLER NA AVALIAÇÃO DO REFLUXO GASTRESOFÁGICO .

THALITA BARBOSA DUTRA DE MIRANDA, ARIELA MAULLER VIEIRA PARENTE, LARISSA BARBOSA DUTRA DE MIRANDA, MÔNICA SILVA CARNEIRO,

AVELINO PEIXOTO NETO, HAYTHAM LOAIY IBRAHIM KARAJAH, WALDEMAR NAVES DO AMARAL

LEONARDO DE SOUZA PIBER, MARCELO IVANDER ANDRADE WANDERLEY1, CARLA MICAELE DE FREITAS, ARTHUR SOUSA BEZERRA,

RONALDO SOUZA PIBER 


\section{INCERTEZAS E BOM-SENSO}

Vivemos, inquestionavelmente, um momento de incertezas, insegurança e ansiedade com a pandemia de Covid-19, declarada pela Organização Mundial de Saúde (OMS) no dia 11 de março de 2020. Mais uma vez a ciência assume o centro dos debates e atenções mundiais na busca da tão almejada cura desse mal que não escolhe raça, nacionalidade, sexo ou classe social. O momento é de alerta, bom-senso e observância de todas as normas preventivas preconizadas pela OMS.

Incentivo à pesquisa e à produção científica é um dos pilares principais da SBUS, uma entidade conceituada que desempenha importante papel no universo médico nacional. Nesse cenário, a Revista de Brasileira de Ultrassonografia - RBUS, tradicionalmente conhecida como Revista Azul, desempenha papel fundamental, se configurando como extraordinária ferramenta de divulgação da pesquisa científica em USG, compartilhando experiências e conhecimento por meio de artigos relevantes e inéditos.

Para ampliar a abrangência da nossa publicação científica, a partir desta edição disponibilizaremos também versões digitais em inglês e espanhol. Outra ótima novidade: cada artigo agora conta com QR Code, tornando os downloads ainda mais ágeis e descomplicados.

Participe você também destas páginas que ajudam a valorizar ainda mais a Ultrassonografia brasileira.

\author{
ANTONIO GADELHA DA COSTA \\ HEVERTON PETTERSEN \\ WALDEMAR NAVES DO AMARAL \\ EDITOR-CHEFE
}

\author{
RUI GILBERTO FERREIRA \\ PRESIDENTE DA SBUS
}




\title{
AVALIAÇÃO ULTRASSONOGRÁFICA E CITOLÓGICA DE 499 NÓDULOS TIREOIDIANOS
}

\author{
ULTRASONOGRAPHIC AND CYTOLOGICAL EVALUATION OF 499 \\ THYROID NODULES
}

\author{
LEONARDO PIBER ${ }^{1,2}$, CARLA FREITAS ${ }^{2}$, THIAGO TEIXEIRA ${ }^{2}$, ARTHUR BEZERRA ${ }^{2}$, MAYRA FERNANDES ${ }^{2}$, \\ REGINA YOSHIASSU ${ }^{2}$
}

\section{RESUMO}

OBJETIVOS: Verificar os achados ultrassonográficos e citológicos em punções aspirativas por agulha fina (PAAF) de tireoide.

MÉTODOS: Estudo retrospectivo transversal em que foram avaliados 499 nódulos tireoidianos por meio de ultrassonografia e exame citológico no período de outubro de 2018 a agosto de 2019 em pacientes de ambos os sexos, em Centro de Diagnóstico privado na cidade de São Paulo. RESULTADOS: Dos 499 nódulos puncionados em 334 pacientes, 44 (8,8\%) pertenciam ao sexo masculino e 455 (91,2\%) ao sexo feminino. Do total de pacientes, 31 (9,3\%) eram homens e 303 (90,7\%) eram mulheres, com idades entre 13 e 88 anos. Foram obtidas três amostras hemorrágicas $(0,6 \%)$, cujos nódulos foram repuncionados. A prevalência de malignidade foi de 4,8\% e a frequência de nódulos benignos foi de $92,4 \%$.

CONCLUSÃO: As análises evidenciam que o perfil ultrassonográfico e citológico dos nódulos tireoidianos está de acordo com a literatura atual, o que pode auxiliar na auditoria dos resultados nos centros de diagnóstico por imagem.

\section{PALAVRAS-CHAVE: DOENÇAS DA GLÂNDULA TIREOIDE, GLÂNDULA TIREOIDE, NEOPLASIAS, NÓDULO, BIÓPSIA GUIADA POR IMAGEM, ULTRASSONOGRAFIA, ULTRASSONOGRAFIA DE INTERVENÇÃO.}

\begin{abstract}
OBJECTIVE: The goal of the study is to verify ultrasound and cytological findings in thyroid fine needle aspiration (FNA) punctures.

METHODS: Retrospective cross-sectional study in which 499 thyroid nodules were evaluated by ultrasound and cytological examination in a period from October 2018 to August 2019. FNA was performed in patients of both sexes, in a private diagnostic center in São Paulo.

RESULTS: Out of the 499 nodules punctured in 334 patients, 44 (8.8\%) were male and 455 (91.2\%) female. In considering the total amount of patients, 31 (9.3\%) were men and 303 (90.7\%) women, aged between 13 and 88. Three (0.6\%) hemorrhagic samples were obtained; therefore punctures were performed again in such patients. The malignancy prevalence was $4.8 \%$ and the frequency of benign nodules in this was $92.4 \%$. CONCLUSION: The analyses show that the ultrasound and cytological profile of the thyroid nodules are in accordance with the current literature, which can assist in the audit of the results in the diagnostic imaging centers.
\end{abstract}

\section{KEYWORDS: THYROID DISEASES, THYROID GLAND, NEOPLASMS, NODULE, IMAGE-GUIDED BIOPSY, ULTRASONOGRAPHY, ULTRASONOGRAPHY INTERVENTIONAL.}

\section{INTRODUÇÃO}

A tireoide é uma glândula de pequeno porte, que se encontra na região cervical infra-hióidea.1 O controle da glândula tireoide é feito pelo hormônio estimulante da tireoide (TSH), que promove uma sinalização e por meio desta são produzidos reguladores de grande importância para o men- to e desenvolvimento do metabolismo. ${ }^{2}$

Dentre as doenças que acometem a tireoide, os nódulos tireoidianos são frequentes, com uma prevalência de 4 a $7 \%$ na população adulta, se o diagnóstico é feito através do exame físico; e de 17 a 67\% nos casos de investigação por meio do ultrassom (US).3,4 A alta sensibilidade do US, o

\footnotetext{
1. Universidade Santo Amaro

2. CDB Inteligência Diagnóstica
}

Endereço para correspondência:

Leonardo Piber

Rua Marechal Deodoro, 135 apt. 62B - Santo Amaro

São Paulo - CEP 04738-000

Email: lpiber@prof.unisa.br 
torna uma excelente forma de rastreamento.

As características ultrassonográficas predizem maior ou menor probabilidade de nódulos benignos ou malignos. $3 \mathrm{O}$ Thyroid Imaging Reporting and Data System publicado pelo American College of Radiology (ACR TI-RADS) é um sistema de categorização dos achados da ultrassonografia (USG) dos nódulos da tireoide5, que correlaciona esses achados com a possível classificação citológica, caracterizando o potencial de malignidade do nódulo de acordo com as características encontradas. O US deve ser realizado no modo B, para diminuir variações entre os observadores. Os nódulos são, então, classificados cinco categorias, sendo a última a de maior risco de malignidade, ou seja, possui um padrão crescente de gravidade6 - (ver figuras 1-10).

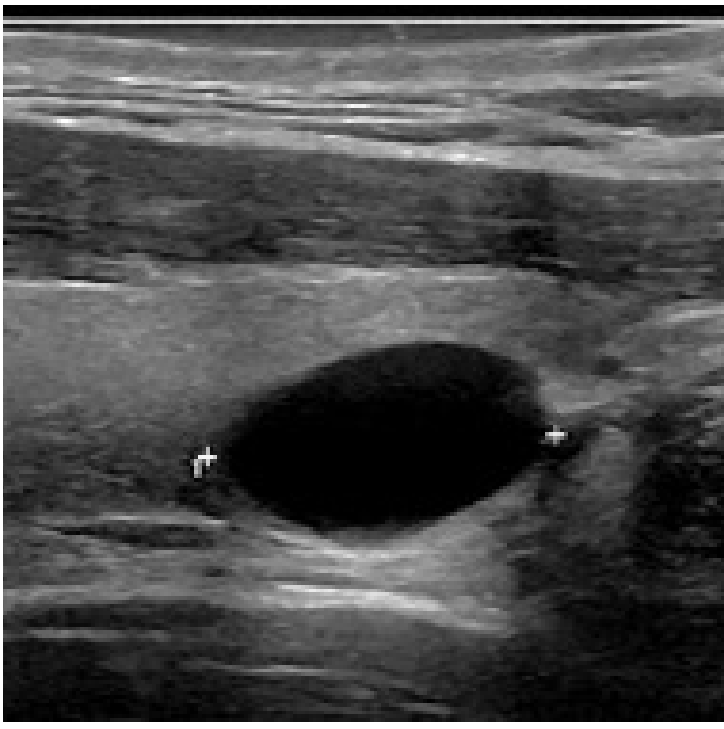

Figura 1 - Descrição: nódulo anecóico, cístico, bem delimitado, sem microcalcificações, medindo 1,5cm. ACR-TIRADS 1. Citologia: Cisto coloide. Bethesda I.

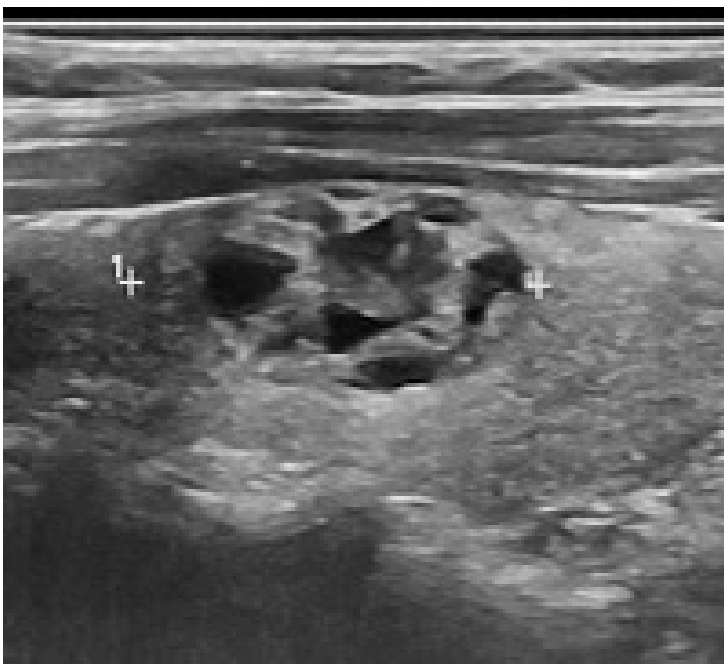

Figura 2 - Descrição: nódulo isoecogênico, misto, bem definido, paralelo à pele, sem microcalcificações, medindo 2,2cm. ACR-TIRADS 2. Citologia: Nódulo coloide, Bethesda II.

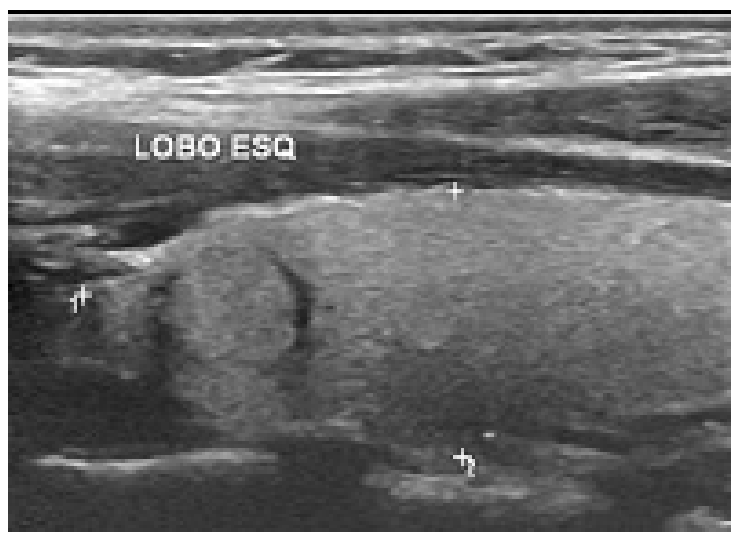

Figura 3 - Descrição: nódulo isoecogênico, sólido, bem definido, paralelo à pele, sem microcalcificações, medindo $0,8 \mathrm{~cm}$. ACR-TIRADS 3. Citologia: Lesão folicular de significado indeterminado, Bethesda III.

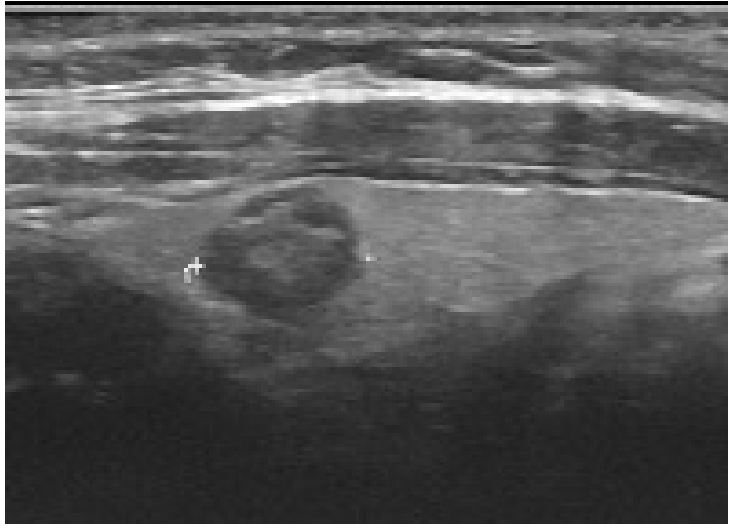

Figura 4 - Descrição: nódulo hipoecogênico, predominantemente sólido, bem definido, regular, paralelo à pele, sem microcalcificações, medindo $0,8 \mathrm{~cm}$. ACR-TIRADS 3. Citologia: Nódulo coloide, Bethesda II.

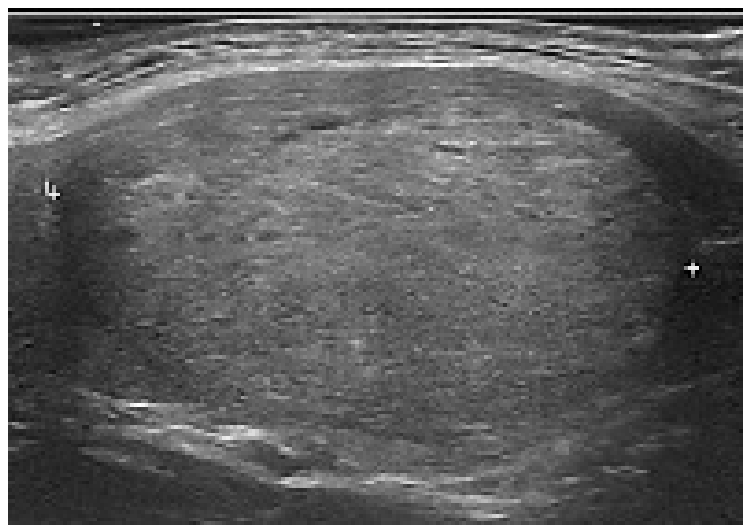

Figura 5 - Descrição: nódulo hipoecogênico, quase totalmente sólido, bem definido, regular, paralelo à pele, sem microcalcificações, medindo 4,1cm. ACR- TIRADS 4. Citologia: Nódulo coloide, Bethesda II. 


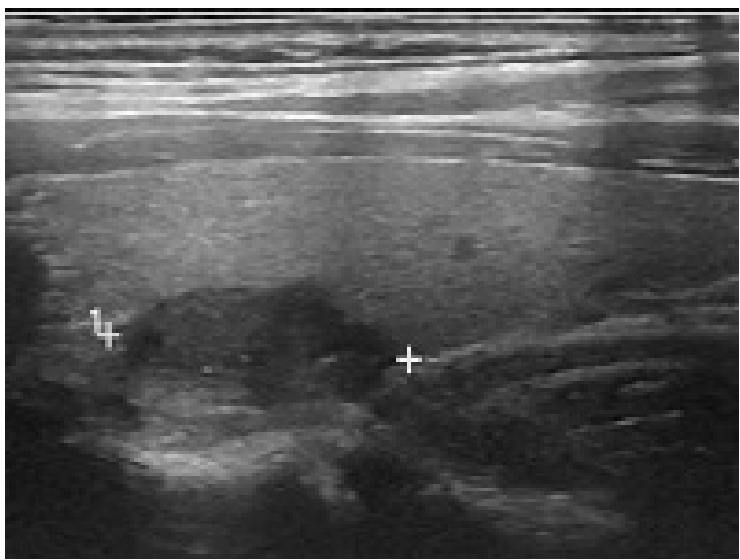

Figura 6 - Descrição: nódulo hipoecogênico, sólido, bem definido, irregular, paralelo à pele, sem microcal- cificações, medindo $1,6 \mathrm{~cm}$. ACR- TIRADS 4. Citologia: Nódulo coloide, Bethesda II.

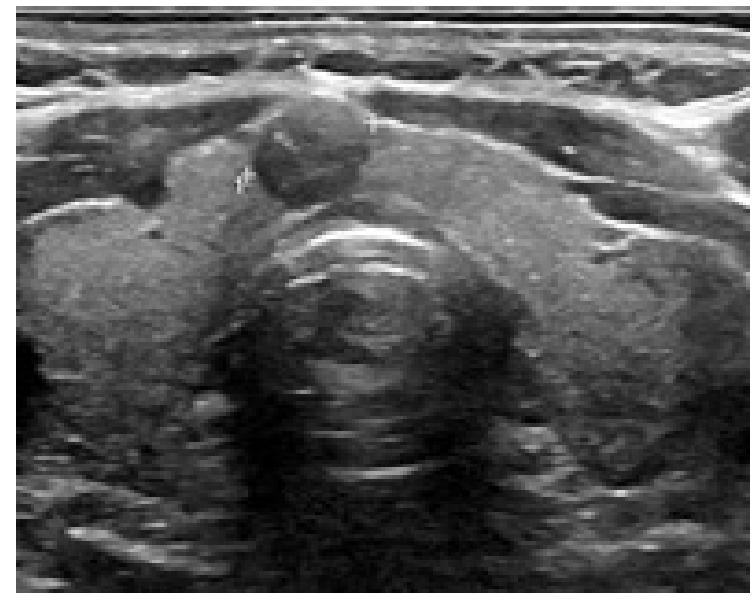

Figura 7 - Descrição: nódulo hipoecogênico, sólido, bem definido, irregular, paralelo à pele, sem microcalcificações, medindo 0,7cm, em região do istmo. ACR- TIRADS 4. Citologia: Carcinoma papilifero, Bethesda V.

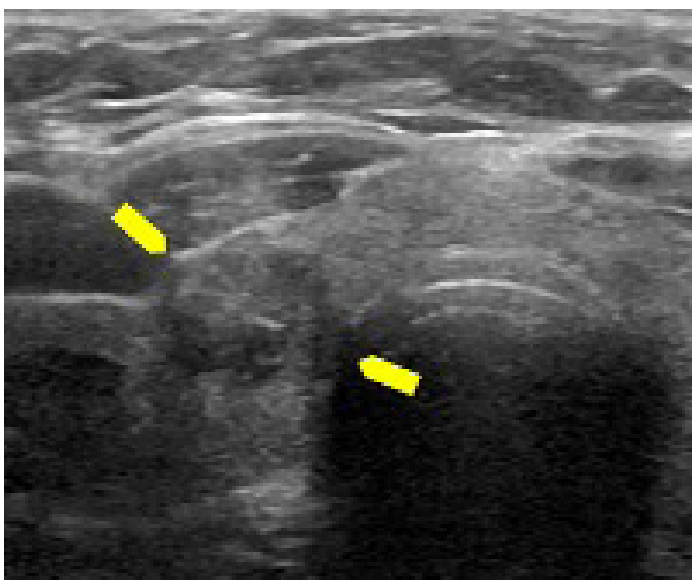

Figura 8 - Descrição: nódulo hipoecogênico, sólido, bem definido, irregular, paralelo à pele, sem microcalcificações, medindo $1,2 \mathrm{~cm}$ (setas amarelas). ACRTIRADS 4. Citologia: Carcinoma papilífero, Bethesda V.

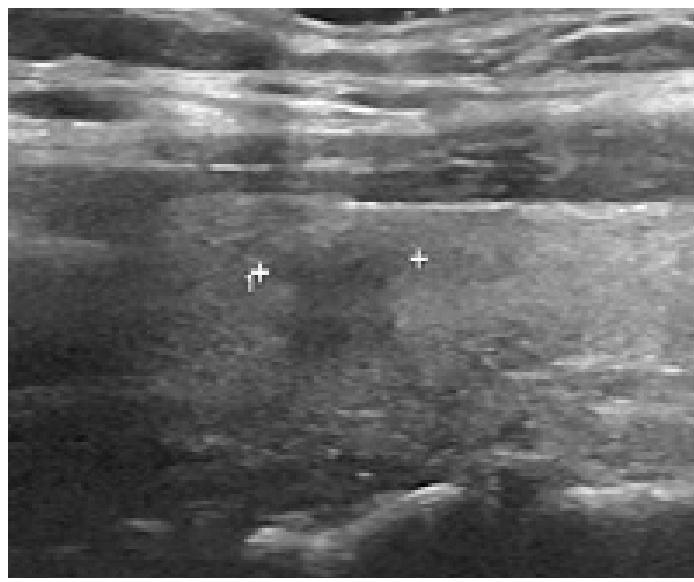

Figura 9 - Descrição: nódulo hipoecogênico, sólido, com limites imprecisos, irregular, paralelo à pele, sem microcalcificações, medindo $0,7 \mathrm{~cm}$. ACR- TIRADS 4 . Citologia: Tireoidite linfocítica, Bethesda II.

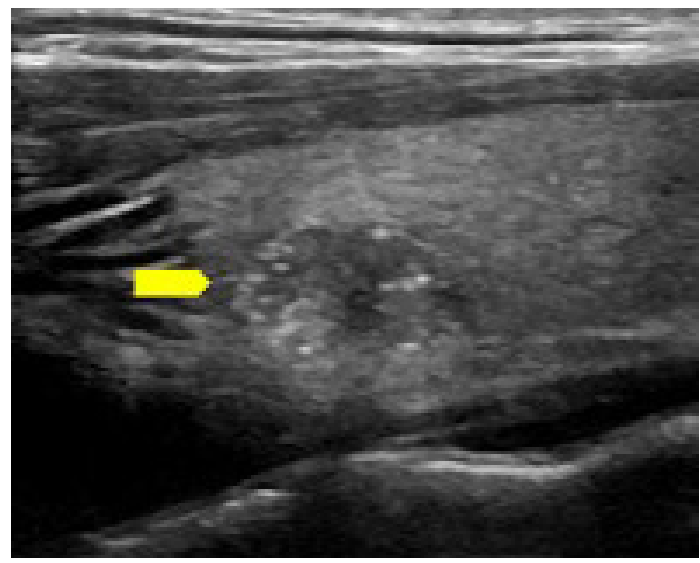

Figura 10 - Descrição: nódulo hipoecogênico, sólido, bem delimitado, com microcalcificações, medindo $1,2 \mathrm{~cm}$ (seta amarela). ACR-TIRADS 5. Citologia: Carci- noma papilífero, Bethesda V.

A classificação de ACR TI-RADS varia de 1 (benigno) a 5 (alta suspeita de malignidade), a partir do TI-RADS 3, a depender do tamanho apresentado pelo nódulo indica-se a punção aspirativa por agulha fina (PAAF) ou o seguimento clínico. Por exemplo, a PAAF é indicada para nódulos maiores ou igual a um centímetro e TI-RADS 5, caso o nódulo seja TIRADS 3 (baixo risco de malignidade) a biópsia é indi- cada se o nódulo apresentar $2,5 \mathrm{~cm}$ ou mais. Isto foi propos- to para evitar procedimentos invasivos, como a biópsia, de forma indiscriminada.?

As características sugestivas de malignidade vistas à ultrassonografia, modo B, são composição nodular sólida maior que $50 \%$, formato irregular, mais alto que largo, microcalcificações, porção excêntrica sólida, alteração na ecogenicidade como hipoecogenicidade acentuada, nódulos sólidos. ${ }^{6,8,9}$

A punção é feita com agulha transdérmica inserida em 
região específica e se associada à USG, é possível visualizar em tempo real o posicionamento da agulha e coletar material de nódulos caracterizados potencialmente como malignos. ${ }^{10}$

O material coletado passa por análise citopatológica, e assim, classificado de acordo com o sistema Bethesda, que é dividido em seis categorias: amostra não diagnóstica (I), benigno (II), atipias/lesão folicular de significado indetermi- nado (III), suspeito para neoplasia folicular ou neoplasia folicular (IV), suspeito para malignidade (V) e maligno (VI)3. Este auxilia na comunicação entre os citopatologistas, dimi- nui procedimentos desnecessários e facilita troca de dados entre laboratórios e instituições. ${ }^{11}$

O principal interesse da biópsia aspirativa está centrado no seu potencial de distinguir nódulos de natureza benigna daqueles que requerem intervenção cirúrgica. A acurácia da PAAF em identificar os nódulos de natureza benigna leva a uma redução no número das intervenções cirúrgicas desnecessárias.

\section{MÉTODOS}

Trata-se de estudo transversal, de seleção completa, com amostragem por conveniência. A população-alvo foi todos os pacientes que agendaram punção aspirativa por agulha fina (PAAF) de tireoide guiada por ultrassonografia para investigação de patologia tireoidiana em centro de diagnóstico por imagem privado, na cidade de São Paulo, de ambos os gêneros, conforme solicitação de seu médico assistente, entre Outubro de 2018 a Agosto de 2019.

Foram excluídos do estudo aqueles que não aceitaram participar ou serem examinados, e aqueles que não assinaram o termo de consentimento livre esclarecido.

Os dados foram extraídos do formulário de solicitação de análise citopatológica padrão do serviço. As variáveis analisadas foram: idade, gênero, características dos nódu- los, tais como, composição, ecogenicidade, forma, margem, presença de calcificação, tamanho, localização, classificação ACR- TIRADS, resultado da citopatologia e classificação de Bethesda.

Os exames ultrassonográficos foram realizados em decúbito dorsal horizontal, com hiperextensão cervical para facilitar o acesso à glândula, com varreduras longitudinais e transversais, com aparelho modelo Logiq 7 da marca General Electric Company (GE).

O procedimento envolveu três etapas: coleta, preparação do material e análise microscópica e interpretação do esfregaço, pelo serviço de citologia.

Esta pesquisa foi aprovada pelo Comitê de Ética e Pes- quisa da Universidade Santo Amaro, cujo número de apro- vação é CAAE 97937018.1.0000.0081.

\section{RESULTADOS}

Dos 499 nódulos puncionados em 334 pacientes (índice de 1,5 nódulos por paciente), sendo $44(8,8 \%)$ nódulos em homens e $455(91,2 \%)$ em mulheres. Do total de pacientes, $31(9,3 \%)$ eram homens e $303(90,7 \%)$ eram mulheres, com idades entre 13 e 88 anos. Foram obtidas três amostras hemorrágicas $(0,6 \%)$, cujos nódulos foram repuncionados. A tabela 1 mostra a quantidade de nódulos puncionados por pacientes. A maioria dos pacientes $(67,0 \%)$ teve um nódulo puncionado.

\begin{tabular}{lll}
\hline número de nódulos & $\begin{array}{l}\text { quantidade de nódulos } \\
\text { puncionados por paciente }\end{array}$ & quantidade de nódulos total \\
\hline 1 & 224 & 224 \\
2 & 76 & 152 \\
3 & 24 & 72 \\
4 & 4 & 16 \\
5 & 3 & 15 \\
6 & 2 & 12 \\
7 & 0 & 0 \\
8 & 1 & 8 \\
\hline Total & 334 & 499 \\
\hline
\end{tabular}

Tabela 1 - Distribuição da quantidade de nódulos tireoidianos, por paciente, puncionados entre Outubro de 2018 e Agosto de 2019. São Paulo, 2020.

A tabela 2 mostra os diversos resultados da análise citopatológica dos nódulos tireoidianos. Destes, 4,8\% foram carcinoma papilífero.

\begin{tabular}{lcc} 
Citopatologia dos nódulos tireoidianos & N & $\%$ \\
\hline Nódulo colóide & 395 & 79,2 \\
Tireoidite linfocitica & 59 & 11,8 \\
Carcinoma papilifero & 24 & 4,8 \\
Atipias de significado indeterminado & 12 & 2,4 \\
Cisto colóide & 6 & 1,2 \\
Neoplasia folicular do tipo células de Hurthle & & \\
Nódulo adenomatoso & 2 & 0,4 \\
\hline Total & 1 & 0,2 \\
\hline
\end{tabular}

Table 2 - Distribution, according to the cytopathological diagnosis, of the punctured thyroid nodules between October 2018 and August 2019. São Paulo, 2020.

Para a comparação das variáveis, optou-se por seguir com dois grupos, nódulos cujo diagnóstico foi carcinoma papilífero e nódulo colóide. Os demais diagnóstico não apresentaram número absoluto suficiente para esta comparação bioestatística descritiva.

A tabela 3 apresenta as variáveis estudadas, destacando- 
-se as características dos nódulos baseadas no ACR-TIRADS. A classificação Bethesda está diretamente relacionada ao diagnóstico citopatológico.

\begin{tabular}{|c|c|c|c|c|}
\hline \multirow{2}{*}{ Variáveis analisadas } & \multicolumn{2}{|c|}{$\begin{array}{l}\text { carcinoma papilifero } \\
(\mathrm{N}=24)\end{array}$} & $\begin{array}{l}\text { nódulo } \\
(\mathrm{N}=395)\end{array}$ & colóide \\
\hline & $\mathrm{N}$ & $\%$ & $\mathrm{~N}$ & $\%$ \\
\hline \multicolumn{5}{|l|}{ gênero } \\
\hline feminino & 20 & 83,3 & 358 & 90,6 \\
\hline masculino & 4 & 16,7 & 37 & 9,4 \\
\hline \multicolumn{5}{|l|}{ idade (anos) } \\
\hline mediana & 42,5 & & 48 & \\
\hline intervalo & 18 a 59 & & 17 a 88 & \\
\hline \multicolumn{5}{|l|}{ composição } \\
\hline sólido ou quase completamente sólido & 18 & 75,0 & 163 & 41,3 \\
\hline misto & 6 & 25,0 & 205 & 51,9 \\
\hline cistico ou quase completamente cistico & 0 & 0,0 & 27 & 6,8 \\
\hline
\end{tabular}

$\begin{array}{lcccc}\text { ecogenicidade } & & & & \\ \text { hipoecóico } & 23 & 95,8 & 252 & 63,8 \\ \text { isoecóico } & 1 & 4,2 & 134 & 33,9 \\ \text { hiperecóico } & 0 & 0,0 & 6 & 1,5 \\ \text { anecóico } & 0 & 0,0 & 3 & 0,8\end{array}$

forma

\begin{tabular}{|c|c|c|c|c|}
\hline mais alto do que largo & 2 & 8,3 & 5 & 1,3 \\
\hline mais largo do que alto & 22 & 91,7 & 390 & 98,7 \\
\hline \multicolumn{5}{|l|}{ margem } \\
\hline regular & 17 & 70,8 & 368 & 93,2 \\
\hline lobulado & 2 & 8,4 & 20 & 5,1 \\
\hline irregular & 5 & 20,8 & 7 & 1,7 \\
\hline
\end{tabular}

calcificação

$\begin{array}{lcccc}\text { ausência } & 8 & 33,3 & 351 & 88,9 \\ \text { macrocalcificação } & 9 & 37,5 & 29 & 7,3 \\ \text { periférica } & 0 & 0,0 & 4 & 1,0 \\ \text { microcaleificação } & 7 & 29,2 & 11 & 2,8\end{array}$

localização

$\begin{array}{lllll}\text { istmo } & 2 & 8,3 & 28 & 7,1 \\ \text { lobo direito } & 10 & 41,7 & 217 & 54,9\end{array}$

\begin{tabular}{|c|c|c|c|c|}
\hline lobo esquerdo & 12 & 50,0 & 150 & 38,0 \\
\hline \multirow{3}{*}{ Variáveis analisadas } & carcinoma & papilifero & nódulo & colóide \\
\hline & $(\mathrm{N}=24)$ & & $(\mathrm{N}=395)$ & \\
\hline & $\mathrm{N}$ & $\%$ & $\mathrm{~N}$ & $\%$ \\
\hline \multicolumn{5}{|l|}{ gênero } \\
\hline feminino & 20 & 83,3 & 358 & 90,6 \\
\hline masculino & 4 & 16,7 & 37 & 9,4 \\
\hline \multicolumn{5}{|l|}{ idade (anos) } \\
\hline mediana & 42,5 & & 48 & \\
\hline intervalo & 18 a 59 & & 17 a 88 & \\
\hline \multicolumn{5}{|l|}{ composição } \\
\hline sólido ou quase completamente sólido & 18 & 75,0 & 163 & 41,3 \\
\hline misto & 6 & 25,0 & 205 & 51,9 \\
\hline cístico ou quase completamente cistico & 0 & 0,0 & 27 & 6,8 \\
\hline \multicolumn{5}{|l|}{ ecogenicidade } \\
\hline hipoecóico & 23 & 95,8 & 252 & 63,8 \\
\hline isoecóico & 1 & 4,2 & 134 & 33,9 \\
\hline hiperecóico & 0 & 0,0 & 6 & 1,5 \\
\hline anecóico & 0 & 0,0 & 3 & 0,8 \\
\hline \multicolumn{5}{|l|}{ forma } \\
\hline mais alto do que largo & 2 & 8,3 & 5 & 1,3 \\
\hline mais largo do que alto & 22 & 91,7 & 390 & 98,7 \\
\hline
\end{tabular}

Tabela 3 - Comparação das características dos nódulos tireoidianos puncionados, com diagnóstico de carcinoma papilífero e nódulo coloide, entre Outubro de 2018 e Agosto de 2019. São Paulo, 2020.

\section{DISCUSSÃO}

A incidência do câncer tireoidiano aumentou nas últimas décadas, visto o avanço dos métodos diagnósticos em detectar aspectos sugestivos de malignidade em nódulos tireoidianos não palpáveis. ${ }^{4,9}$ A caracterização do nódulo segundo o aspecto da ultrassonografia é classificado segundo o ACR-TIRADS, o que permite uma melhor compreensão e comunicação entre os profissionais da saúde. ${ }^{5}$

Nódulos da tireoide são encontrados em 19\% a 67\% das pessoas adultas, isto por meio do ultrassom, dos quais cerca de $10 \%$ são malignos. ${ }^{4,9}$ Neste estudo a taxa de malignidade foi de 4,8\%, estando de acordo com a literatura existente. Já a frequência de nódulos benignos neste estudo foi de $92,4 \%$, prevalência maior se comparada com o descrito por outros autores, cujo valor se encontra entre 69 e $81 \% .^{12}$ 
Há determinadas situações como celularidade insuficiente para análise e amostras hemorrágicas, no qual não é possível realizar o diagnóstico. No presente estudo o total de amostras hemorrágicas foi de $0,6 \%$; sendo o percentual esperado de amostras hemorrágicas de 1 e $15 \% .^{12}$

De todas as neoplasias endócrinas, 96\% são represen- tadas pelo câncer de tireoide, o qual é mais comum em indivíduos do sexo feminino. ${ }^{4} \mathrm{O}$ que também foi visualizado neste estudo, no qual 20 dos 24 nódulos $(83,3 \%$ ) caracterizados como carcinoma papilífero pertenciam a pacientes do sexo feminino, enquanto que apenas quatro eram do sexo masculino $(16,7 \%)$.

Este estudo, assim como os supracitados possui uma quantidade maior de indivíduos do sexo feminino com nódulos tireoidianos, sendo a proporção entre homens e mulheres, de aproximadamente, 1:10. Em um estudo semelhante a proporção de homens e mulheres era de 1:11.13 Quando se caracteriza o perfil citológico em carcinoma pa pilífero desse estudo, a proporção passa a ser de 1:5 entre homens e mulheres.

No presente estudo apenas $31(9,3 \%)$ dos pacientes eram do sexo masculino e $303(90,7 \%)$ eram do sexo feminino. Os valores encontrados são semelhantes a outros estudos, como esse, realizados em São Paulo, assim como em outros estados. Por exemplo, o trabalho de Ceratti12, realizado em São Paulo, trouxe uma porcentagem de 9,6\% de homens e $90,4 \%$ de mulheres, da mesma forma o estudo feito em Aracajú-SE revelou que apenas 5,2\% dos pacientes eram homens enquanto $94,8 \%$ correspondia a pacientes do sexo feminino. ${ }^{14}$

Dentre as características ecográficas mais prevalentes ao diagnóstico de carcinoma papilífero, pode-se destacar a hipoecogenicidade, consistência sólida, margem irregular, e presença de micro e macrocalcificações, como prevê a Classificação ACR-TIRADS.

As análises evidenciam que o perfil ultrassonográfico e citológico dos nódulos tireoidianos está de acordo com a literatura atual, o que pode auxiliar na auditoria dos resultados nos centros de diagnóstico por imagem.

\section{AGRADECIMENTOS}

Agradecimento à Dras. Maria Teresa Natel de Almeida, Maria Antonieta Longo Galvão e Danielle Chacon.

\section{REFERÊNCIAS}

1. Toneto MG, Prill S, Debon LM, Furlan FZ, Steffen N. The history of the parathyroid surgery. Revista do Colégio Brasileiro de Cirurgiões, 2016; 43(3), 214-22.

2. Lof C, Patyra K, Kero A, Kero J. Genetically modified mouse models to investigate thyroid development, function and growth. est Practice \& Research Clinical Endocrinology \& Metabolism. 2018.

3. de Souza Neta AM, de Andrade CIS, Cabral BAF, Cruz JF. Estudos dos nódulos tireoidianos submetidos à punção aspirativa por agulha fina em Aracaju-SE. 18a Semana de Pesquisa da Universidade Tiradentes. "A prática interdisciplinar alimentado a Ciência". 24 a 28 de outubro de 2016.

4. Baldini E, Sorrenti S, Tartaglia F et al. New perspectives in the diagnosis of thyroid follicular lesions. International Journal of Surgery, 2017; 41:
S7-S12

5. Migda B, Migda M, Migda MS, Slapa RZ. Use of the Kwak Thyroid Image Reporting and Data System (K-TIRADS) in differential diagnosis of thyroid nodules: systematic review and meta-analysis. European Radiology 2018; 28(6): 2380-8.

6. Rahal Junior A, Falsarella PM, Rocha RD et al. Correlação entre a classificação Thyroid Imaging Reporting and Data System [TI-RADS] e punção aspirativa por agulha fina: experiência com 1.000 nódulos. Einstein 2016; 14: 2 .

7. Tessler FN, Middleton WD, Grant EG et al. ACR Thyroid Imaging, Reporting and Data System (TI-RADS): White Paper of the ACR TI-RADS Committee. Journal of the American College of Radiology, 2017; 14(5).

8. Li W, Zhu Q, Jiang Y, Zhang Q, Meng Z, Sun J, Dai Q. Partially cystic thyroid nodules in ultrasound-guided fine needle aspiration: Prevalence of thyroid carcinoma and ultrasound features. Medicine 2017; 96 (46)

9. Rosário PW, Ward LS, Carvalho GA, Graf H, Maciel RMB, Maciel LMZ, Maia AL, Vaisman M. Thyroid nodule and differentiated thyroid cancer: update on the Brazilian consensus. Arq Bras Endocrinol Metab. 2013; 57(4).

10. Rosini I, Salum NC. Protocolo de cuidados para punção aspirativa por agulha fina de mama e tireoide. Texto \& Contexto Enfermagem 2014; 23 (4).

11. Wesola, Martajelén, Michal. Bethesda System in the evaluation of thyroid nodules: Review. Advances in Clinical and Experimental Medicine 2017; 26(1): 177-82.

12. Ceratti S, Giannini P, Souza RAS, Junior OR. Aspiração por agulha fina guiada por ultrassom de nódulos tireoidianos: avaliação do número ideal de punções. Colégio Brasileiro de Radiologia e Diagnóstico por Imagem. 2012; 45 (3).

13. de Souza DAT, Freitas HMP, Muzzi M, Carvalho ACP, Marchiori E. Punção aspirativa por agulha fina guiada por ultrassonografia de nódulos tireoidianos: estudo de 63 casos. Colégio Brasileiro de Radiologia e Diagnóstico por Imagem. 2004; 37 (5).

14. Cruz JF, Macena LB, Cruz MAF, Coutinho PM, Oliveira FT. Perfil dos pacientes com nódulos tireoidianos submetidos à punção aspirativa por agulha fina. Interfaces Científicas - Saúde e Ambiente. 2015; 3: 47-56 


\title{
ULTRASSONOGRAFIA PARA MEDIDA DA TRANSLUCÊNCIA NUCAL E O RASTREIO GENÉTICO PRÉ NATAL
}

\author{
ULTRASONOGRAPHY FOR MEASURING NUCHAL TRANSLUCENCY \\ AND PRENATAL GENETIC SCREENING
}

\author{
LORHAYNE AFONSO SIQUEIRA ${ }^{1}$, TÁRIK KASSEM SAIDAH ${ }^{2}$, PATRÍCIA GONÇALVES EVANGELISTA ${ }^{3}$, \\ WALDEMAR NAVES DO AMARAL ${ }^{3}$
}

\section{RESUMO}

INTRODUÇÃO: A ultrassonografia de rotina no início da gestação possibilita uma melhor avaliação da idade gestacional, detecção precoce de gestações múltiplas e de malformação fetal clinicamente insuspeita. Após esse primeiro rastreio recomenda-se em caso de alterações, exames mais precisos para diagnosticar cromossomopatias.

OBJETIVO: Analisar a eficácia do método de ultrassonografia para medida da translucência nucal (TN) no rastreamento de anomalias cromossômicas confirmados por biópsia de vilosidade coriônica ou da amniocentese e ainda definir a eficiência da TN como teste diagnóstico para anomalias fetais, estabelecer a cromossomopatia mais frequente e verificar se a TN pode ser incorporada como elemento rastreados de aneuploidias.

MÉTODOS: Trata-se de um estudo observacional, descritivo, retrospectivo analítico com gestantes atendidas de 2007 até 2017 na Clínica Fértile para realização de rastreio ultrassonográfico de transluscência nucal (TN) realizados com idade gestacional entre a 11 a e a 13 a semana e seis dias de gravidez. A medida da TN foi considerada aumentada quando se apresentou $>2,5 \mathrm{~mm}$. O cariótipo fetal foi estabelecido por meio da análise citogenética de material obtido por meio de biópsia de vilo corial ou amniocentese.

RESULTADOS: Foram estudadas 219 gestantes, dentre estes 216 com alterações de TN (>=a 2,5 mm), submetidos a confirmação por biópsia de vilosidade coriônica e 113 com cariótipos normais. A sensibilidade: 100\%, a especificidade: 97,3\% o valor preditivo positivo (VPP): 49\%, valor preditivo negativo (VPN): 100\% e acurácia:49,8\%. A idade materna de maior prevalência foi de 18 a 35 anos, com exames de cariótipos normais ea confirmação por biopsia de vilo corial foi o exame de escolha e a principal alteração cariótipa foi $47 X X+21$, síndrome de Down. CONCLUSÃO: A TN como teste diagnóstico para aneuploidias fetais apresentou sensibilidade de 100\%, VPN 100\%, especificidade 97,3\%, VPP 49\% e acurácia 49,7\%. A cromossomopatia fetal mais frequente foi a trissomia do 21 (Síndrome de Down) $47 X X+21$. Considerando que o critério do teste diagnóstico importante para o rastreamento de doenças é a sensibilidade, a TN deve ser incorporada como tal, pois a sensibilidade foi plena nesse estudo.

\section{PALAVRAS-CHAVE: ULTRASSONOGRAFIA. TRANSLUCÊNCIA NUCAL, RASTREAMENTO. ANOMALIAS CROMOSSÔMICAS}

\begin{abstract}
INTRODUCTION: Routine ultrasonography at the beginning of pregnancy enables a better assessment of gestational age, early detection of multiple pregnancies and early detection of clinically unsuspected fetal malformation. After this first screening it is recommended in case of changes, more accurate examinations to diagnose chromosomal abnormalities.

OBJECTIVE: To analyze the effectiveness of the ultrasound method for measuring nuchal translucency (NT) in screening for chromosomal abnormalities confirmed by chorionic villus biopsy or amniocentesis and to define the efficiency of NT as a diagnostic test for fetal abnormalities, to establish the most frequent chromosomal abnormalities and to verify whether TN can be incorporated as aneuploid trace elements.

METHODS: This is an observational, descriptive, retrospective analytical study of pregnant women attended from 2007 to 2017 at the Fértile Clinic to perform nuchal translucency ultrasound screening performed at gestational age between 11th and 13th weeks and six days of age of pregnancy. NT measurement was considered increased when it was $<2.5 \mathrm{~mm}$. Fetal karyotype was established by cytogenetic analysis of material obtained by coronal villus biopsy or amniocentesis.

RESULTS: A total of 219 pregnant women were studied, among them 216 with NT alterations ( $>=2.5 \mathrm{~mm}$ ), submitted to confirmation by chorionic
\end{abstract}

1. Hospital e Maternidade Dona íris.

2. UniEvangélica

3. Universidade Federal de Goiás.
Endereço para correspondência:

Waldemar Naves do Amaral

Alameda Cel. Joaquim de Bastos, 243 - St. Marista

Goiânia - CEP 74175-150

Email: waldemar@sbus.org.br 
villus biopsy and 113 normal ones. Sensitivity: 100\%, Specificity: 97,3\%, Positive Predictive Value (PPV): 49\%, Negative Predictive Value (NPV): $100 \%$ and accuracy: $49.8 \%$. The most prevalent maternal age was 18 to 35 years, with normal karyotype exams and confirmation by chorionic villus biopsy was chosen and the main karyotype change was $47 x x+21$.

CONCLUSION: NT as a diagnostic test for fetal aneuploidies presented 100\% sensitivity, 100\% NPV, 97,3\% specificity, PPV 49\% and accuracy $49.7 \%$. The most frequent fetal chromosomal abnormality was 21 (Down syndrome) trisomy $47 X X+21$. Considering that the criterion of the important diagnostic test for disease screening is sensitivity, NT should be incorporated as such, since sensitivity was full in this study.

\section{KEYWORDS: ULTRASONOGRAPHY. NUCHAL TRANSLUCENCY, TRACKING. CHROMOSOMAL ABNORMALITIES}

\section{INTRODUÇÃO}

O diagnóstico pré-natal (DPN) é um conjunto de técnicas destinado a investigar a saúde fetal ainda no período de vida intrauterina, com intuito de rastrear anomalia genética ou congênita ${ }^{1}$.

A ultrassonografia de rotina no início da gestação possibilita uma melhor avaliação da idade gestacional, detecção precoce de gestações múltiplas e detecção precoce de malformação fetal clinicamente insuspeita.

É, indiscutivelmente, aquela que mais diagnostica, em frequência e em número, tanto doenças genéticas quanto não-genéticas e, por esse motivo, aliado ao seu baixo custo e à sua característica não invasiva, deve ser incentivada e priorizada no diagnóstico pré-natal ${ }^{2}$.

A translucência nucal configura-se como imagem ultrassonográfica hipoecogênica, onde encontra-se o acúmulo de líquido na região posterior do pescoço, que ocorre com mais exuberância entre a $10^{\mathrm{a}}$ e a $14^{\mathrm{a}}$ semanas de gestação, sendo o principal exame de rastreio realizado no Brasil. Perante um resultado positivo de um teste de rastreio oferecer-se-á a possibilidade de um teste diagnóstico, o qual constitui ainda, inevitavelmente, um procedimento invasivo, porém de alta precisão ${ }^{3,4}$.

Após esse primeiro rastreio recomenda-se em caso de alterações, exames mais precisos para diagnosticar cromossomopatias, trata-se de exames que colocaram a possibilidade de realizar o diagnóstico através de métodos invasivos no pré-natal o que foi um grande avanço, pois viabilizou a coleta direta de material fetal para análise em laboratório, permitindo a realização de diversos exames, como o cariótipo para doenças cromossômicas, os ensaios enzimáticos para erros inatos do metabolismo e a análise molecular ainda em vida intra-útero ${ }^{5}$.

Esses são feitos através da coleta de uma amostra do líquido que fica em volta do bebê (amniocentese) ou de um pequeno pedaço da placenta (biópsia de vilo corial, BVC) para pesquisar anomalias cromossômicas. $\mathrm{O}$ exame é realizado através da introdução de uma agulha dentro da barriga da grávida, levando a um maior risco de abortamento. Por isso, esses testes não são oferecidos para todas as gestantes ${ }^{6}$.

Atualmente, o "padrão ouro" para o diagnóstico pré-natal para cromossomopatias é fornecido pela técnica de cariótipo, que possui acurácia elevada, mas é dependente de procedimentos invasivos de coleta de amostras de material fetal diretamente do útero materno, por meio da biópsia de vilo corial (BVC) durante o primeiro trimestre de gestação ou da coleta de líquido amniótico, no segundo trimestre ${ }^{7}$.

O objetivo deste estudo é analisar a eficácia do método de ultrassonografia para medida da translucência nucal (TN) no rastreamento de anomalias cromossômicas confirmados por biópsia de vilosidade coriônica ou da amniocentese.

\section{MÉTODOS}

Trata-se de um estudo observacional, descritivo, retrospectivo analítico com gestantes atendidas de 2007 até 2017 na Clínica Fértile para realização de rastreio ultrassonográfico de transluscência nucal (TN) realizados com idade gestacional entre a 11 a e a 13a semana e seis dias de gravidez.

A medida da TN foi considerada aumentada quando se apresentou $>2,5 \mathrm{~mm}$ (ver figuras 1 e 2). O cariótipo fetal foi estabelecido por meio da análise citogenética de material obtido por meio de biópsia de vilo corial ou amniocentese.

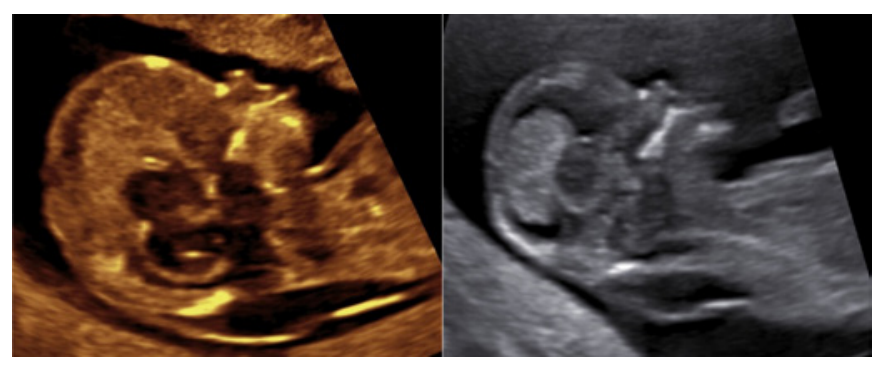

Figura 1 e 2. Dois casos de translucência nucal alterada (Cortesia Faria \& Pettersen $)^{9}$

Os dados foram digitados e manipulados em Excel, para posterior tratamento dos dados utilizando o programa Statistical Package for Social Science (SPSS) do Windows (versão 21.0).

As variáveis categóricas foram apresentadas em forma de tabela, com valores absolutos ( $\mathrm{f}$ ) e valores percentuais (\%).

A eficiência foi avaliada pela tabela de contigêcia, atra- ves da sensibilidade, especificidade, valor preditivo positivo, valor preditivo negativo e acurácia.

Quanto aos aspectos éticos, destaca-se que a pesquisa foi fundamentada de acordo com a Resolução n. 466/2012, sendo assim os direitos dos envolvidos assegurados, com aprovação do Comitê de Ética.

\section{RESULTADOS}

Foram estudadas 219 gestantes, dentre estes 216 com alte- 
rações de TN $(>=$ a $2,5 \mathrm{~mm})$ e três com TN normais. Todos foram submetidos a confirmação por biópsia de vilosidade coriônica ou amniocentese

\begin{tabular}{llll}
\hline \multirow{2}{*}{ TN } & \multicolumn{2}{c}{ Cariótipo } & Total \\
\cline { 2 - 3 } & Alterado & Normal & \\
\hline$>2,5$ & 106 & 110 & 216 \\
$\leq 2,5$ & - & 3 & 3 \\
Total & 106 & 113 & 219 \\
\hline
\end{tabular}

Tabela 1 - Distribuição dos casos de estudo genético de acordo com Testes positivos e negativos dos cariótipos com TN alterada e TN normal, realizados na clínica Fértile, Goiânia, Goiás, 2019.

A sensibilidade: 100\%, a especificidade: $97.3 \%$, o valor preditivo positivo: $49 \%$, valor preditivo negativo: $100 \%$ e acurácia: 49,8\%. A idade materna de maior prevalência foi de 18 a 35 anos, com exames de cariótipos normais e a confirmação por biopsia de Vilo corial foi a escolha e a principal alteração cariótipa foi $47 \mathrm{XX}+21$ (ver figura 3).

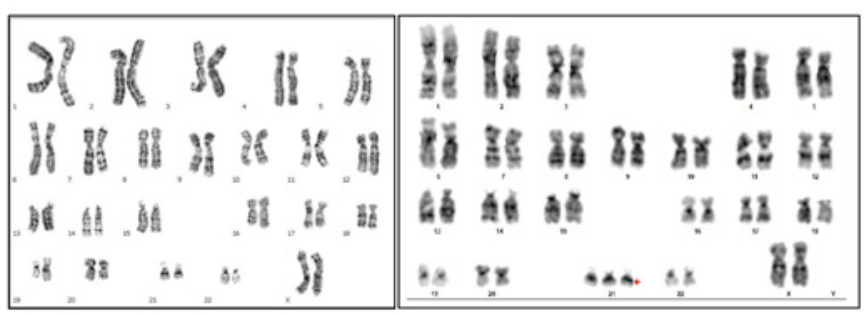

Figura 3. A. Ilustra estudo citogenético normal $(46, X X)$. B. llustra alteração cariótipa na síndrome de Down $(47, \mathrm{XX},+21)$ - (Cortesia Faria \& Pettersen) ${ }^{9}$

\begin{tabular}{|c|c|c|c|}
\hline Variáveis & $\mathrm{TN}>2,5$ & $\mathrm{TN} \leq 2,5$ & TOTAL (\%) \\
\hline \multicolumn{4}{|l|}{ Idade Materna } \\
\hline$<18$ anos & 3 & - & $3(1,3 \%)$ \\
\hline 18 a 35 anos & 144 & 2 & $146(66,7 \%)$ \\
\hline$>35$ anos & 69 & 1 & $70(32,0 \%)$ \\
\hline \multicolumn{4}{|l|}{ Cariótipo } \\
\hline Normal & 110 & 3 & $113(51,6 \%)$ \\
\hline Alterado & 106 & $\cdot$ & $106(48,4 \%)$ \\
\hline \multicolumn{4}{|l|}{ Exame } \\
\hline Líquido amniótico & 78 & - & $78(35,6 \%)$ \\
\hline Biópsia vilo corial & 138 & 3 & $138(64,4 \%)$ \\
\hline \multicolumn{4}{|c|}{ Alterações cariótipas } \\
\hline $47 \mathrm{XX}+13$ & 4 & $\cdot$ & $4(3,8 \%)$ \\
\hline $47 X X+18$ & 13 & - & $13(12,4 \%)$ \\
\hline $47 \mathrm{XX}+21$ & 26 & - & $26(24,8 \%)$ \\
\hline $45 \times 0$ & 9 & $\cdot$ & $9(8,6 \%)$ \\
\hline Outras Alterações & 54 & - & $54(50,5 \%)$ \\
\hline
\end{tabular}

Tabela 2 - Distribuição dos casos de estudo genético de acordo com perfil das pacientes analisadas na clínica Fértile, Goiânia, Goiás, 2019.

\section{DISCUSSÃO}

Segundo Vieira (2016) 8 a utilização de exames pré-natais é essencial para fazer uma avaliação detalhada na gravidez tanto da saúde do feto como da mãe. A realização precoce de um diagnóstico pré-natal pode reduzir a mortalidade de neonatos e a ultrassonografia é o primeiro exame realizado para rastreio de possiviveis alterações.

Foram estudadas 219 gestantes, dentre estes $216 \mathrm{com}$ alterações de TN $(>=$ a $2,5 \mathrm{~mm})$, submetidos a confirmação por biópsia de vilosidade coriônica ou amniocentese e 3 com TN normais.

Calculando-se levando em consideração como valor alterado ou não (TN $>=2,5$ ou $\mathrm{TN}<2,5$ ), tivemos: A sensibilidade: $100 \%$, a especificidade: $97,3 \%$, o valor preditivo positivo: $49 \%$, valor preditivo negativo: $100 \%$ e acurácia: $49,8 \%$.

O primeiro estudo do Brasil foi realizado por Faria et al ${ }^{9}$ em 1997 no qual estudaram 231 fetos e encontraram uma sensibilidade de $100 \%$.

Nos estudos de Murta e França ${ }^{4} 1.152$ fetos foram analisados e destes 124 casos realizou-se estudo citogenético no material obtido por meio da biópsia de vilosidade coriôni- ca ou da amniocentese e em 1028 o resultado teve como base o fenótipo do recém-nascido. Foram diagnosticados 23 casos de anomalias cromossômicas na população estudada. Dentre esses, a medida da TN foi maior que o percentil 95 em 16 (sensibilidade de 69,5\%). No grupo de fetos normais (1129 casos) a medida da TN foi maior que o percentil $95 \mathrm{em} 41$ avaliações (especificidade de $96,3 \%$, valor preditivo positivo e negativo de $28,0 \%$ e $99,3 \%$, respectivamente, taxa de falso-positivo de 3,7\% e razão de probabilidade de 19,1).

Nos estudos de Saldanha et al. ${ }^{10}, 14,2 \%$ dos casos, o cariótipo esteve alterado e em $85,8 \%$ o cariótipo ou fenó- tipo foi normal, em fetos com TN aumentada e cariótipo normal, quanto maior a medida da TN maior a frequência de malformações estruturais, em especial defeitos cardíacos, resultados gestacionais adversos e alterações na avaliação pós-natal foram encontrados.

Vieira (2013) 11 analisaram 116 casos de translucência nucal acima do percentil 95, sendo que em 79 (68\%) foi realizado cariótipo fetal, dentro dessas alterações os fetos com cariótipo normal, houve um abortamento na $15^{\mathrm{a}}$ semana gestacional com pentalogia de Cantrel, um óbito na $24^{\text {a }}$ semana com diversas anomalias estruturais, um óbito neonatal sem causa definida e dois casos de comunicação intraventricular (CIV) detectados no ecocardiograma fetal.

Para Almeida et $\mathrm{al}^{3}$ a oferta de testes diagnósticos invasivos deve ser mantida para gestações com resultados positivos no rastreio e ainda o aconselhamento deverá reforçar a noção de que um resultado negativo não é garantia de uma gravidez não afetada, pois falsos negativos podem ocorrer.

A idade materna de maior prevalência foi de 18 a 35 anos, com exames de cariótipos normais e a confirmação por biópsia de vilo corial foi a escolha e a principal alteração cariótipa foi $47 \mathrm{XX}+21$. 
Emer et al. ${ }^{12}$ avaliaram 840 exames amniocentese e foram diagnosticados 60 casos sendo nove de trissomia do cromossomo 13, 26 do cromossomo 18 e 25 do cromossomo 21.

Já Pereira et al. ${ }^{13}$ encontraram 142 casos de cariótipos anormais, sendo as aneuploidias $(45,1 \%)$ as mais frequentes, seguidas pelas alterações estruturais $(38,7 \%)$ e mosaicismos $(16,2 \%)$. Almeida et al., (2014) encontraram como prevalência as trissomias dos cromossomos 21, 18 e 13 sendo responsável por $70 \%$ de todas as aneuploidias detectadas no período pré-natal.

Quando são realizados exames de rastreamento no pré-natal, conclui-se que as aneuploidias que estão entre as anormalidades genéticas mais comuns segundo Sbragia et al. ${ }^{14}$ são as trissomias que envolvem os cromossomos $13,18 \mathrm{e}$ 21. Entre as trissomias mais frequentes observadas ao nascimento, podemos observar a síndrome de Down (trissomia do cromossomo 21), precedida pela síndrome de Edwards (trissomia do 18).

Em relação ao rastreio pré-natal, Henriques ${ }^{15}$ alerta que o rastreio pré-natal de cromossomopatias levanta várias questões éticas com que as grávidas, os casais, os profissionais de saúde já que não oferece uma opção terapêutica para as cromossomopatias. A única medida preventiva possível é a interrupção da gravidez em raros os casos. Isto coloca os casais perante decisões difíceis, logo no início da gravidez, decisões essas que têm que ser tomadas rapidamente. Por isso uma boa informação à esses casais se faz necessário e isso deve incluir: 1) uma explicação breve sobre as patologias a rastrear; 2) as características dos testes oferecidos e 3) as implicações de fazer os testes: opções disponíveis após um rastreio positivo (risco aumentado), o risco de aborto iatrogênico com a amniocentese, opções disponíveis após o diagnóstico de uma anomalia fetal (interrupção da gravidez, continuação da gravidez e preparação para o nascimento de uma criança com necessidades especiais).

Pereira et $\mathrm{al}^{13}$ destaca a importância de esclarecer que, mesmo que o cariótipo tenha um resultado normal, há a possibilidade de não serem identificadas algumas alterações, necessitando de exames mais específicos e os laudos citogenéticos devem, além de apresentar o cariótipo, esclarecer os profissionais da saúde sobre o fato de que, em casos de indivíduos com constituição cromossômica normal que apresentem malformações, é recomendado o encaminhamento para aconselhamento genético, que orientará sobre o diagnóstico, a conduta terapêutica e o risco de recorrência de problemas genéticos.

A TN como teste diagnóstico para aneuploidias fetais apresentou sensibilidade de 100\%, VPN 100\%, especificidade 97,3\%, VPP 49\% e acurácia 49,7\%.

A cromossomopatia fetal mais frequente foi a trissomia do 21 (Síndrome de Down) $47 \mathrm{XX}+21$.

Considerando que o critério do teste diagnóstico importante para o rastreamento de doenças é a sensibilidade, a TN deve ser incorporada como tal, pois a sensibilidade foi plena nesse estudo.

\section{REFERÊNCIAS}

1. Bernal L M \& Lopez G. Diagnóstico pré-natal: retrospectiva. Nova 2014; 12(21): 23-36.

2. Pinto Júnior W. Diagnóstico pré-natal. Ciênc. Saúde Coletiva 2002; 7(1): 139-57.

3. Almeida $\mathrm{O}$ et al. A nova era do rastreio pré-natal. Acta Obstet Gine- col Port, 2014; 8(3): 284-90.

4. Murta CGV \& França LC. Medida da Translucência nucal no rastreamento de anomalias cromossômicas. RBGO 2002; 24(3): 167-73.

5. Sanseverino MTV et al. Diagnóstico pré-natal: avanços e perspectivas. Revista HCPA 2001; 3(1): 301-16.

6. Alldred $S$ et al. First trimester serum tests for Down's syndrome screening. Cochrane Database of Systematic Reviews, 2015: 1.

7. Andari VCM. Testes genéticos não invasivos no pré-natal: benefícios e limitações dos exames disponíveis. 2015. Dissertação (mestrado). Faculdade de Ciências Médicas da Santa Casa de São Paulo.

8. Vieira AA. Saúde materno-fetal e técnicas de diagnóstico. Disponível em: < http://www.repositorio.uniceub.br/bitstream/235/9055/1/21437970.pdf >. Acesso em: 13 abr. 2016.

9. Faria M, Quintino S, Pettersen H. Rastreamento ultrassonográfico de anomalias cromossômicas através da medida da translucência nucal Análise de 231 fetos. RBGO 1997; 19: 19-30.

10. Saldanha FAT et al. Translucência nucal aumentada e cariótipo nor- mal: evolução pré e pós-natal. Rev. Assoc. Med. Bras. 2009; 55(5): 575-80.

11. Vieira LA. Evolução perinatal e pediátrica de crianças com translu- cência nucal aumentada e cariótipo normal RBGO 2013; 35(6): 274-80.

12. Emer CSC et al. Prevalência das malformações congênitas identifi- cadas em fetos com trissomia dos cromossomos 13, 18 e 21. RBGO 2015; 37(7): 333-8

13. Pereira TM et al. Frequência das anormalidades cromossômicas: im portância para o diagnóstico citogenético. Arq. Ciênc. Saúde 2009; 16(1): 31-3.

14. Sbragia L. Tratamento das malformações fetais intraútero. RBGO 2010 32(1): 47-54.

15. Henriques S. Rastreio pré-natal de cromossomopatias e defeitos do tubo neural. Como actuar? Revista Portuguesa de Medicina Geral e Familiar. 2009; 25(3): 320-31. 


\title{
PREVALÊNCIA DE LESÕES NEUROLÓGICAS DIAGNOSTICADAS POR ULTRASSONOGRAFIA TRANSFONTANELA EM RECÉM NASCIDO TERMO
}

\author{
PREVALENCE OF NEUROLOGICAL INJURIES DIAGNOSED BY \\ TRANSFONTANELLE ULTRASONOGRAPHY IN TERM NEWBORN
}

\author{
LORENA CABRAL DE CASTRO LOURENZO', MIDIÃ FONSECA LIMA', SIMONE CARRIJO SANTOS', \\ PATRÍCIA GONÇALVES EVANGELISTA²
}

\section{RESUMO}

INTRODUÇÃO: A ultrassonografia (USG) é o procedimento de neuroimagem mais amplamente utilizado, pois fornece informações sobre lesão cerebral perinatal para a previsão de resultados a longo prazo A USG transfontanelar (USTF) é um exame de rotina para aqueles com idade gestacional (IG) menor que 34 semanas e existem muitos estudos que falam da prevalência de lesões para esse grupo e poucos estudos relacionados a achados em recém-nascido $(R N)$ termo. Estudar os achados da USTF são essenciais na assistência à saúde de prematuros, visando assim melhores prognósticos. OBJETIVO: Mensurar os principais achados em USTF em RN termo.

MÉTODOS: Estudo transversal descritivo quantitativo e retrospectivo, desenvolvido numa maternidade pública de referência em Goiânia-GO. RESULTADOS: Foram analisados todos os RNs internados na UTI de janeiro a dezembro de 2019 num total de 265, sendo 50 considerados termos em relação a idade gestacional e que foram indicados a fazer a USFT (excluindo seis casos com dados incompletos) totalizando um total de 44 pacientes. O perfil materno foi de mulheres entre 18 e 30 anos (62\%), primigesta (50\%), menos de sete consultas pré-natais (62\%), cesariana (62\%) com fatores de risco associados a doença hipertensiva na gravidez (DHEG) e infecções do trato urinário (43\%). O perfil dos RNs é de feminino (75\%), 38 semanas (38\%), apgar 1 o menor que sete (65\%), apgar 5 o maior que oito (75\%), adequado para idade gestacional (AIG) (62\%) e acima de 2.501 gramas (62\%). Foram registrados $25 \%$ de óbitos no grupo de pacientes com alterações sendo que $100 \%$ diagnosticado com leucomalácia. CONCLUSÃO:Foram realizados 44 exames sendo que $82 \%$ normais e $18 \%$ alterado, a principal alteração encontrada nesse grupo foi a leucomalácia com 50\%. O perfil materno foi de mulheres entre 18 e 30 anos, primigesta que realizaram menos de sete consultas pré-natais e que tiveram os partos por cesariana com fatores de risco associados a DHEG e infecções do trato urinário. O perfil dos RNs é de feminino, nascidos de 38 semanas, com apgar 10 menor que sete, apgar $5^{\circ}$ maior que oito, com peso adequado a idade gestacional com bebês acima de 2.501 gramas.

PALAVRAS-CHAVE: LESÕES, TRANSFONTANELA, ULTRASSONOGRAFIA, DIAGNÓSTICO.

\begin{abstract}
INTRODUCTION: Ultrasonography (USG) is the most widely used neuroimaging procedure, as it provides information on perinatal brain injury to predict long-term results. Transfontanellar USG (TFUS) is a routine examination for those with lower gestational age (GI) than 34 weeks and there are many studies that talk about the prevalence of injuries for this group and few studies related to findings in term newborns (NB). Studying the findings of the USTF are essential in the health care of premature babies, aiming at better prognosis.

OBJECTIVE: To measure the main findings in USTF in term newborns.

METHODS: Descriptive quantitative and retrospective cross-sectional study, developed in a public maternity of reference in Goiânia-GO. RESULTS: All NBs admitted to the ICU from January to December 2019 were analyzed in a total of 265, 50 of which were considered terms in relation to gestational age and who were indicated to perform the USFT (excluding six cases due to incomplete forms) totaling a final total 44 patients. Maternal profile was women between 18 and 30 years old (62\%), primiparous (50\%), less than seven prenatal consultations (62\%), cesarean section (62\%) with risk factors associated with preeclampsia and urinary tract infections (43\%). Profile of the newborns is female (75\%), 38 weeks
\end{abstract}

1. Médica residente em neonatologia do Hospital

e Maternidade Dona íris.

2. Doutoranda em Ciências da Saúde da UFG.
Endereço para correspondência:

Waldemar Naves do Amaral

Alameda Cel. Joaquim de Bastos, 243 - St. Marista

Goiânia - CEP 74175-150

Email: waldemar@sbus.org.br 
(38\%), first 10 less than seven (65\%), $5^{\circ}$ more than eight (75\%), AIG (62\%) and more than 2,501 grams (62\%). 25\% of deaths were registered in the group of patients with abnormalities, $100 \%$ of whom were diagnosed with leukomalacia.

CONCLUSION: 44 tests were performed, $82 \%$ of which were normal and 18\% abnormal. The main alteration found in this group was leukomalacia with 50\%. Maternal profile was women between 18 and 30 years old, primiparous who had less than seven prenatal consultations and who had deliveries by cesarean section with risk factors associated with preeclampsia and urinary tract infections. The profile of the newborns is female, born at 38 weeks, with an Apgar score less than seven, an Apgar score greater than eight, with a weight appropriate to gestational age with babies over 2,501 grams.

KEYWORDS: LESIONS, TRANSFONTANELLE, ULTRASONOGRAPHY, DIAGNOSIS.

\section{INTRODUÇÃO}

Desde o final da década de 1970, a ultrassonografia (USG) é o procedimento de neuroimagem mais amplamente utilizado, pois fornece informações sobre lesão cerebral perinatal para a previsão de resultados a longo prazo'.

Atributos favoráveis à ultrassonografia que o tornam quase indispensável para os cuidados de rotina do recém-nascido incluem fácil acesso, baixo custo, portabilidade, falta de radiações ionizantes e isenção de sedação ou anestesia ${ }^{2}$.

É muito útil em muitas situações clínicas, possibilitando selecionar quais pacientes se beneficiarão de outras técnicas mais invasivas ou mais caras, ou que requeiram sedação, como a ressonância magnética. As desvantagens da técnica são que ela depende do operador e que é necessária uma janela acústica apropriada. Também possui limitações no estudo de trauma obstétrico, na avaliação de malformações complexas e na avaliação de danos à substância branca ${ }^{3}$.

A triagem de ultrassonografia craniana é sugerida nos primeiros 4-7 dias de vida com uma repetição do ultrassom craniano de 10-14 dias. Quando usado dessa maneira, o ultrassom craniano apresenta $100 \%$ de sensibilidade para a detecção de lesões intraventriculares graves hemorragia (IVH) e lesão grave da substância branca. Se o exame de ultrassonografia é normal, sugere-se exame de acompanhamento na idade gestacional corrigida 36 a 40 semanas (termo equivalente) para rastrear evidências de lesões mais graves na substância branca ${ }^{4}$.

Sabe-se que a gestação é medida a partir do primeiro dia do último período menstrual normal e pode contada por semanas gestacionais completas, onde considerada pré-termo as gestações com menos de 37 semanas completas e termo de 37 semanas a menos de 42 semanas completas 5 .

A US transfontanela (USTF) é um exame de rotina para aqueles com idade gestacional (IG) menor que 34 semanas e existem muitos estudos que falam da prevalência de lesões para esse grupo e poucos estudos relacionados a achados em RN termo, estudar os achados da USTF são essenciais na assistência à saúde de prema- turos, visando assim melhores prognósticos.

\section{MÉTODOS}

Estudo transversal descritivo quantitativo e retrospectivo, desenvolvido numa maternidade pública de referência em Goiânia-GO. O hospital faz parte da rede Municipal de Saúde de Goiânia com UTI e UCIN exclusivamente aos usuários do Sistema Único de Saúde (SUS).

A pesquisa foi realizada no período de janeiro a dezembro de 2019, sendo incluídos todos os recém-nascidos termos que passaram na UTIN no período estabelecido (sendo excluídos os recém-nascidos termos em que o prontuário estavam incompleto e não possuíam dados suficientes para a análise).

Para coleta de dados foi desenvolvido um instrumento de coleta para dados secundários com as variáveis maternas: idade materna, número de filhos, número de consultas pré-natal, fatores de risco maternos e tipo de parto. Já as variáveis neonatais foram escore de Apgar no primeiro e quinto minuto de vida, idade gestacional, sexo e peso e as USTF: tipo de lesão apresentada. Os itens coletados foram inseridos em uma planilha eletrônica (Excel, Microsoft Corporation, EUA) e utilizou-se o sistema Epilnfo 2002 (Centers for Disease Control and Prevention, EUA) para a análise de tabelas e gráficos.

$\mathrm{O}$ presente projeto de pesquisa foi fundamentado na Resolução N0. 466/2012, sendo assim os direitos dos envol- vidos assegurados, aprovado pelo Comitê de Ética indicado pela Plataforma Brasil.

\section{RESULTADOS}

Foram analisados todos os RNs internados na UTI de janeiro a dezembro de 2019 num total de 265, sendo 50 considerados termos em relação a idade gestacional e que foram indicados a fazer a USFT (excluindo seis pacientes que estavam incompletas) totalizando um total de 44 prontuários.

\begin{tabular}{ccc}
\hline USTF & N & $\%$ \\
\hline Normal & 36 & 82 \\
Alterada & 8 & 18 \\
\hline
\end{tabular}

Tabela 1 - Distribuição dos resultados das USTF realizados em RN termo no HMDI, Goiânia (GO), Brasil, 2020. 


\begin{tabular}{lcc}
\hline & \multicolumn{2}{c}{ Número de pacientes $(\mathrm{N}=8)$} \\
\cline { 2 - 3 } & $\mathrm{N}$ & $\%$ \\
\hline IDADE MATERNA & 25 \\
$\leq 17$ & 2 & 62 \\
$18-30$ & 5 & 13 \\
231 & 1 & \\
\hline NÚMERO DE GESTAÇÕES & & 50 \\
1 & 4 & 37 \\
$2-3$ & 3 & 13 \\
$\geq 4$ & 1 & \\
\hline CONSULTAS PRÉ-NATAIS & & 62 \\
$<7$ & 5 & 38 \\
$\geq 8$ & 3 & 62 \\
\hline TIPO DE PARTO & & 38 \\
Cesárea & 5 & \\
Normal & 3 & 43 \\
\hline PRINCIPAIS FATORES DE RISCO & & 43 \\
DHEG & 3 & 14 \\
Infecção do Trato Urinário & 3 & \\
Diabetes & 1 & \\
\hline Fonte: Dados da pesquisa, 2019. & &
\end{tabular}

Tabela 2 - Distribuição das características maternas de RNs na UTIN que realizaram USTF no HMDI, Goiânia (GO), Brasil, 2020.

\begin{tabular}{|c|c|c|}
\hline & \multicolumn{2}{|c|}{ Número de pacientes $(\mathrm{N}=8)$} \\
\hline & $\mathrm{N}$ & $\%$ \\
\hline \multicolumn{3}{|l|}{ SEXO } \\
\hline Feminino & 6 & 75 \\
\hline Masculino & 2 & 25 \\
\hline \multicolumn{3}{|c|}{ IDADE GESTACIONAL } \\
\hline 37 semanas & 1 & 12 \\
\hline 38 semanas & 3 & 38 \\
\hline 39 semanas & 2 & 25 \\
\hline 40 semanas & 2 & 25 \\
\hline \multicolumn{3}{|l|}{ APGAR $1^{\circ}$} \\
\hline$<7$ & 5 & 62 \\
\hline$\geq 8$ & 3 & 38 \\
\hline \multicolumn{3}{|l|}{ APGAR $5^{\circ}$} \\
\hline$<7$ & 2 & 25 \\
\hline$\geq 8$ & 6 & 75 \\
\hline \multicolumn{3}{|c|}{ PESO PARA Ȧ IDADE GESTACIONAL } \\
\hline AIG & 5 & 62 \\
\hline GIG & - & 0 \\
\hline PIG & 3 & 38 \\
\hline \multicolumn{3}{|c|}{ FAIXA DE PESO (EM GRAMAS) } \\
\hline$<2.500$ & 3 & 38 \\
\hline$\geq 2.501$ & 5 & 62 \\
\hline
\end{tabular}

Tabela 3 - Distribuição das características dos de RNs na UTIN que realizaram USTF no HMDI, Goiânia (GO), Brasil, 2020.

\begin{tabular}{cll}
\hline Alteraçöes encontradas & N & $\%$ \\
\hline Leucomalácia & 4 & 50 \\
Calcificaçōes Talâmicas & 3 & 38 \\
Hemorragias & 1 & 12 \\
\hline Fonte: Dados da pesquisa, 2019. & &
\end{tabular}

Tabela 4 - Distribuição dos resultados das USTF alteradas realizados em RN termo no HMDI, Goiânia (GO), Brasil, 2020.
Foram registrados $25 \%$ de óbitos no grupo de pacientes com alterações sendo que 100\% diagnosticado com leucomalácia.

\section{DISCUSSÃO}

A ultrassonografia é uma técnica de diagnóstico não invasiva e tem sido usada para detectar lesões intracranianas em neonatos há muito tempo. Este estudo avaliou 44 exames de USFT realizados em RNs a termo sendo que $82 \%$ estavam dentro da normalidade e $18 \%$ alterado.

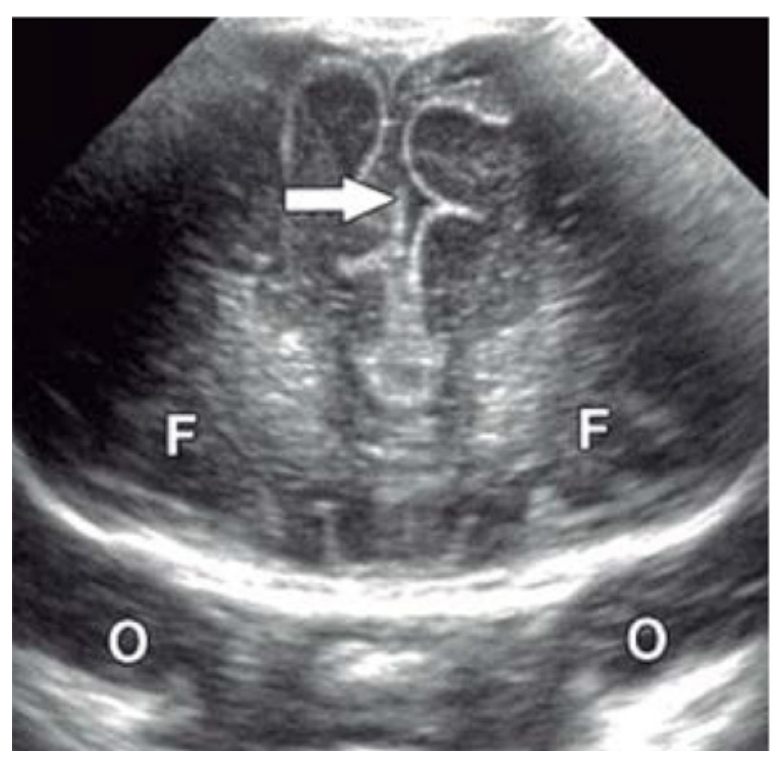

Figura 1 - Imagem de USTF em corte coronal do lobo frontal ${ }^{5}$.

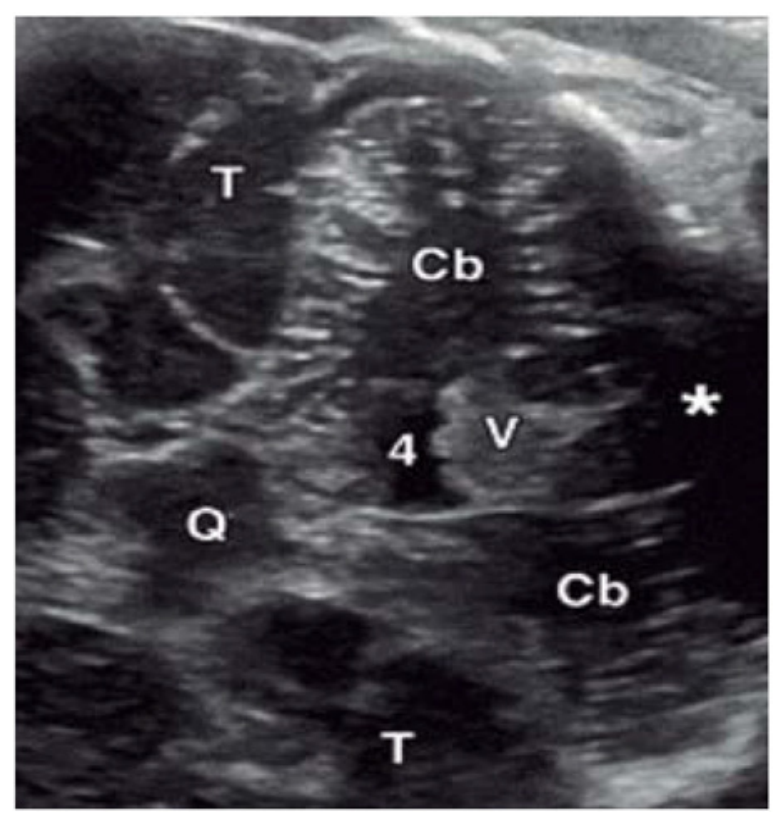

Figura 2 - Imagem de USTF exibindo hemisférios cerebelares (Cb), quarto ventrículo (4), cisterna magna (asterisco), placa quadrigeminal $(\mathrm{Q})$, vermis (V) e lobos temporais $(\mathrm{T})^{5}$ 
A principal alteração encontrada nesse grupo foi a leucomalácia com $50 \%$. Hsu et al., ${ }^{6}$ avaliaram entre setembro de 2004 e agosto de 2009 em 3186 neonatos a termo encontraram 93,6\% dentro da normalidade com 6,3\% de alterações menores $0,1 \%$ de alterações maiores.

Santos e Prado ${ }^{7}$ pesquisaram 52 prontuários de RN. Quanto ao diagnóstico ultrassonográfico, 63\% dos RNs apresentaram resultado normal. As USTF anormais (37\%) foram classificadas em cinco tipos de injúrias: hemorragia intracraniana (HIC) e hemorragia peri-intraventricular (HPIV) perfazendo 9\% dos afetados, encefalopatia hipóxicoisquêmica (EHI, incluindo leucomalácia periventricular) com $17 \%$, dilatação ventricular (DV) com $9 \%$ e malformações cerebrais com $2 \%$ da população.

O perfil materno foi de mulheres entre 18 e 30 anos, primigesta que realizaram menos de sete consultas pré-natais e que tiveram os partos por cesariana com fatores de risco associados a DHEG e infecções do trato urinário. O perfil dos Rns é de feminino, nascidos de 38 semanas, com Apgar $1^{\circ}$ min menor que sete, Apgar $5^{\circ}$ min maior que oito, com peso adequado para a idade gestacional e acima de 2.500 gramas. Baumert et al., ${ }^{8}$ analisaram 2675 recém-nascidos a termo entre os anos 2003-2005. Hemorragia periventricular / intraventricular foi diagnosticada em 392 neonatos $(14,65 \%)$. A idade gestacional média do grupo foi de 39,11 $\pm 1,26$ semanas e variou de 37 a 43 semanas e encontraram uma maior prevalência do sexo masculino e baixo peso ao nascer, discordando com os nossos achados.

Haataja et al. ${ }^{9}$, analisaram 103 bebês e revelam que anormalidades acidentais no ultrassom em recém-nascidos a termo, em particular hemorragia intraventricular, embora comuns, parecem ter um bom prognóstico e o médico deve ter um olhar mais atento aqueles com lesões na substância branca. $O$ dano à substância branca é um fator de risco pri- mordial para paralisia cerebral, e a principal apresentação é a leucomalácia periventricular. Embora a etiologia dos danos à substância branca na prematuros está amplamente relacio- nado a alterações circulatórias, a etiologia em bebês nascidos a termo é menos bem compreendida ${ }^{10}$.

Hsu et al., ${ }^{6}$ o teste de triagem ultrassonográfica craniana pode desempenhar um papel no diagnóstico precoce de anomalias intracranianas de recém-nascidos termos.

Hayward ${ }^{11}$ sugere que a ultrassonografia seja a investiga- ção neurorradiológica inicial nessa faixa etária e que todos os bebês a termo em uma unidade de cuidados especiais sejam rotineiramente examinados.

Foram poucos estudos encontrados que analisam a ultrassonografia transfontanela em RNs a termo. Jensen e Homer ${ }^{12}$ o fato de neonatos nascidos a termo aparentemente saudáveis não serem rastreados por imagens da cabeça é considerado o elo perdido entre o insulto que escapa ao diagnóstico e o desenvolvimento de atraso neuropsicomotor.

\section{CONCLUSÃO}

Foram realizados 44 exames sendo que $82 \%$ normais e $18 \%$ alterado, a principal alteração encontrada nesse grupo foi a leucomalácia com 50\%.

O perfil materno foi de mulheres entre 18 e 30 anos, primigesta que realizaram menos de 7 consultas pré-natais e que tiveram os partos por cesariana com fatores de risco associados a DHEG e infecções do trato urinário.

O perfil dos RNs é de feminino, nascidos de 38 semanas, com Apgar $1^{\circ}$ min menor que sete, Apgar $5^{\circ}$ min maior que oito, com peso adequado a idade gestacional e acima de 2.500 gramas.

\section{REFERÊNCIAS}

1. Diwakar RK \& Khurana O. Cranial sonography in preterm infants with short review of literature. J Pediatr Neurosci., 2018; 13(2): 141 49.

2. Gupta P, Sodhi KS, Saxena AK, Khandelwal N, Singhi P. Neonatal cranial

sonography: A concise review for clinicians. J Pediatr Neurosci., 2016;

11(1): 7-13.

3. Llorens-Salvador R \& Moreno-Flores A. The ABCs of transfontanellar ultrasound and more. Radiologia, 2016; 58(2): 129-41.

4. Riedesel EL. Neonatal cranial ultrasound: advanced techniques an dima-

ge interpretation. J Pediatr Neurol., 2018; 16(1): 106-24.

5. Lowe LH \& Bailey Z. State-of-the-art cranial sonography: Part 1, Modern techniques and image interpretation. American Journal of Roentgeno-

logy, 2011; 196(1): 1028-33.

6. Hsu CL, Lee KL, Jeng MJ et al. Cranial ultrasonographic findings in heal-thy full-term neonates: A retrospective review. Journal of the Chinese

Medical Association, 2012; 75(8): 389-95.

7. Santos DSS \& Prado MSG. Ocorrência de lesões neurológicas em recém-nascidos diagnosticadas por ultrassonografia transfontanela. Rev

Enferm UFPE 2017; 11(10): 4081-8.

8. Baumentt M, G Brozek, M Paprotny, Z Walencka, H Sodowska, W Cno-ta, K Sodowski. Epidemiology of peri/intraventricular haemorrage in newborns at term. Journal Of Physiology And Pharmacology, 2008; 59(4): 67-75.

9. Haataja L, Mercuri E, Cowan F, Dubowitz L. Cranial ultrasound abnor- malities in full term infants in a postnatal ward: outcome at 12 and 18 months. Arch Dis Child Fetal Neonatal., 2000; 82(1): 128-33.

10. Berger S, Bender S, Sefkow S, Klingmüller V, Künzel W, Jensen A. Peri / intraventricular haemorrhage: a cranial ultrasound study on 5286 ne- onates. Eur J Obst Gyn Reprod Biol, 1997; 75(2): 191203.

11. Hayward C. Transfontanellar ultrasound of term infants. Clin Radiol., 1994; 35(5): 337-41.

12. Jensen LA \& Holmer B. White matter damage in 4,725 term-born in-fants is determined by head circumference at birth: the missing Obst Gynecol Intern., 2018; 1(1). 


\title{
A ULTRASSONOGRAFIA NO DIAGNÓSTICO DE OBSTRUÇÃO INTESTINAL FETAL - UM RELATO DE CASO
}

\author{
ULTRASONOGRAPHY IN THE DIAGNOSIS OF FETAL INTESTINAL \\ OBSTRUCTION - A CASE REPORT
}

\author{
VALDIVINA ETERNA FALONE'; WALDEMAR NAVES DO AMARAL FILHO'; TARIK KASSEM SAIDAH4 ; PATRÍCIA MENDONÇA \\ LEITE', THAYNARA DE MORAES PACHECO'; LORENA TASSARA QUIRINO VIEIRA²; ANTÔNIO DE MORAIS JÚNIOR3, \\ WALDEMAR NAVES DO AMARAL ${ }^{1}$
}

\section{RESUMO}

A obstrução intestinal é a principal causa de emergência cirúrgica em neonatos, tendo como sua entidade mais prevalente a atresia. A atresia colônica é a mais rara delas e o diagnóstico ultrassonográfico não é muito frequente, especialmente devido a achados inespecíficos e que muitas vezes não representam patogenicidade no feto. Esse trabalho objetiva descrever um caso de atresia colônica diagnosticada no pré-natal através de ultrassonografia.

PALAVRAS-CHAVE: ATRESIA COLÔNICA; ULTRASSONOGRAFIA; PRÉ-NATAL

\begin{abstract}
Bowel obstruction is the main cause of neonatal surgical emergencies and atresia is the most prevalent representant of it. Colonic atresia on the other hand, is very rare among the others intestinal atresias and its ultrasonographic diagnosis is not frequent, specially due to its unspecific and sometimes non-pathogenic findings. This paper aims to describe a case of colonic atresia diagnosed with ultrasonography during prenatal care.
\end{abstract}

KEYWORDS: COLONIC ATRESIA; ULTRASSONOGRAPHY; PRENATAL

\section{INTRODUÇÃO}

A obstrução intestinal é a causa mais comum de emergências neonatais, ocorrendo em 1 a cada 1.500 nascidos vivos. Há algumas décadas, no entanto, crianças que nasciam com tal condição, quase sempre vinham a óbito. Avanços nas técnicas cirúrgicas desde então contribuíram enormemente para que a mortalidade fosse reduzida. Além disso, um papel importante na redução deste número deve ser atribuído ao avanço dos métodos de diagnóstico no pré-natal, a exemplo da ultrassonografia (USG) ${ }^{1}$.

Dentre as várias causas para obstrução, destacam-se as atresias intestinais, o mecônio ileal, a doença de Hirshprung e a mal rotação intestinal, com ou sem volvo, sendo a mais comum as atresias, seguidas da mal rotação e então do íleo meconial ${ }^{1}$.

A atresia possui prevalência de 1 caso para cada 2.500 nascidos vivos e pode ser duodenal, jejunal, ileal, jejunoileal ou colônica, sendo a duodenal a mais encontrada. Nas ultrassonografias de pré-natal, pode-se observar a presença de polihidrâmnio, que se torna maior quanto mais proximal for a obstrução, além da dilatação de alças intestinais ${ }^{2}$.

$\mathrm{Na}$ atresia duodenal, o diagnóstico deve ser suspeitado quando há um achado de polihidrâmnio na quase totalidade de casos em conjunto a uma "dupla bolha". Nessa afecção é comum a associação a defeitos em outros sistemas, bem como com a trissomia do cromossomo 21. A atresia jejuno ileal não está tão associada a outras malformações como a duodenal e é comum sua multiplicidade. Na ultrassonografia é caracterizada pela dilatação de alças delgadas em aspecto de tripla ou quadrupla bolha. Por fim, a atresia colônica, a mais rara delas, geralmente não ocorre

\footnotetext{
1. Faculdade de Medicina da UFG

2. PUC- GOIÁS

3. Hospital UNIQUE

4. UniEvangélica
}

Endereço para correspondência:

Waldemar Naves do Amaral

Alameda Cel. Joaquim de Bastos, 243 - St. Marista

Goiânia - CEP 74175-150

Email:waldemar@sbus.org.br 
em multiplicidade e sua evidência no pré-natal se dá pela dilatação de alças. Muitos casos, no entanto, não podem ser detectados na ultrassonografia ${ }^{3}$.

O íleo meconial é resultado da oclusão intestinal de um mecônio mais espesso, sugerido por uma hiperecogenicidade, acompanhada ou não de dilatação. Está presente em pelo menos $15 \%$ de paciente portadores de fibrose cística ${ }^{4}$.

A doença de Hirshprung, por sua vez, é causada por uma migração defeituosa de células ganglionares, aproximadamente na $12^{\text {a }}$ semana de gestação, o que culmina em uma aganglinose intestinal, reconhecida por dilatação de alça. Polihidrâmio, nesse caso, não é comumente visu- alizado ${ }^{4}$

Por fim, a mal rotação intestinal é resultado de uma fixação embrionária incorreta, o que acarreta rotação de vasos mesentéricos e pode culminar em uma isquemia. A visualização ultrassonográfica é possível quando ocorre volvo intestinal, traduzida dilatação das alças ${ }^{4}$.

\section{RELATO DE CASO}

AFCA, feminino, G4P3A1, 30 anos. Paciente foi submetida à ultrassonografia morfológica ao longo de 33 semanas de gestação. Ao exame, foi observado dilatação de alças intestinais grossas indicando suspeita de obstrução por atresia (figuras 1-3). Paciente entrou em trabalho de parto três semanas depois, ao completar 36 semanas e 5 dias de gestação. Logo após o nascimento, recém-nascido foi submetido à primeira abordagem para correção cirúrgica. Após 20 dias, foi feita a segunda cirurgia corretiva. Neonato permaneceu na UTI por 56 dias e se encontra saudável.

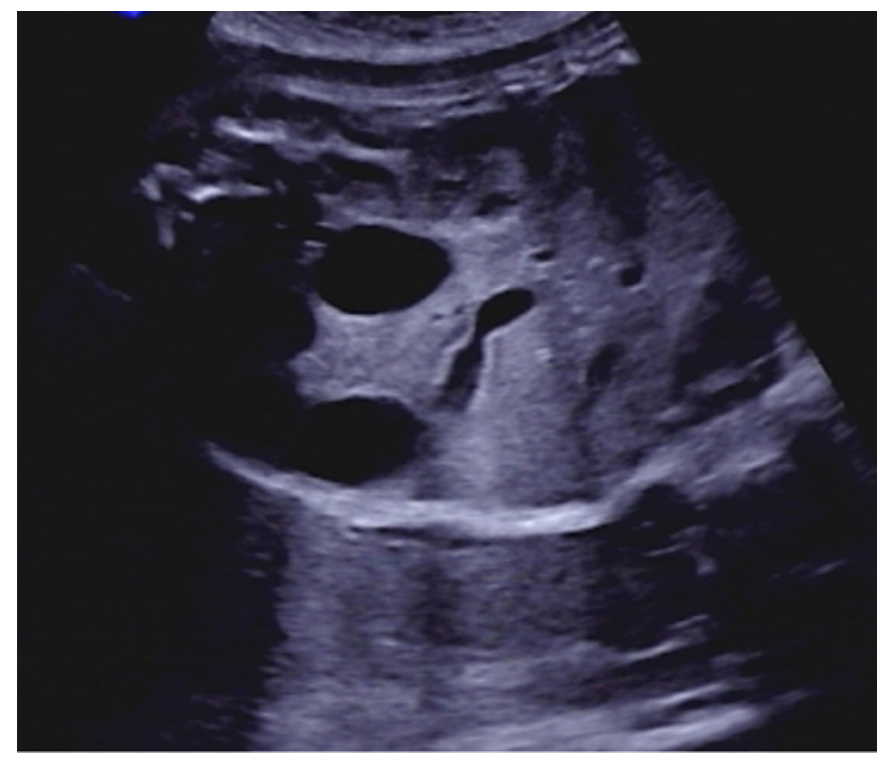

Figura 1: Ultrassonografia obstétrica: distensão de intestino grosso (conteúdo anecóico).

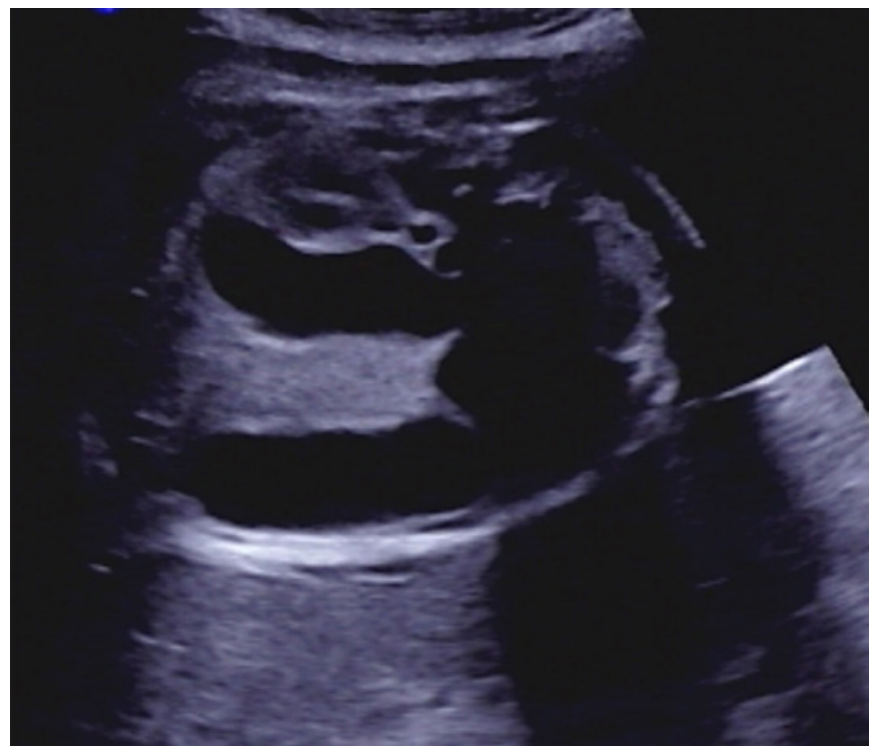

Figura 2: Ultrassonografia obstétrica: distensão de intestino grosso (conteúdo anecóico)

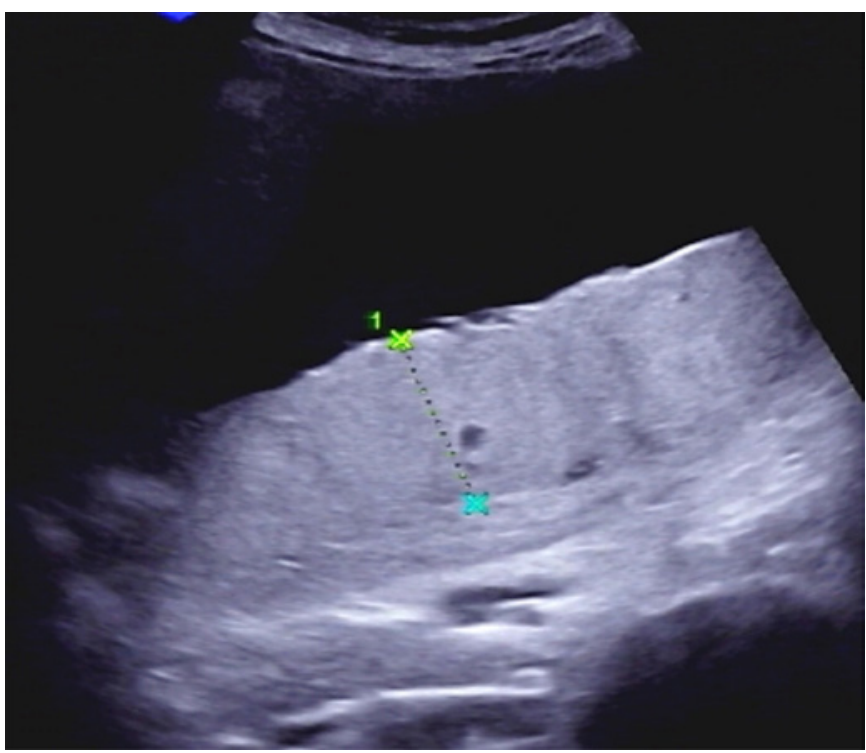

Figura 3: Ultrassonografia obstétrica: polidrâmnio.

\section{DISCUSSÃO:}

A atresia colônica apresenta-se na vida neonatal com vômito, distensão de alça e dificuldade para eliminação de mecônio. É uma condição rara que constitui apenas de 1,8 a $15 \%$ das atresias intestinais e pode ser confundida com outras condições como doença de Hirschsprung, síndrome do tampão meconial e íleo meconial ${ }^{3}$.

O diagnóstico pré-natal pela USG de obstruções intestinais em geral, comumente ocorre no $3^{\circ}$ trimestre de gestação, no entanto, a acurácia é variável. Esse méto do 
pode-se tornar limitante por depender do operante e de sua técnica e por apresentar campo de visão restrito. Além disso, muitos achados não são muito específicos e outros constituem-se como variantes não patológicas ${ }^{5}$.

Como mencionado, por exemplo, polihidraminio e até a dilatação de alças podem estar presentes em outras condições de obstrução. No entanto, a localização da dilatação e até mesmo a ausência de sinais típicos de outras atresias como o sinal de dupla, tripla ou quádrupla bolha, falam a favor de um diagnóstico de atresia colônica.

Ainda que nem sempre a ultrassonografia seja capaz de fornecer o diagnóstico correto e excluir os diferenciais, através de diagnóstico antecipado, pode-se oferecer aos pais da criança aconselhamento em relação a condição, especialmente nos casos em que a obstrução faz parte de algum outro diagnóstico, como é o caso do îleo meconial na fibrose cística ${ }^{6}$.

Além disso, ao se diagnosticar precocemente uma obstrução intestinal, é possível elaborar um plano terapêutico para a criança, envolvendo equipe multidisciplinar e centro de assistência capaz de atender qualquer complicação intraparto ou após o nascimento da criança. Um planejamento de intervenção antecipado é capaz de reduzir taxas de mortalidade e complicações no período neonatal ${ }^{6}$.

Um estudo retrospectivo realizado no Texas Children's Fetal Center em Houston, no Texas, de Janeiro de 2006 até Fevereiro de 2016, para mostrar o resultado do diag- nóstico pré-natal de obstrução gastrointestinal fetal. As taxas de sobrevivência encontradas foram de $88 \%$, sendo que nos casos de obstrução do intestino grosso, foi de $100 \%{ }^{5}$. Tal informação se difere bastante da mortalidade extremamente alta de décadas atrás. Dados sugerem que até 1950, apenas 125 crianças haviam sobrevivido de obs- truções intestinais congênitas ${ }^{1}$.

É sabido na medicina que o diagnóstico precoce em diversas áreas é responsável por melhorar o prognóstico do paciente e até reduzir custos para o Sistema de Saúde. Assim, avanços no método ultrassonográfico, bem como a capacitação adequada de profissionais da área da saúde e estudos no campo são aspectos de grande valia na obs- tetrícia e na medicina fetal.

\section{REFERÊNCIAS:}

1. Verma A, Rattan KN, Yadav R. Neonatal intestinal obstruction: A 15 year experience in a tertiary care hospital. Journal of Clinical and Diagnostic Research 2016; 10: 10-13.

2. Durante AP, Baratella JRS, Velhote MCP, Hercowitz B, Napolitano-Neto P, Salgado-Filho H, Lira JOO; Mari JA, Monteiro RP. Obstrução intesti- nal neonatal : Diagnóstico e Tratamento. Projeto Diretrizes Associação Médica Brasileira e Conselho Federal de Medicina 2005; 1 -12.

3. Figueiredo S, Helena L, Ribeiro V, Barcelos B, Augusto M, Costa B, Oli- veira GL, Esteves E, Silveira S. Atresia do trato gastrointestinal: avaliação por métodos de imagem. Radiologia Brasileira 2005; 38: 141-50.

4. Barnewolt, CE. Congenital abnormalities of the gastrointestinal tract. Se- minars in Roetgenology2004; 39: 263-81.
5. Lau P, Cruz S, Cassady CI, Mehollin-Ray AR, Ruano R, Keswani S, Lee TC, Olutoye OO, Cass D. Prenatal diagnosis and outcome of fetal gas-

trointestinal obstruction. Journal of Pediatric Surgery 2017; 52: 722-25. 6. Rubesova, E. Fetal bowel anomalies - US and MR assessment. Pediatric

Radiology 2012; 42: 101-06. 


\title{
ASPECTO ULTRASSONOGRÁFICO DO
}

\section{DISPOSITIVO ANTICONCEPCIONAL FEMININO \\ PERMANENTE ESSURE ${ }^{\circledR}$ - RELATO DE CASO}

\author{
ULTRASONOGRAPHIC ASPECT OF THE PERMANENT FEMALE \\ ANTICONCEPTIONAL DEVICE ESSURE ${ }^{\circledR}$ - CASE REPORT
}

\begin{abstract}
LEONARDO DE SOUZA PIBER ${ }^{1,2}$, CAIO VINÍCIUS DA FONSECA SILVA ${ }^{1}$, GEORGIA DE SÁ CAVALCANTE TEIXEIRA ${ }^{1}$, GABRIELA RAMOS REZENDE DEL CASTILHO1 , MATHEUS FLORENTINO DOS SANTOS ${ }^{1}$, REBECA GUIMARÃES RIBEIRO DE ALMEIDA ${ }^{2}$, MARIA TERESA NATEL DE ALMEIDA ${ }^{2}$, MARIA ELENA GUIMARÃES RIBEIRO DE ALMEIDA ${ }^{2}$
\end{abstract}

\section{RESUMO}

O Essure $e^{\circledast}$ um método contraceptivo que age através da oclusão tubária histeroscópica. O objetivo deste relato de caso é mostrar as imagens ultrassonográficas do dispositivo Essure ${ }^{\circledR}$ bem posicionado, por ser caso incomum na prática diária em diagnóstico por imagem.

\section{PALAVRAS-CHAVE: ANTICONCEPÇÃO, DISPOSITIVOS ANTICONCEPCIONAIS FEMININOS, ULTRASSONOGRAFIA, GINECOLOGIA, SAÚDE DA MULHER.}

\section{ABSTRACT}

Essure ${ }^{\circledast}$ is a contraceptive method that acts through hysteroscopic tubal occlusion. The purpose of this case report is to show the ultrasound images of the Essure ${ }^{\circledast}$ device well positioned, as it is an unusual case in the daily practice in diagnostic imaging.

\section{KEYWORDS: CONTRACEPTION, FEMALE CONTRACEPTIVE DEVICES, ULTRASONOGRAPHY, GYNECOLOGY, WOMEN'S HEALTH.}

\section{INTRODUÇÃO}

A esterilização feminina, por ligadura ou oclusão tubária, é o método mais efetivo e usado para planejamento familiar no mundo1. Os métodos para esterilização feminina incluem salpingectomia, ligação tubária, oclusão tubária laparoscópica e oclusão tubária histeroscópica2. O último, comercializado como Essure ${ }^{\circledR}$ da Bayer AG (Leverkusen, Alemanha), envolve a inserção de bobinas de liga de níquel / titânio contendo fibras de polietileno nas trompas de falópio, que causam uma reação fibrótica para obstruir as trompas e impedir a fertilização3. As vantagens apresentadas do procedimento incluem a não necessidade de incisões e/ou de anestesia geral4. A figura 1 mostra o dispositivo; figura 2 mostra a posição intratubária do dispositivo e a figura 3, o aspecto histeroscópico após o implante.

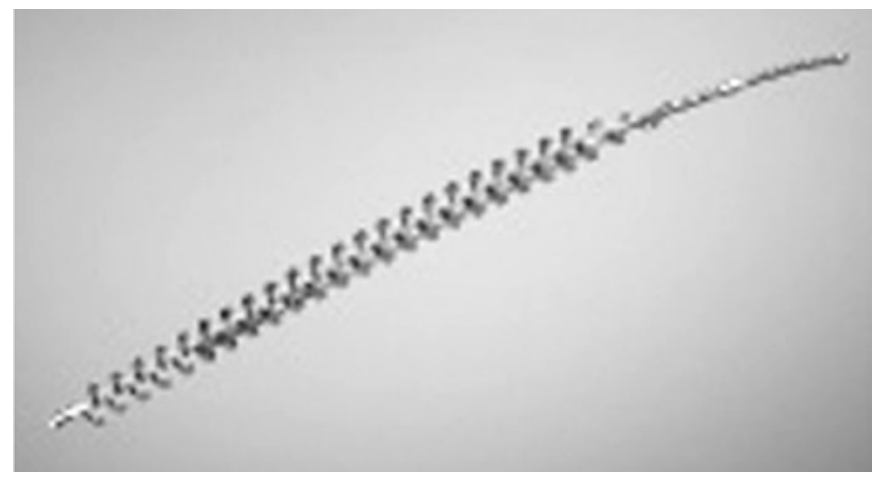

Figura 1 - 0 dispositivo intratubário Essure ${ }^{\circledast .5}$
1. Faculdade de Medicina da

Universidade Santo Amaro

2. CDB Inteligência Diagnóstica
Endereço para correspondência:

Leonardo Piber

Rua Marechal Deodoro, 135 apt. 62B - Santo Amaro

São Paulo - CEP 04738-000

Email: lpiber@prof.unisa.br 


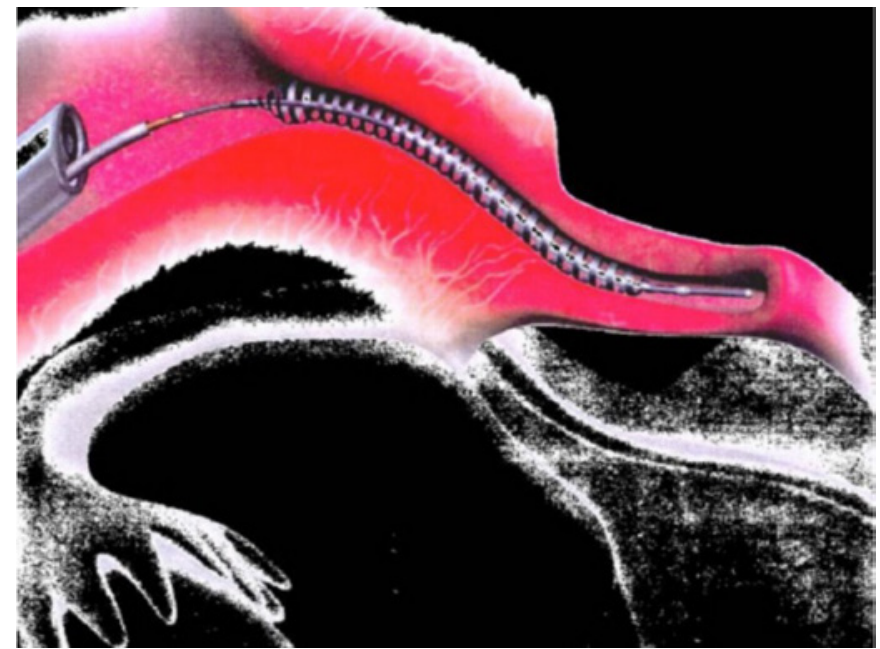

Figura 2 - Desenho demonstrando colocação do Essure ${ }^{\circledR}$.

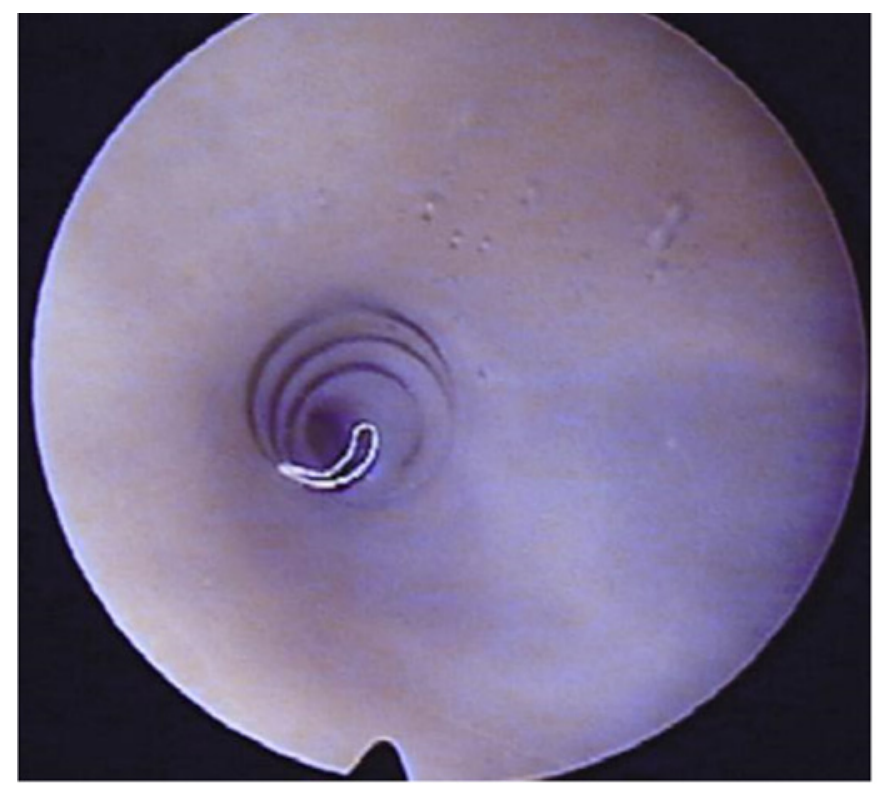

Figura 3 - Aspecto histeroscópico do Essure ${ }^{\circledR}$ após inserção.

O Essure ${ }^{\circledR}$, da Bayer AG (Leverkusen, Alemanha) foi o primeiro dispositivo mecânico aprovado pelo Food and Drug Administration (FDA), em 2002, para esterilização transcervical, e, em 2009, a Agência Nacional de Vigilância Sanitária (ANVISA) o aprovou no Brasil ${ }^{6}$.

O sistema é composto pelo dispositivo intratubário, um sistema de liberação e um cateter para acessar cada tuba pela via transcervical. O microdispositivo é uma mola de expansão dinâmica composta por um anel interno de aço inoxidável envolto por um anel externo de níquel e titânio que, sendo expansível, mantém o dispositivo na junção úte- rotubária durante o tempo necessário para ocorrer a fibrose. Fibras de poliéster estão ao redor da estrutura central e causam uma reação do tecido ao redor, seguida de fibrose, ocasionando uma oclusão irreversível das tubas. Este processo leva aproximadamente três meses e, durante este período, a mulher deve manter o método anticoncepcional que usava previamente ${ }^{7}$.

A revisão após a implantação do dispositivo é considerada a parte final do procedimento, sendo obrigatória aos três meses, para verificar se o implante está na pelve e em posição apropriada. Nos Estados Unidos, é solicitada uma histerossalpingografia (HSG) e, em outros países, realiza-se uma radiografia simples da pelve ou ultrassonografia. Se os dispositivos estiverem satisfatoriamente colocados na junção útero-tubária, a paciente pode abandonar o méto- do alternativo que utilizado para sua anticoncepção. Se a posição for insatisfatória, é solicitada uma $\mathrm{HSG}^{8}$. Porém a ultrassonografia transvaginal realizada três meses após a inserção do Essure ${ }^{\circledR}$ mostrou a mesma acurácia que a histerossalpingografia para detecção do correto posicionamento do dispositivo?.

O objetivo deste relato de caso é mostrar as imagens ultrassonográficas do dispositivo Essure ${ }^{\circledR}$ bem posicionado, por ser caso incomum na prática diária do imaginologista.

\section{RELATO DO CASO}

Paciente sexo feminino, 38 anos, assintomática, em exa- mes de rotina. Ilustra-se o aspecto ultrassonográfico do dis- positivo Essure, caracteristicamente ecogênico, na topografia das tubas uterinas, sendo possível avaliar sua relação com as estruturas dos tecidos moles adjacentes. Como a serosa é bem demarcada e facilmente identificável, a ultrassonografia permite a identificação da junção serouterotubal, o ponto onde a trompa de Falópio atravessa a serosa uterina, que é um marco anatômico importante para avaliar a localização da inserção de Essure. As figuras 4, 5 e 6 mostram a posição dos dispositivos bilateralmente.

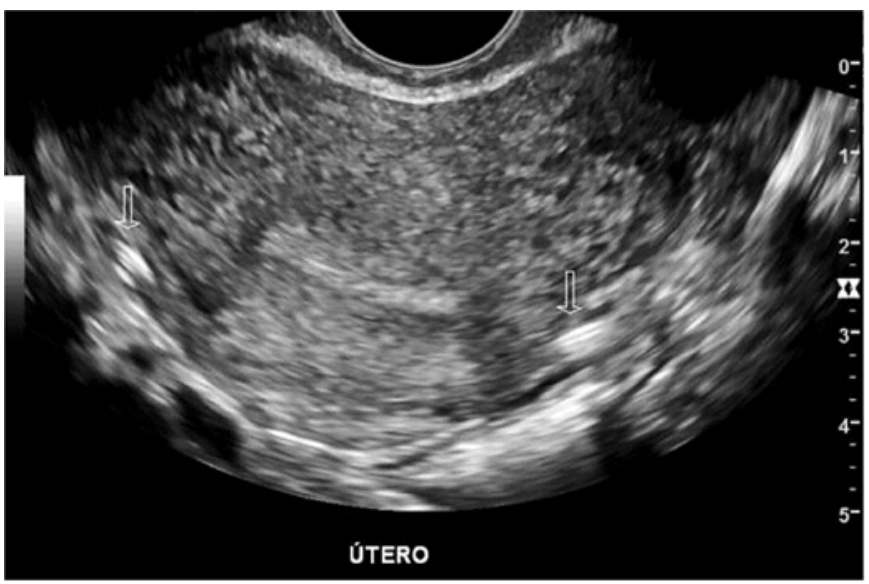

Figura 4 - Imagem ecogênica tubuliforme na topografia das tubas uterinas, identificada na junção serouterotubal, simétrica e bilateralmente. 


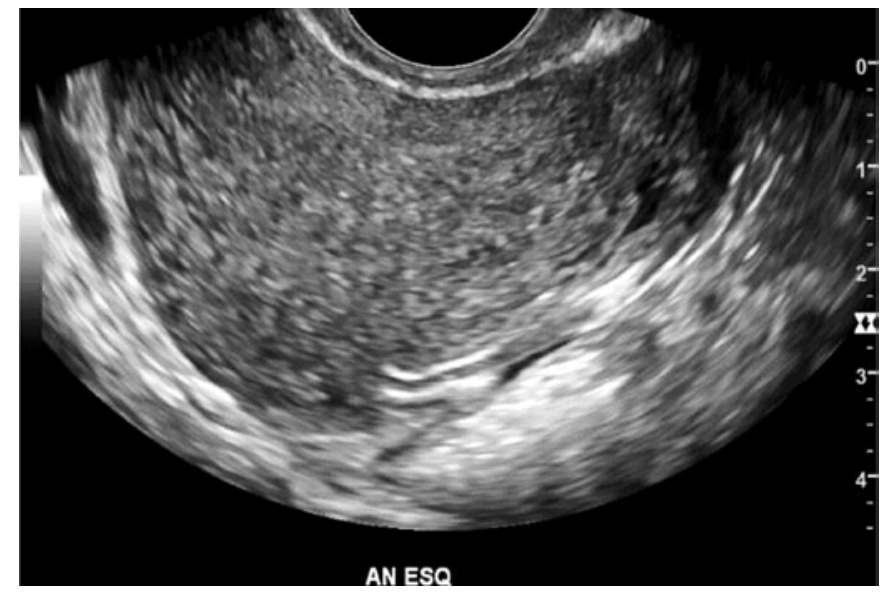

Figura 5 - Imagem ecogênica tubuliforme na topografia da tuba uterina esquerda, evidenciada como duas linhas hiperecogênicas paralelas.

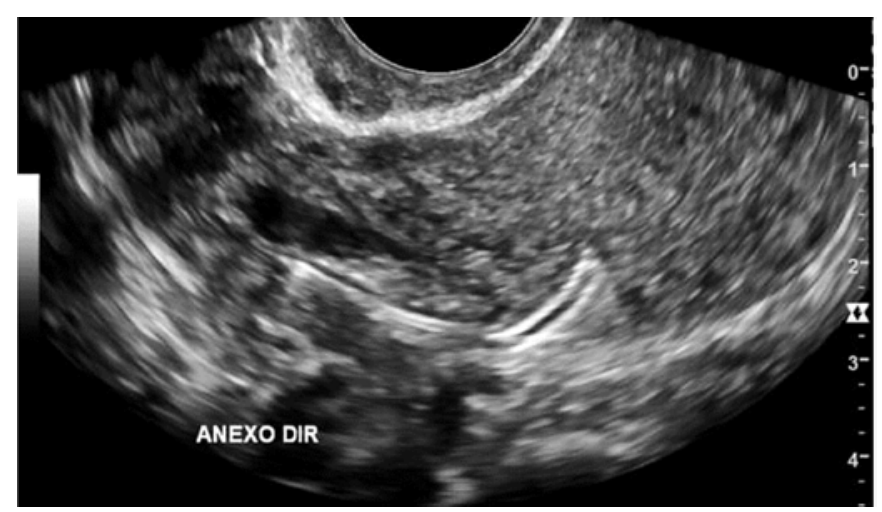

Figura 6 - Imagem ecogênica tubuliforme na topografia da tuba uterina direita, evidenciada como duas linhas hiperecogênicas paralelas.

\section{DISCUSSÃO}

O Essure ${ }^{\circledR}$ revolucionou a esterilização feminina ao permitir uma contracepção definitiva mediante um procedimento rápido, minimamente invasivo e de ambulatório, sem necessidade de recurso a anestesia, com rápido retorno à atividade laboral e igualmente eficaz ${ }^{10}$.

Vários estudos confirmaram a segurança, efetividade e baixa taxa de eventos adversos da técnica; no entanto, desde 2013 , o produto tem sido objeto de controvérsia, com muitas mulheres a reportar complicações com necessidade de reoperação ${ }^{11}$. Em 2015 foi publicada uma revisão que confirma a semelhante efetividade do Essure ${ }^{\circledR}$ na prevenção da gravidez, mas com um risco 10 vezes superior de reintervenção, quando comparado com a esterilização laparoscópica ${ }^{12}$.

Desde agosto de 2017, o certificado CE de conformidade do Essure ${ }^{\circledR}$ está suspenso na União Europeia pelo organismo National Standards Authority of Ireland, tendo o Infarmed emitido uma circular informativa no mesmo mês recomendando "como medida de precaução, que o dispositivo médico Essure ${ }^{\circledR}$ não seja adquirido nem utilizado enquanto durar a suspensão do certificado"13.

Depois de várias publicações mundiais relatarem possíveis eventos adversos ${ }^{14-16}$, em Julho de 2018, a Bayer decidiu descontinuar de forma voluntária a venda e distri- buição do dispositivo até final do mês de Dezembro, de forma a finalizar a sua comercialização ${ }^{17}$.

A ultrassonografia mostra-se adequada para localização pós-inserção precoce, pois a varredura pode assegurar o posicionamento correto do dispositivo e aliviar a ansiedade da paciente, ou ainda, diagnosticar mal posicionamento precoce.

Ressalta-se com este caso a importância da educação continuada através da documentação fotográfica diagnóstica e a integração entre ultrassonografistas e ginecologistas.

\section{REFERÊNCIAS}

1. Harrington EK, Gordon D, Osgood-Roach I, Jensen JT, Aengst J. Conceptualizing risk and effectiveness: a qualitative study of women's and providers' perceptions of nonsurgical female permanent contra- ception. Contraception. 2015; 92(2): 128-34.

2. Ahlborg J, Cordero C, Cullins V et al. Female sterilization. In: Lan- dry E, ed. Contraceptive sterilization: global issues and trends. New York, NY: Engender Health, 2002: 139-60.

3. Bayer Health Care Pharmaceuticals. Essure permanent birth control: Instructions for use. Milpitas, CA: Bayer Healthcare LLC, 2002.

4. Dhruva SS, Ross JS, Gariepy AM. Revisiting Essure-toward safe and effective sterilization. N Engl J Med 2015; 373: e17.

5. Shah, V, Panay N, Williamson R, Hemingway A. Hysterosalpingogram: an essential examination following Essure hysteroscopic sterilisation. The British Journal of Radiology 2011; 1005(84): 805-12.

6. Munro MG, Nichols JE, Levy B, Vleugels MP, Veersema S. Hyste- roscopic sterilization: 10-year retrospective analysis of worldwide pregnancy reports. J Minim Invasive Gynecol. 2014; 21 (2): 245-51. 7. Chapelle CF, Veersema S, Brölmann HA, Jansen FW. Effectiveness and feasibility of hysteroscopic sterilization techniques: a systematic review and meta-analysis. Fertil Steril. 2015; 103(6): 1516-25.

8. Veersema S. Hysteroscopy and contraception. Best Pract Res Clin Obstet Gynaecol. 2015; 29(7): 940-50.

9. Kerin JF, Munday D, Ritossa M, Rosen D. Tissue encapsulation of the proximal Essure micro-insert from the uterine cavity following hys- teroscopic sterilization. J Minim Invasive Gynecol 2007; 14: 202-04. 10. Félix N, Carvalho C, Amaral PI, Sousa F, Delgado E, Machado AI et al . Essure $\AA$ : efetividade, complicações e satisfação em 13 anos de experiência. Acta Obstet Ginecol Port 2019; 13(1): 20-6.

11. "Women report complications from Essure birth control" Acessado em Março 2020; http://articles.chicagotribune.com/2013-12-22/he- alth/ ct-essure-safety-met-20131222_1_essure-conceptus-fallopian-tubes.

12. Mao J, Pfeiter S, Schlegel P, Sedrakyan P. Safety and efficacy of hys- teroscopic sterilization compared with laparoscopic sterilization: an observational cohort study. BMJ. 2015; 351: h5162.

13. Infarmed, Autoridade Nacional do Medicamentos e Produtos de Saúde, I.P. Acessado Março de 2020. http://www.infarmed.pt/documents/15786/1878969/Suspens\%C3\%A3o+do+dispositivo+m\%C3\%A9dico+Essure+do+fabricante+Bayer+Healthcare\%2C+LLC/4aca2815-9e93-4e72-8a4e-864548873072.

14. Summary safety review - ESSURE permanente birth control system assessing the risk of complications and the potencial need for device removal. Acessado em Março de 2020. https://www.canada.ca/en/ health-canada/services/drugs-health-products/medeffect-canada/ safety-reviews/summary-safety-essure-permanent-birth-control-sys- tem-assesing-risk.html. 
15. French National Agency for Medicines and Health Products Safety. Temporary Specialist Scientific Committee for permanent steriliza- tion device Essure. Acessado em Março de $2020 \mathrm{http} / / /$ ansm.sante. fr/LANSM/Comites-scientifiques-specialists-temporaires/Comites- -scientifiques-temporaires/Comites-scientifiques-temporaires/CSST- -Dispositif-de-sterilisation-definitive-Essure

16. Bouillon K, Bertrand M, Beder G, et al. Association of hysteroscopic vs laparoscopic sterilization with procedual, gynecological, and me- dical outcomes. JAMA. 20158; 319(4): 375-87.

17. Bayer to voluntarily discontinue U.S. sales of Essure at end of 2018 for business reasons. Acessado em Março de 2020. https://www. bayer.us/ en/newsroom/press-releases/article/?id=123229 


\title{
LINFOMA NA GRAVIDEZ COM FETO VIVO: RELATO DE CASO
}

\section{LYMPHOMA DURING PREGNANCY WITH LIVE FETUS: CASE REPORT}

\author{
VALDIVINA ETERNA FALONE'; WALDEMAR NAVES DO AMARAL FILHO'; TARIK KASSEM SAIDAH3 ; ADRIELLY JOICE \\ MENDES SANTANA BRANDÃO', THAYNARA DE MORAES PACHECO'; LORENA TASSARA QUIRINO VIEIRA²; \\ MATHEUS FERREIRA GONÇALVES ${ }^{1}$, WALDEMAR NAVES DO AMARAL ${ }^{1}$
}

\section{RESUMO}

Os linfomas são neoplasias do sistema imune com origem nas células B, Tou Natural Killer que leva ao aparecimento de massas tumorais. Podem ser classificados como Hodgkin e Não Hodgkin. O câncer é a segunda maior causa de morte em mulheres em idade reprodutiva, sendo que os linfomas são a quarta neoplasia mais diagnosticada em gestantes, dado o pico de incidência da doença durante a fase reprodutiva feminina. $O$ objetivo deste relato é apresentar um caso de linfoma durante gestação com feto vivo.

PALAVRAS-CHAVE: LINFOMA, GRAVIDEZ, LINFOMA NA GRAVIDEZ

\begin{abstract}
Lymphomas are neoplasms of the immune system originating from B, T or Natural Killer cells that lead tumor masses. They can be classified as Hodgkin and Non-Hodgkin. Cancer is the second most prevalent cause of death in women during reproductive age, and lymphomas are the fourth most diagnosed cancer in pregnant women, given the peak incidence of the disease during the female reproductive phase. The aim of this report is to present a case of lymphoma during pregnancy with a live fetus.
\end{abstract}

\section{KEYWORDS: LYMPHOMA, PREGNANCY, LYMPHOMA IN PREGNANCY}

\section{INTRODUÇÃO}

Os linfomas são neoplasias do sistema imune com origem nas células B, T ou Natural Killer que leva ao apareci- mento de massas tumorais. Podem ser classificados como Hodgkin e Não Hodgkin. A estimativa brasileira para 2018 era de 2.530 novos casos de Linfoma Hodgkin e 10.180 Não Hodgkin, acometendo 1.050 e 4.810 mulheres, respectivamente ${ }^{1}$. O câncer é a segunda maior causa de morte em mulheres em idade reprodutiva, sendo que os linfomas são a quarta neoplasia mais diagnosticada em gestantes, dado o pico de incidência da doença com a fase reprodutiva feminina ${ }^{2}$.

O diagnóstico para linfoma Hodgkin e Não Hodgkin é feito com exame histopatológico de biópsia linfonodal. $\mathrm{O}$ linfoma de Hodgkin é classificado como Clássico, tendo quatro subtipos (esclerose nodular, celularidade mista, depleção linfocitária e rico em linfócitos) e linfoma Hodgkin com predomínio linfocitário nodular. Já o linfoma Não Hodgkin é classificado como indolente (40\%) ou de alto grau (60\%) ${ }^{1}$.
A excisão do linfonodo só pode ser feita de forma segura para o feto no primeiro trimestre. Ademais, o esta- diamento é feito com anamnese, exame físico, laboratorial e biópsia de medula óssea. Evitar o uso de exames de imagem com alta carga de radiação. Considerar ressonância nuclear magnética sempre que possível. O tratamento com radioterapia e quimioterapia durante a gravidez deve levar em consideração o risco-benefício para a saúde da gestante e do feto. Os riscos de quimioterapia no primeiro trimestre vão de abortamento espontâneo até malformações ${ }^{3}$.

\section{RELATO DE CASO}

Paciente de 33 anos, G5P2A2, com antecedentes pessoais de tireoidite de Hashimoto e diabetes gestacional nas gestações anteriores. $\mathrm{Na} 30^{\mathrm{a}}$ semana de gestação notou o surgimento de nodulações em ambas axilas. Procurou serviço médico onde foi realizada biópsia de linfonodos, que revelou presença de linfoma no dia 02/03/19. Também foram identificados nódulos acometidos nas mamas. Apesar

\footnotetext{
1. Faculdade de Medicina da UFG

2. PUC- GOIÁS

3. UniEvangélica
}

Mailing address:

Waldemar Naves do Amaral

Alameda Cel. Joaquim de Bastos, 243 - St. Marista

Goiânia - CEP 74175-150

Email: waldemar@sbus.org.br 
da doença materna, feto de 34,5 semanas com sinais vitais normais (ver figuras 1 e 2 ).

Feto a termo com RN e placenta saudável. Quimio- terapia logo após o parto, seguido de radioterapia com óbito materno após 6 meses.

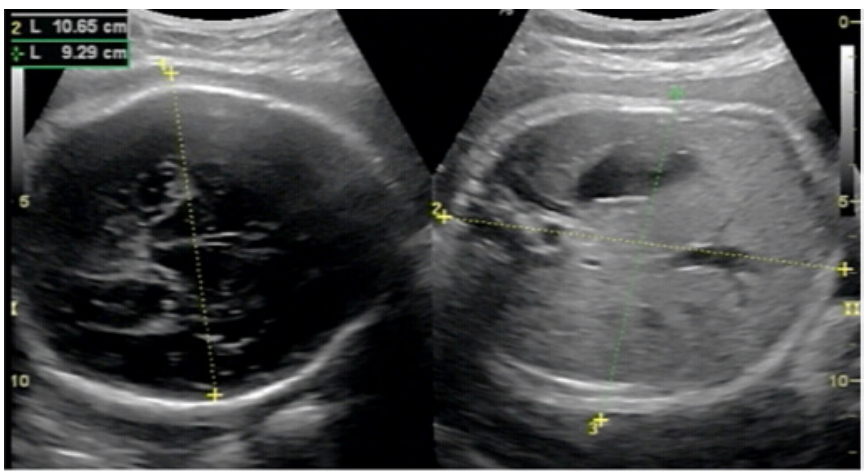

Figura 1: Ultrassonografia obstétrica evidenciando feto normal. Fonte: Clínica Fértile

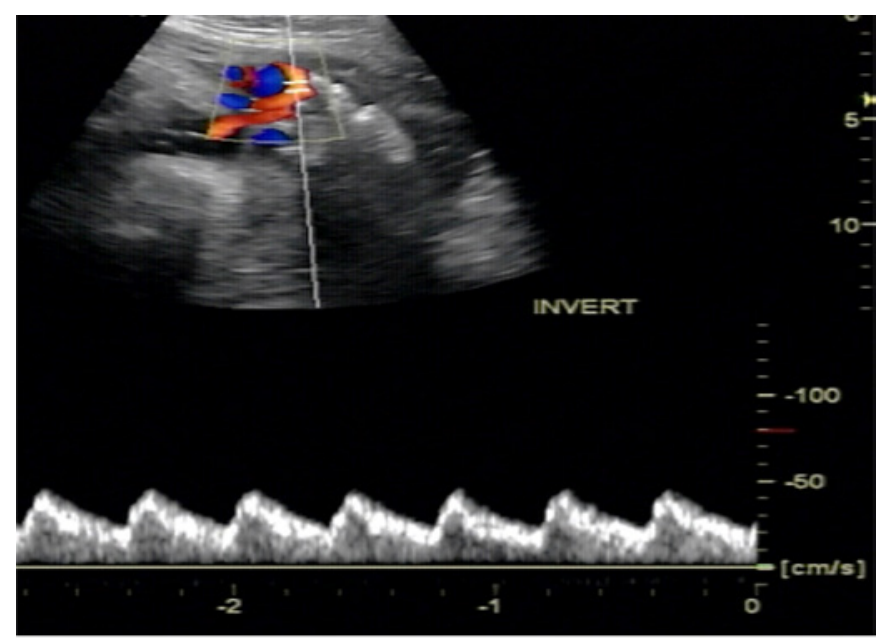

Figura 2: Doppler obstétrico evidenciando artéria umbilical normal. Fonte: Clínica Fértile

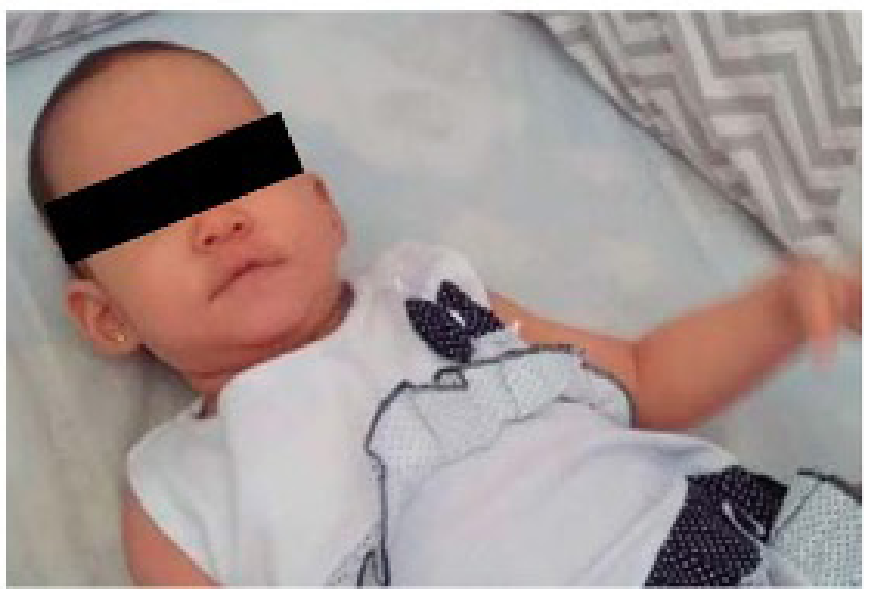

\section{DISCUSSÃO}

Dentre os exames para estadiamento de LH estão exames de imagem como radiografia e tomografia computadorizada de tórax, abdome e pelve, com alta emissão de radiação ionizante. Diante disso, exames alternativos são a ressonância nuclear magnética e a ultrassonografia (USG), mais adequados para a fase de gestação, embora a ultras- sonografia seja um exame examinador dependente ${ }^{2}$.

Embora questione-se sobre aumento de risco de par- to prematuro, baixo peso ao nascer e maior número de abortos de fetos, estudos mostram que não se pode des- cartar a possibilidade de anormalidades congênitas em filhos de mães Hodgkin. A USG morfológica vem, nesse casso, como aliada para detectar malformações e aneu- ploidias fetais. O seguimento ultrassonográfico garante maior acurácia da idade gestacional e avaliação de ana- tomia e desenvolvimento fetal permitindo segurança na tomada de decisão quanto ao tratamento da paciente e segurança do feto ${ }^{4}$.

Em estudo inglês comparando 129 crianças de mães que tiveram câncer durante a gravidez e fizeram algum tipo de tratamento após o segundo trimestre de gesta- ção com filhos de mães saudáveis, pode-se observar que não houve diferenças significativas entre desenvolvimento inicial e avaliação cardiológica entre as crianças ${ }^{5}$. Já estu- do dinamarquês mostrou elevado grau de prematuridade entre recém-nascidos de mães com LH comparado aos bebês de mães saudáveis ${ }^{2}$.

\section{CONSIDERAÇÕES}

O tratamento em gestantes com câncer é possível, desde que se evite atrasos no diagnóstico. Apesar das complicações associadas, a vantagem do tratamento já está evi- denciada e deve ser discutido e devidamente esclarecido com a paciente para que esta exerça sua autonomia na tomada de decisão de seu tratamento ${ }^{3}$.

\section{REFERÊNCIAS}

1. INCA. Estimativa 2018: incidência de câncer no Brasil / Instituto Nacional de Câncer José Alencar Gomes da Silva. Coordenação de Prevenção e Vigilância. - Rio de Janeiro: INCA, 2017. http://www1.inca.gov. br/estimativa/2018/index.asp. acessado em 30 de ago. 2019.

2. Kassab C, Perini GF, Bollmann PW, Kerbauy FR, Hamerschlak N. Linfoma de Hodgkin e gestação: série de casos e proposta de protocolo para tratamento. Einstein (São Paulo). 2011;9 (2 Pt 1): 216-9. https://doi. org/10.1590/S1679-45082011RC1992.

3. Atala A, Neto AEH, Riani LR, Soares GMT, Miranda MAV, Gomide BO, Silva MN, Silva RN. Linfoma de Hodgkin e gestação. Relato de caso e revisão de literatura. Universidade Federal de Juiz de Fora (Minas Gerais). Ver Bras Clin Med 2010; 8(3): 276-82.

4. Peralta CFA; Barini R. Ultrassonografia obstétrica entre a 11a e a 14a semanas: além do rastreamento de anomalias cromossômicas. Rev. Bras. Ginecol. Obstet. 2011; 33 (1): 49-57.

5. INCA. Terapia antineoplásica em situações clínicas especiais: uma visão integral do cuidado. Pacientes gestantes. https://www.inca.gov.br/ bvscontrolecancer/publicacoes/Boukai_Terapia_antineoplasica_clinicas_especiais_cuidado_pacientes_gestantes.pdf

Figura 3: Bebê saudável com 7 meses de vida! Fonte: arquivos do autor 


\title{
FASCIÍTE NODULAR: UM CASO SIMULANDO PATOLOGIA SUSPEITA À ULTRASSONOGRAFIA
}

\author{
NODULAR FASCIITIS: A CASE SIMULATING SUSPICIOUS PATHOLOGY \\ AT ULTRASONOGRAPHY
}

\author{
ANA CAROLINA SILVA ${ }^{1,2}$, LUIZA CAIXETA ${ }^{1,2}$, GABRIEL TOFANI ${ }^{1,2}$, LAIO RASPANTEE ${ }^{1,2}$, ELIZABETH DE AYUB ${ }^{2}$, \\ LETICIA AZEREDO ${ }^{2}$, LEONARDO PEREIRA ${ }^{2}$, CARLOS HENRIQUE SILVA ${ }^{2}$
}

\begin{abstract}
RESUMO
A fasciíte nodular é um tumor benigno que acomete os tecidos subcutâneos, cuja etiologia ainda não foi completamente elucidada. Acomete predominantemente as extremidades superiores de pacientes que se encontram entre a segunda e quarta décadas de vida. Sua apresentação clínica e imaginológica pode se assemelhar a um tumor maligno, especialmente devido ao seu crescimento rápido, tornando-se assim um desafio diagnóstico. O tratamento usualmente é a exérese cirúrgica da lesão. O objetivo deste estudo é relatar um caso de fasciíte nodular, que se apresentou em localização não habitual e simulou tumoração suspeita ao ultrassom, além de fazer uma breve revisão de literatura sobre esta patologia e seus aspectos ultrassonográficos.
\end{abstract}

\section{PALAVRAS-CHAVE: FASCIIITE NODULAR, ULTRASSONOGRAFIA, ELASTOGRAFIA, RESSONÂNCIA MAGNÉTICA, NÓDULO.}

\begin{abstract}
Nodular fasciitis is a benign tumor of the subcutaneous tissue, and its etiology has not yet been truly elucidated. It predominantly affects the upper extremities of patients between the second and fourth decades of life. The clinical and imaging features of this entity can resemble those of malignant tumors, especially due to the rapid growth, thus, becoming a diagnostic challenge. Treatment usually consists of surgical removal of the lesion. The objective of this study is to report a case of a patient with nodular fasciitis of unusual location and simulated suspect tumor at ultrasonography and to briefly review current literature about this pathology and its sonographic characteristics.

\section{KEYWORDS: NODULAR FASCIITIS, ULTRASONOGRAPHY, ELASTOGRAPHY, MAGNETIC RESONANCE IMAGING, NODULE.}

\section{INTRODUÇÃO}

A fasciíte nodular (FN) é uma condição benigna em que ocorre proliferação autolimitada de fibroblastos e miofibroblastos e que foi descrita pela primeira vez em 1955, por Konwaler et. $\mathrm{a}^{11}$. Caracteristicamente apresenta crescimento rápido, alta celularidade e elevada atividade mitótica ${ }^{1-3}$, podendo, então, ser confundida com tumores malignos como os sarcomas ${ }^{1-5}$.

Acomete preferencialmente adultos jovens, entre 20 e 45 anos, sem predileção de gênero ${ }^{2,6}$. As regiões anatômicas de maior acometimento segundo a literatura são os membros superiores, principalmente os antebraços ${ }^{1,2,7}$. Frequentemente se localiza na região subcutânea, mas há relatos de serem identificados em planos mais profundos como os intramusculares e intra-articulares ${ }^{4,6}$.

\section{RELATO DE CASO}

Paciente de 30 anos, sexo feminino, negra, foi encaminhada ao serviço de ultrassonografia devido ao surgimento de nódulo palpável, localizado abaixo da fúrcula esternal, com relato de crescimento rápido e progressivo.

Ao exame físico, evidenciou-se lesão nodular endurecida, medindo aproximadamente $5 \mathrm{~mm}$. O exame ultrassonográfico de partes moles com Doppler revelou nódulo de limites precisos, contornos irregulares, espiculado, marcadamente hipoecóico, com discreto aumento da ecogenicidade dos te-

\footnotetext{
1 Ciências Médicas de Minas Gerais (PGCM-MG)

- Fundação Educacional Lucas Machado (FELUMA).

2 Rede Mater Dei de Saúde
}

Mailing address:

Ana Carolina de Faria e Silva

Rua Venezuela, 610, apt.404 - Sion

Belo Horizonte - CEP 30.315-250

E-mail: sfaria.carol@gmail.com 
cidos circunjacentes, localizado no plano subcutâneo, mostrado na figura 1. O nódulo mediu aproximadamente $6 \times 3$ x $5 \mathrm{~mm}$ (figura 2), com seu centro distando $4 \mathrm{~mm}$ do plano da pele e $26 \mathrm{~mm}$ inferiormente à fúrcula esternal (figura 3 ). Durante o estudo com Doppler colorido, o nódulo apresentou vascularização interna de fácil captação e o estudo com Doppler espectral revelou fluxo pulsátil, com padrão arterial de baixa resistência (IR: 0,61), evidenciados na figura 4. Em estudo complementar com elastografia dinâmica por compressão (strain elastography), o nódulo apresentou-se duro, com uma rigidez cerca de 5,3 vezes superior à dos tecidos circunjacentes (figura 5).

Após a realização do estudo ultrassonográfico, a paciente foi encaminhada ao serviço de cirurgia plástica, que procedeu à exérese da lesão. Tal procedimento foi realizado sem intercorrências e a peça cirúrgica foi encaminhada ao laboratório de anatomia patológica. A análise anatomopatológica revelou proliferação fusocelular relativamente monomórfica, sem atipias significativas e com extravasamento de hemácias, mostrado nas lâminas da figura 6 .

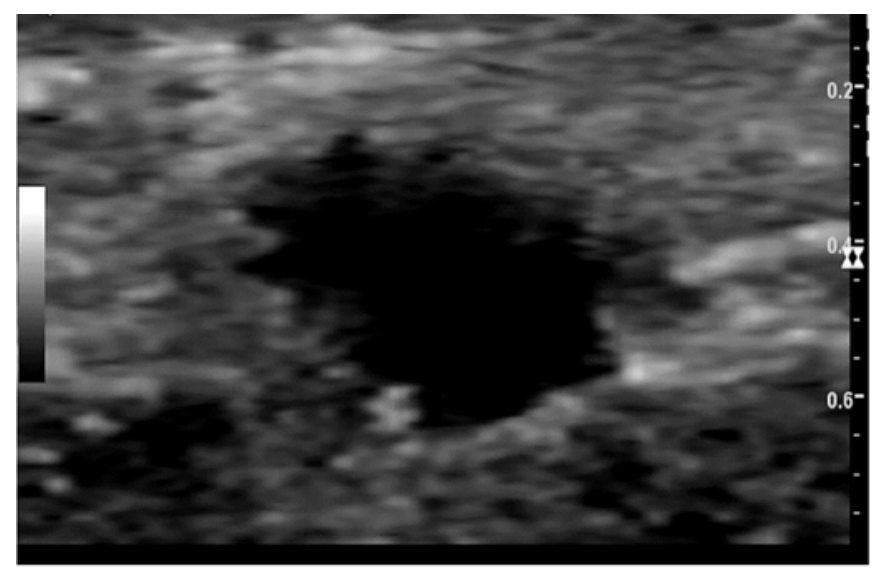

Figura 1: Nódulo sólido, marcadamente hipoecóico, de contornos irregulares e limites pouco precisos.

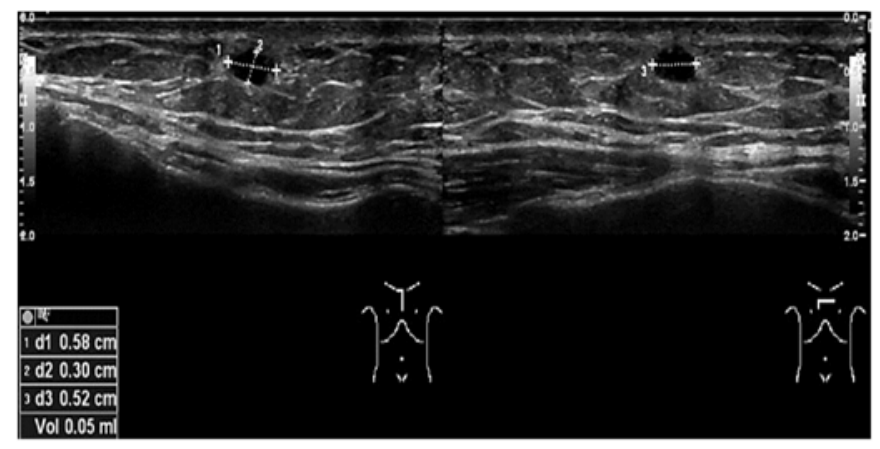

Figura 2: Medidas do nódulo nos planos longitudinal (esquerda) e transversal (direita), com volume estimado em $0,05 \mathrm{~cm} 3$.

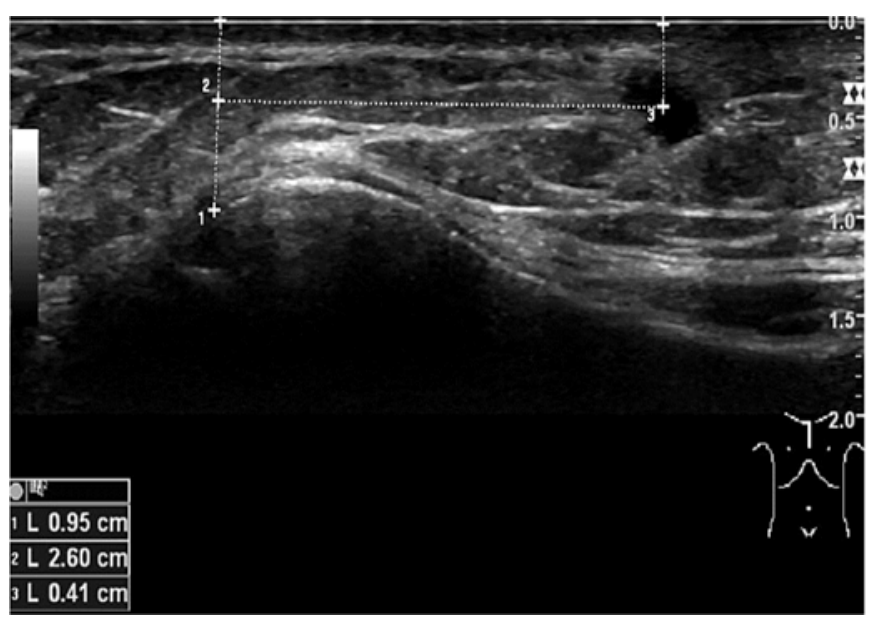

Figura 3 - $O$ centro da lesão dista aproximadamente $4 \mathrm{~mm}$ da pele e $26 \mathrm{~mm}$ caudal à fúrcula esternal.

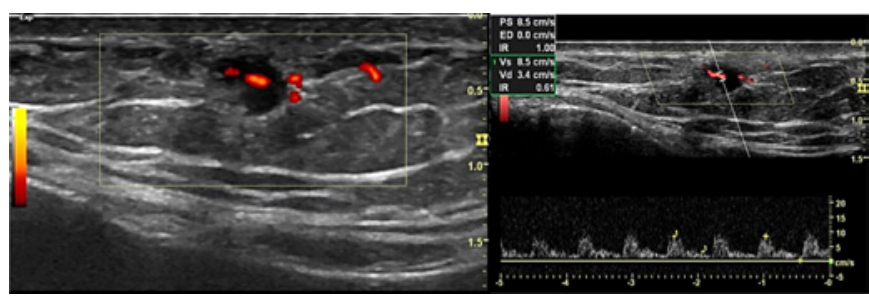

Figura 4 - 0 nódulo exibe fácil captação de fluxo central ao estudo Power Doppler (esquerda), com padrão de fluxo arterial de baixa resistência ao estudo Doppler Espectral (direita).

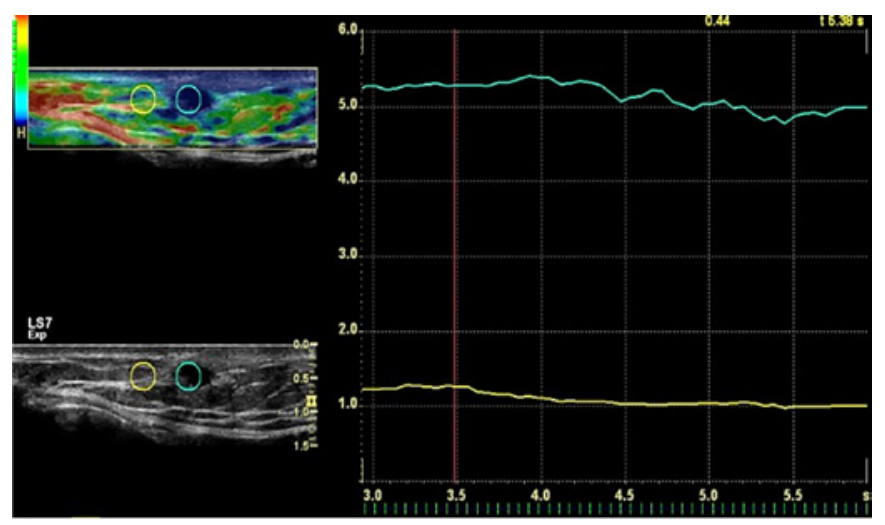

Figura 5 - Elastografia por compressão evidenciou rigidez do nódulo (círculo azul) 

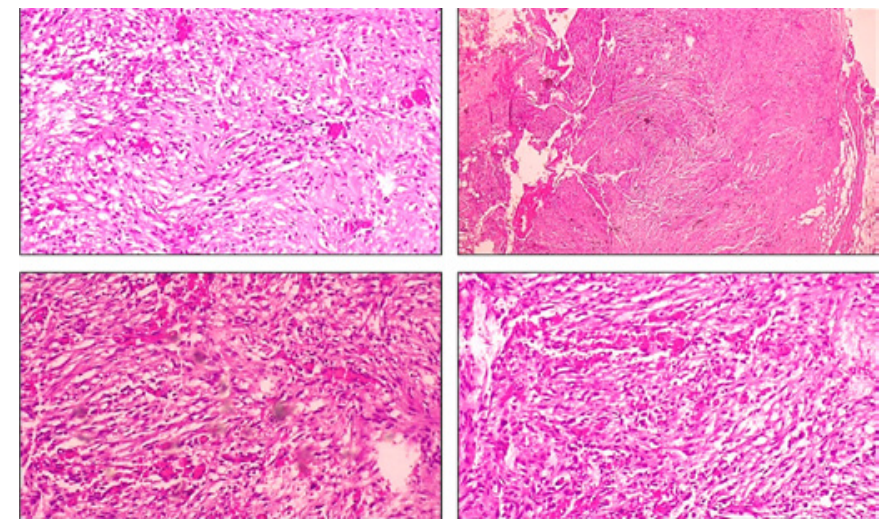

Figura 6 - Proliferação fusocelular relativamente monomórfica, sem atipias significativas e com extravasamento de hemácias.

\section{DISCUSSÃO}

A fasciíte nodular é uma lesão benigna, caracterizada pela proliferação de fibroblastos e constantemente confundida histologicamente com sarcomas ${ }^{1-5}$.

Sua etiologia não foi completamente esclarecida, mas Velagaleti et al., revisaram publicações apontando o envolvimento de anormalidades clonais nos mecanismos de reparação tecidual relacionados com o gene FGR7 (fator de crescimento de fibroblastos) localizado no cromossomo $15^{8}$. Já Oliveira, AM e Chou, MM. (2013) observaram elevada expressão de RNAm do gene USP6 (protease ubiquitina-específica) nessas lesões e levantaram a hipótese de um mecanismo oncogênico envolvendo rearranjos genômicos no locus desse gene6.

A FN comumente se apresenta como um nódulo único, de crescimento rápido ( 2 a 4 semanas), com diâmetro que raramente excede $5 \mathrm{~cm}$ 6,7,9 e pode ou não vir acompanhada de dor 4,7. Há relatos de associação com trauma local em 10 a $15 \%$ dos $\operatorname{casos}^{1,2,6}$. As regiões anatômicas mais aco- metidas são as extremidades superiores e o tronco, seguidos da cabeça e pescoço e extremidades inferiores ${ }^{1,2,4,7,9}$, mas podem acometer qualquer parte do corpo ${ }^{1,9}$. Já na população pediátrica, a cabeça e pescoço são as regiões mais afetadas 1,2. Sintomas como dormência, parestesia e irradiação de dor são infreqüentes e denotam compressão de nervos periféricos ${ }^{4}$.

Ela pode assumir três formas principais, que são baseadas na sua localização anatômica: a forma subcutânea (que é a mais comum); a forma intramuscular (que mimetiza lesões malignas) e a forma fascial ${ }^{2,4}$.

Microscopicamente, a FN basicamente consiste em fibroblastos arranjados em feixes curtos e fascículos espalhados dentro de um estroma mixoide ou fibroso ${ }^{6}$. Baseado na composição histológica predominante, a lesão pode ser: fibrosa, mixoide ou celular ${ }^{6}$. Células gigantes osteoclasto-símile podem estar presentes, assim como um infiltrado de linfócitos e extravasamento de eritrócitos, sem depósito de hemossiderina ${ }^{2}$. Apresenta grande variação de padrão morfológico e frequentemente pode ser mista, constituída de células fusiformes, delgadas, semelhantes a fibroblastos ${ }^{7}$. No caso descrito, a macroscopia da lesão demonstrou-se predominantemente fibrosa.

A ultrassonografia usualmente evidencia achados bastante inespecíficos, tais como massa sólida, bem definida, ovoide ou lobulada, isoecogênica ou hipoecogênica ${ }^{1}$. Em alguns casos, pode também apresentar sombra acústica posterior ${ }^{2}$.

À semelhança dos achados ultrassonográficos, a FN habitualmente se apresenta, na ressonância magnética, como lesão bem delimitada, arredondada ou ovalada, porém sem um padrão específico de intensidade de sinal nas diferentes sequências ${ }^{4,9}$. Na sequência ponderada em T1, a FN geralmente se apresenta com aumento de sinal em relação ao tecido muscular adjacente e levemente heterogênea. Já na ponderação em T2 as lesões são relativamente homogêneas e hiperintensas em relação ao tecido adiposo subcutâneo ${ }^{4}$. Contudo, a depender dos componentes histológicos das lesões, estas podem se apresentar ligeiramente hipointensas em todas as sequências ${ }^{9}$. Devido a este fato, alguns autores ${ }^{9}$ advogam que os subtipos mixóide e celular mostram sinal mais intenso do que o do músculo em T1 e são também hiperintensas em relação à gordura nas sequências ponderadas em $\mathrm{T} 2$, enquanto que no subtipo fibroso, a lesão se apresenta hipointensa em relação ao tecido muscular em todas as ponderações. Tais propriedades dos diferentes subtipos histológicos e a localização da lesão vão influenciar o padrão de realce ao meio de contraste com gadolínio9. Alta celuraridade e densa vascularização estão relacionados a um realce precoce após injeção intravenosa de gadolínio que se mostrou homogêneo principalmente quando a lesão estava localizada na topografia do subcutâneo? ${ }^{9}$ Tendo em vista apenas aspectos de imagem, os diagnósticos diferenciais são diversos e incluem fibromatose agressiva, adenomegalia, dermatofibroma, fibrossarcoma e fibrohistiocitoma maligno ${ }^{2,4}$. Dessa forma, o diagnóstico de FN não pode ser firmado usando apenas os resultados dos exames de imagem ${ }^{2}$.

A elastografia por compressão (strain elastography) é uma técnica ultrassonográfica baseada na deformação es- tática de um material linear, isotrópico e elástico ${ }^{10,11}$. De maneira mais simples, ela pode descrever o deslocamento (compressão) ou rigidez de determinado tecido em resposta a aplicação de uma força no local e com isso tecidos rígidos tendem a se deformar menos e apresentam menor tensão do que os tecidos complacentes quando a mesma força é aplicada ${ }^{12}$.

Estudos recentes evidenciam que a elastografia tem alta sensibilidade e especificidade para diferenciação de lesões benignas de malignas, quando a técnica é aplicada adequadamente ${ }^{13}$.

O tratamento de escolha é a excisão cirúrgica da le- 
são ${ }^{2,4,7}$, mas alguns autores sugerem alternativas como observação e injeção de corticóides no interior da lesão ${ }^{4}$. A recorrência é bastante rara, sendo reportada em torno de $1-2 \%$ até $10 \% 0^{2,4,7}$, provavelmente por ressecção incomple$\mathrm{ta}^{2}$. Nesta paciente o tratamento oferecido foi a exérese cirúrgica completa da lesão, sem necessidade de tratamento complementar.

A fasciíte nodular é um tumor benigno relativamente infrequente, com apresentação clínica e imaginológica pouco características, com diversos diagnósticos diferenciais, inclusive com patologias de natureza maligna.

A ultrassonografia pode ser considerada como método inicial para avaliação destas lesões devido a sua ampla acessibilidade, disponibilidade e o não uso de radiação ionizante, podendo oferecer informações valiosas para a elaboração de uma hipótese diagnóstica. Ferramentas como Doppler colorido, Doppler pulsado e elastografia são úteis para aumentar a sensibilidade da ecografia em modo $B$.

O diagnóstico final é feito após realização de biópsia ou exérese cirúrgica da lesão. A peça retirada é encaminhada para análise anatomopatológica e em algumas situações o estudo imuno-histoquímica deve ser realizado para confirmação diagnóstica.

\section{REFERÊNCIAS}

1. Di Serafino M, Maurea S, Vallone G. Nodular fasciitis of the chest: case report of a rare presentation. Musculoskeletal surgery. 2011; 95(3): 251-3.

2. Roberti A, Roberti MdRF, Carneiro SdS, rapoport A, Dedivitis RA. Fasciíte nodular em região cervical: relato de caso. Revista Paraense de Medicina. 2007; 21: 41-4.

3. Aydin $\mathrm{O}$, Oztuna $\mathrm{V}$, Polat $\mathrm{A}$. Three cases of nodular fasciitis: primary diagnoses by fine needle aspiration cytology. Cytopathology: official journal of the British Society for Clinical Cytology. 2001; 12(5): 346-7.

4. Leung LY, Shu SI, Chan AC, Chan MK, Chan CH. Nodular fasciitis: MRI appearance and literature review. Skeletal radiology. 2002; 31 (1): 9-13.

5. Wirman JA. Nodular fasciitis, a lesion of myofibroblasts: an ultrastructural study. Cancer. 1976; 38(6): 2378-89.

6. Oliveira AM, Chou MM. USP6-induced neoplasms: the biologic spectrum of aneurysmal bone cyst and nodular fasciitis. Human pathology. 2014; 45(1): 1-11.

7. Souza LS, Almeida WLd, Costa ALD, Silva APS, Souza LLd. Fasceíte nodular. Rev Bras Cir Cabeça Pescoço. 2009; 38(4): 274-5.

8. Velagaleti GV, Tapper JK, Panova NE, Miettinen M, Gatalica Z. Cytogenetic findings in a case of nodular fasciitis of subclavicular region. Cancer genetics and cytogenetics. 2003; 141 (2): 160-3.

9. Wang XL, De Schepper AMA, Vanhoenacker F, De Raeve H, Gielen J, Aparisi F, L Rausin, Somville J. Nodular fasciitis: correlation of MRI findings and histopathology. Skeletal radiology. 2002; 31(3): 155-61.

10. Ophir J, Cespedes I, Ponnekanti H, Yazdi Y, Li X. Elastography: a quantitative method for imaging the elasticity of biological tissues. Ultrasonic imaging. 1991; 13(2): 111-34.

11. Gao L, Parker KJ, Lerner RM, Levinson SF. Imaging of the elastic properties of tissue--a review. Ultrasound in medicine \& biology. 1996; 22(8): 959-77.

12. Choi YJ, Lee JH, Baek JH. Ultrasound elastography for evaluation of cervical lymph nodes. Ultrasonography. 2015; 34(3): 157-64.

13. Qiong Xie, Yi Bing Li, Haoping Li, Hongli Ji. Elastography for the differentiation of benign and malignant cervical lymph node: a meta-analysis. Int J Clin Exp Me. 2016; 9(8): 16094-101. 


\title{
DIAGNÓSTICO PRENATAL DE ESQUIZENCEFALIA COM EVOLUÇÃO PROGRESSIVA UNILATERAL PARA BILATERAL - RELATO DE CASO
}

\author{
PRENATAL SCHIZENCEPHALY DIAGNOSIS WITH PROGRESSIVE \\ UNILATERAL TO BILATERAL EVOLUTION - CASE REPORT
}

RENATO MURTA, MARCOS FARIA, LUCCA PENNA FARIA, BRUNO PENNA FARIA, HEVERTON PETTERSEN

\section{RESUMO}

A esquizencefalia é uma malformação congênita rara do sistema nervoso central (SNC). Pertencente ao grupo de defeitos de migração celular do $S N C$, surge entre o 20 e o 50 mês de gestação, caracterizada por substância cinzenta dismórfica delineando as fendas no córtex cerebral que se estendem medialmente a partir do espaço subaracnóidea comunicando com o ventrículo cerebral ipsilateral.

Este relato é de um feto que foi encaminhado com o diagnóstico de ventriculomegalia e ao exame morfológico foi identificado uma patologia rara do SNC, a esquizencefalia tipo Il unilateral.

Durante monitorização evoluiu para a forma bilateral com aumento progressivo da fenda, espaço subaracnóideo, ventrículo cerebral e identificação de anomalias cerebrais associadas. Essa evolução da forma unilateral para bilateral não é descrita na literatura médica. Pode presumir que o diagnóstico foi muito precoce e embora o evento tivesse sido bilateral, sua manifestação precisou de certo tempo para tornar-se identificado ao exame ultrassonográfico.

Será abordado etiologia, anomalias associadas, diagnóstico diferencial e fatores prognósticos na esquizencefalia.

$$
\begin{aligned}
& \text { PALAVRAS-CHAVE: ESQUIZENCEFALIA, DIAGNÓSTICO, PRÉ-NATAL, ULTRASSOM, EVOLUÇÃO, } \\
& \text { ETIOLOGIA, FATORES PROGNÓSTICOS. }
\end{aligned}
$$

\begin{abstract}
Schizencephaly is a rare congenital malformation of the central nervous system (CNS). Belonging to the group of CNS cell migration defects, it appears between the 2nd and 5th month of gestation, characterized by a gray dysmorphic substance outlining the slits in the cerebral cortex that extend medially from the subarachnoid space communicating with the ipsilateral cerebral ventricle.

This report is from a fetus that was referred with the diagnosis of ventriculomegaly and a morphological examination identified a rare pathology of the CNS, unilateral type II schizencephaly.

During monitoring it evolved to a bilateral form with progressive increase in the cleft, subarachnoid space, cerebral ventricle and identification of associated brain abnormalities. This evolution from unilateral to bilateral form is not described in the medical literature. You can assume that the diagnosis was very early and although the event had been bilateral, its manifestation took some time to become identified on ultrasound examination.
\end{abstract}

An etiology, associated anomalies, differential diagnosis and prognostics factors in schizencephaly will be addressed.

\section{KEYWORDS: SCHIZENCEPHALY, DIAGNOSIS, PRENATAL CARE, ULTRASOUND, EVOLUTION, ETIOLOGY, PROGNOSTIC FACTORS}

\section{INTRODUÇÃO:}

A esquizencefalia é uma malformação congênita rara do sistema nervoso central (SNC), com uma prevalência de 1.5:100.000 nascimentos vivos ${ }^{1,2}$. Foi descrita pela primeira vez em 1946 por Yakovlev e Wadworth quando definiram esquizencefalia como uma fenda congênita no manto cerebral em um estudo post-mortem ${ }^{3}$.

Pertencente ao grupo de defeitos de migração celular
GENUS - Grupo de Ensino em Ultrassonografia Belo Horizonte

GENNUS - Núcleo de Medicina Fetal

Faculdade Ciências Médicas de Minas Gerais
Endereço para correspondência: Renato Murta

Rua Jaceguai, 208, sl.1022 - Prado

Belo Horizonte - CEP 30.411-040

Email: renato.jardim@hotmail.com 
do SNC, surge entre o $2^{\circ}$ e o $5^{\circ}$ mês de gestação, sendo caracterizada por substância cinzenta dismórfica delineando as fendas no córtex cerebral. Estas fendas estendem-se medialmente a partir do espaço subaracnóideo, comunicando com o ventrículo cerebral homolateral. A identificação da substância cinzenta margeando a fenda é uma característica patognomônica da lesão diferenciando-a da porencefalia severa. A esquizencefalia unilateral é a mais frequente (60\%) do que a fenda bilateral e em 75-95 \% dos casos a localização anatômica predominante é nos lobos frontal e parietal 3-5.

\section{ETIOLOGIA:}

A maioria dos casos de esquizencefalia é esporádica e não familiar, não havendo uma causa etiológica reconhecida. Já foram aventadas teorias como migração neuronal anômala e obstrução da artéria cerebral média em consequência de um processo inflamatório intrauterino, como na infecção por citomegalovírus ${ }^{3,4}$.

A teoria da migração neuronal anormal precoce envolve o pregueamento e a fusão das camadas da piamater com o ependima. A figura 1 ilustra corte histológico coronal com 10,17 e 28 semanas gestacional exibindo o pregueamento e a fusão das camadas da piamater com o ependima, e posterior desenvolvimento do córtex cerebral ${ }^{5}$.

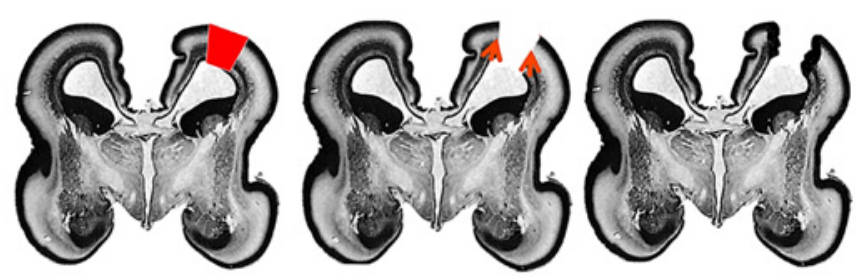

Figura 1. Ilustra o pregueamento e fusão das camadas epial e ependimal no córtex cerebral com 1, 17 e 28 semanas de gestação ${ }^{5}$.

A figura 2 ilustra as modificações decorrente no córtex cerebral e sua evolução no decorrer da gestação. Na figura, o quadrado vermelho representa o dano focal de toda a espessura do córtex cerebral precoce e posterior destruição do tecido cerebral. Durante o período da migração neuronal, por volta da 28 semanas, formam-se as regiões de polimicrogiria, vistas na bordas da fenda da esquizencefalia 5 .

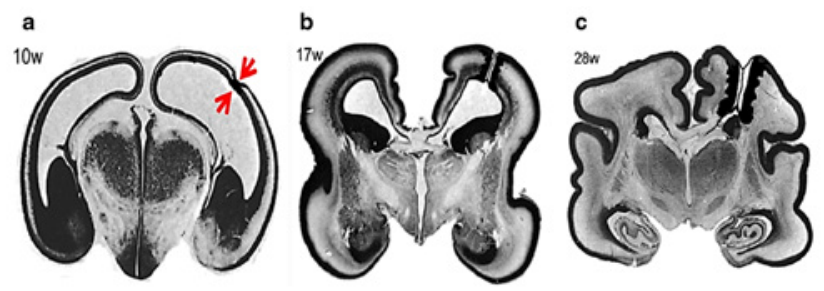

Figura 2. Ilustra as modificações no córtex cerebral e sua evolução no decorrer da gestação ${ }^{5}$.
Por outro lado, se o evento ocorrer posteriormente ao sexto mês de gestação, não existe migração neuronal adequada suficiente para contornar a lesão existente e portanto não há organização suficiente para desenvolver polimicrogiria. Dessa forma, há produção de um dano cerebral por reabsorção do tecido lesado e, devido a uma migração neuronal inadequada, tem-se a ausência de substância cinzenta na bordas das lesões, resultando em formação de cistos porencefálicos, diferente da esquizencefalia.

Por outro lado, a teoria da obstrução vascular da artéria cerebral média corrobora com o fato que a maioria da esquizencefalia é vista na região do sulco lateral do cérebro, território irrigado pela artéria cerebral média, inclusive nas formas bilaterais 3,4 .

Alguns autores apontam como etiologia certos fatores genéticos, como as mutações no gene EMX2 que regulam o desenvolvimento estrutural do prosencéfalo. A mutação causa uma lesão na matrix germinativa periventricular prejudicando a migração celular entre a $67^{\mathrm{a}}$ semana da gestação ${ }^{4,6}$. Outros genes como EPG5 e COL4A1 causando vulnerabilidade na parede vascular são considerados como responsáveis pela esquizencefalia 7,8 .

Outros fatores relacionados foram idade abaixo de 20 anos, abuso de álcool, drogas entorpecentes, exposição a solventes orgânicos, morte de um gemelar, trombocitopenia aloimune, trombofilias, infecções congênitas, trauma materno e warfarina ${ }^{8}$.

\section{APRESENTAÇÃO CLÍNICA:}

A esquizencefalia está dividida em dois tipos clínicos: tipo I ou fechada, a fenda cerebral não comunica com o ventrículo sendo o diagnóstico pré-natal difícil. Griffiths PD fez uma revisão com 11 fetos encontrou esquizencefalia tipo I (fechada) em $45 \%$ dos casos quando utilizou estudo por ressonância magnética ${ }^{5}$.

A tipo II ou aberta, a fenda comunica com o ventrículo sendo preenchida por líquido e com características que podem ser descritas no pré-natal, ocorrendo em 55-60\% dos $\operatorname{casos}^{5}$. As margens da fenda são contornadas por substância cinzenta displástica e heterotópica ${ }^{1,8}$.

Ambos os tipos de esquizencefalia podem ser unilateral ou bilateral. A forma unilateral é caracterizada por um curso marcadamente mais suave; podendo ser assintomático ou apresentar crises epiléticas, defeitos motores suaves e visão anormal. A bilateral é uma malformação grave e irreversível do SNC que se manifesta com crises convulsivas de difícil controle, retardo mental grave, cegueira, graus variados de defeitos motores ${ }^{8}$.

Não existem relatos de esquizencefalia diagnosticado por ultrassonografia antes de 20 semanas de gestação. Howe et al avaliaram 18 casos de esquizencefalia pré-natal e todos tinham idade gestacional superior a 21 semana de gestação ${ }^{8}$.

\section{ANOMALIAS ASSOCIADAS:}

A literatura descreve a associação da esquizencefalia com 
anomalias cromossômicas, síndromes genéticas, infecções congênitas e morte de gemelar em monocoriônica. Outras patologias cerebrais concomitantes têm sido descritas como hidrocefalia $(30 \%$ dos casos e quase exclusivamente com tipo II), ventriculomegalia $(85 \%)$, agenesia de corpo caloso e septo pelúcido (40-70\%), atrofia do nervo óptico (30\%), cisto aracnoide e malformações cerebelares, displasia corti- cal, heterotopia, paquigiria, polimicrogiria, leucomalácia pe- riventricular ${ }^{1,8}$.

Griffiths PD reportou septo pelúcido ausente ou interrompido em $64 \%$ dos fetos com tendência a sua ausência nos fetos com esquizencefalia tipo II (aberta) ${ }^{5}$.

\section{DIAGNÓSTICO DIFERENCIAL:}

O diagnóstico diferencial deve ser feito com agenesia de corpo caloso, hidrocefalia, holoprosencefalia, encefalocele, cisto aracnoide e porencefalia. A lesão porencefálica é um desafio a parte, em especial no tipo I, sendo diferenciada da esquizencefalia, na ressonância magnética, pela ausência de substância cinzenta no contorno da lesão.

\section{RELATO DE CASO:}

Paciente ARSC, 19 anos, branca, ciclo regular, concepção natural, primigesta, data da última menstruação desconhecida; sem história de patologias anteriores. Foi encaminhada ao nosso serviço com um diagnóstico de ventriculomegalia severa unilateral.

No dia 31.12.2019 foi realizado o primeiro exame ultrassonográfico na gestante sendo identificado uma fenda unilateral esquerda comunicando o sistema ventricular ao espaço subaracnóideo na região do lobo parietal - (figuras 3). O diagnóstico foi de esquizencefalia tipo II, unilateral. Não visibilizado nenhuma outra anomalia estrutural maior associada.
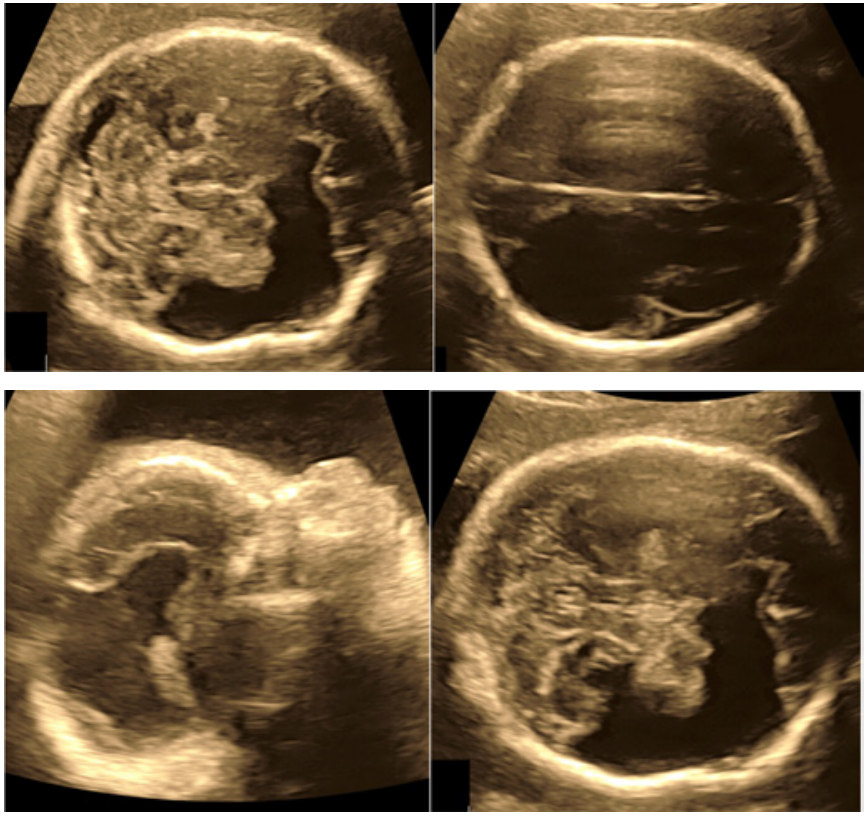

Figura 3. Imagens ultrassonográficas exibem área anecóica em região do lobo parietal esquerdo (esquizencefalia tipo II unilateral).
No dia 28.01.2020 foi realizado o segundo exame, sendo observado uma evolução de unilateral para bilateral; comunicando os sistemas ventriculares aos espaços subaracnóideos bilateralmente - (figuras 4). Não identificado nenhuma outra anomalia estrutural maior associada.
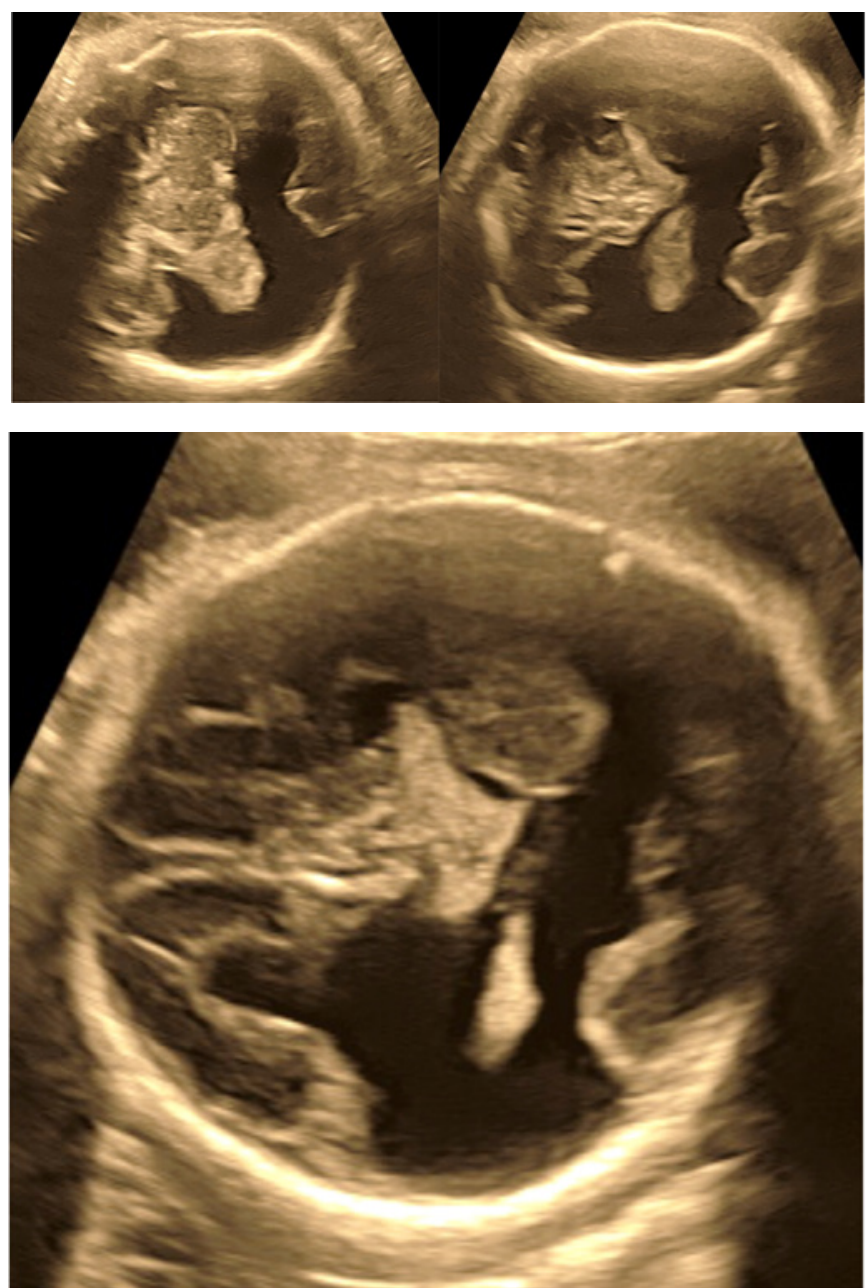

Figura 4. Imagens ultrassonográficas exibem área anecóica em região do lobo parietal bilateral (esquizencefalia tipo II bilateral).

No dia 14.02.2020 foi realizado um terceiro exame ultrassonográfico, no qual foi observado uma imagem anecóica comunicando o espaço subaracnóideo direito ao ventrículo direito, imagem anecóica de mesmas características comunicando o espaço subaracnóideo esquerdo ao ventrículo esquerdo e ausência de cavum do septo pelúcido, notando-se aumento das comunicações dos espaços subaracnóideos aos ventrículos. Sem outras anomalias estruturais maiores associadas.

No dia 10.03.2020 foi realizado um quarto exame ultrassonográfico que revelou um aumento progressivo do espaço subaracnóideo, da fenda e dos ventrículos cerebrais, ausência de cavum do septo pelúcido. Percebe-se plexo coróide flutuando na cavidade ventricular - (figuras 5). 

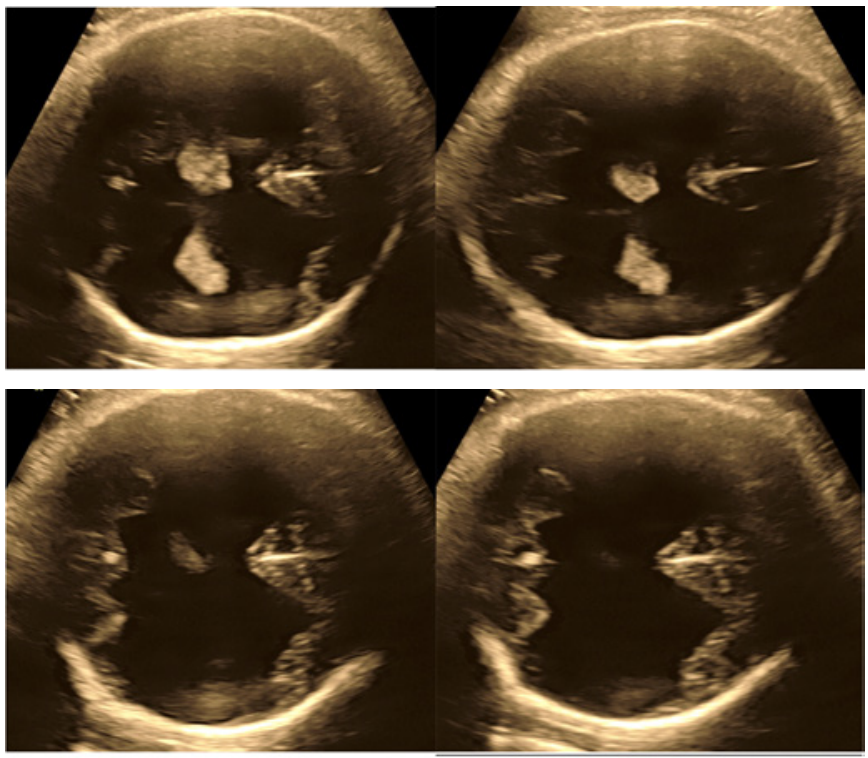

Figura 5. Imagens ultrassonográficas exibem área anecóica em região do lobo parietal bilateral (esquizencefalia tipo II bilateral).

\section{DISCUSSÃO:}

A esquizencefalia geralmente está associada a outras malformações do SNC, como ventriculomegalia, polimicrogiria, paquigiria, heterotopia, lissencefalia, ausência de cavum do septo pelúcido, agenesia do corpo caloso, hipoplasia do nervo óptico.

Embora o padrão ouro para diagnóstico de esquizencefalia seja estudo por ressonância magnética existem raros casos descritos na literatura. A maior série foi des- crita por Nabavizadeh et al que estudaram 10 fetos com ressonância magnética intraútero e confirmaram com estudo pós-natal, incluindo oito casos bilateral. Um achado interessante foi a discordância na classificação entre o pré-natal e pós-natal com $47 \%$ das esquizencefalia tipo II (aberta) detectadas intraútero tornaram tipo I (fechado) no período pós-natal. Relataram que cerca de $26 \%$ das polimicrogirias fetais não foram detectadas ${ }^{10}$.

Outra evidencia circunstancial nesse trabalho de Nabavizadeh et al, é o achado de depósito de hemossiderina e/ ou hemorragia na fenda e nos ventrículos dos fetos acometidos por esquizencefalia no estudo por ressonância magnética. Além disso, mais da metade dos fetos apresentavam microcefalia decorrente de destruição do tecido cerebral. Estes achados corroboram com a teoria que a principal etiologia para os casos de esquizencefalia seja decorrente de sangramento e/ou destruição da matriz cerebral ${ }^{10}$.

As manifestações clínicas da esquizencefalia incluem diferentes níveis de retardo do desenvolvimento, convulsões neuropsicomotoras e graus diferentes de alterações na visão e fala. Hunt et al estudaram 21 pacientes com esquizencefalia (16 unilateral e 5 bilateral). A maioria dos pacientes com déficit neurológico foram detectados antes de um ano de idade, especialmente nas fendas bilaterais.
A principal apresentação clínica foi hemiparesia na esquizencefalia unilateral e convulsões na forma bilateral. Cerca de $81 \%$ dos pacientes manifestaram convulsão epiléptica clonica tônica generalizada, sendo que 38\% dos casos desenvolveram epilepsia refratária. A maioria dos pacientes desenvolveram déficit motor, intelectual e linguagem, em especial na esquizencefalia bilateral ${ }^{11}$.

Este relato é de um feto que foi encaminhado com o diagnóstico de ventriculomegalia e ao exame morfológico foi identificado uma patologia rara do SNC a esquizencefalia tipo II unilateral. Durante monitorização evoluiu para a forma bilateral com aumento progressivo da fenda, espaço subaracnóideo, ventrículo cerebral e identificação de anomalias associadas como ausência do cavum do sep- to pelúcido e do corpo caloso. Essa evolução da forma unilateral para bilateral não é descrita na literatura médica. Pode presumir que o diagnóstico foi muito precoce e embora o evento tivesse sido bilateral sua manifestação precisou de certo tempo para tornar-se identificado ao exame ultrassonográfico.

O diagnóstico diferencial é feito para distinguir esse distúrbio de holoprosencefalia, hidranencefalia e cistos aracnóideos bilaterais. Casos de esquizencefalia tipo I e porencefalia na maioria das vezes só poderão ser distinguidos ao exame de ressonância magnética na qual a substância cinzenta displásica e heterotrópica contorna a lesão cística na esquizencefalia tipo I.

Na maioria dos casos uma etiologia não será identifica. O prognóstico a longo prazo dependerá do tamanho e localização da lesão, se unilateral ou bilateral e se existem malformações cerebrais associadas. O neonato deverá ser avaliado por neurologista pediátrico e o seguimento com ressonância magnética é recomendado.

Portanto um diagnóstico pré-natal preciso é importante para o adequado aconselhamento genético reprodutivo dos pais.

\section{REFERÊNCIAS:}

1. Howe DT, Rankin I, Draper ES. Schizencephaly prevalence, prenatal diagnosis and clues to etiology: A register-based study. Ultrasound Obstet Gynecol 2012; 39: 75-82.

2. Brant WE, Helms CA. Fundamentals of Diagnostic Radiology. 3rd ed Philadelphia: Lippincott Williams \& Wilkins; 2007. p. 226-7.

3. Yakovlev PI, Wadsworth RC. Schizencephalies: a study of the congenital clefts in the cerebral mantle; clefts with hydrocephalus and lips separated. J Neuropathol Exp Neurol 1946; 5: 169-206.

4. Barkovich AJ, Norman D. MR imaging of schizencephaly. AJR Am J Roentgenol 1988; 150: 1391-6.

5. Griffiths PD. Schizencephaly revisited. Neuroradiology. 2018; 60(9) 945-60.

6. Tietjen I, Erdogan F, Currier S, Apse K, Chang BS, Hill RS et al. EMX 2-independent familial schizencephaly: Clinical and genetic analy- ses. Am J Med Genet A 2005; 135: 166-70.

7. Sato Y, Shibasaki J, Aida N, Hiiragi K, Kimura Y, Akahira-Azuma M, Enomoto Y, Tsurusaki Y, Kurosawa K. Novel COL4A1 mutation in a fetus with early prenatal onset of schizencephaly. Hum Genome Var. 2018; 24(5): 4

8. Halabuda A, Klasa L, Kwiatkowski S, Wyrobek L, Milczarek O, Gergont A. Schizencephaly - diagnostics and clinical dilemmas. Childs Nerv Syst. 2015; 31(4): 551-6. 
9. Dies KA, Bodell A, Hisama FM, Guo CY, Barry B, Chang BS, Barkovich AJ, Walsh CA. Schizencephaly: association with young maternal age, alcohol use, and lack of prenatal care. J Child Neurol. 2013; 28(2): 198-203.

10. Nabavizadeh SA, Zarnow D, Bilaniuk LT, Schwartz ES, Zimmerman RA, Vossough A. Correlation of prenatal and postnatal MRI findings in schizencephaly. Am J Neuroradiol 2014; 35(7): 1418-24.

11. Hung PC, Wanga HS, Choua ML, Lina KL, Hsieha MY, Choua IJ, Wongb AMC. Schizencephaly in children: A single medical center retrospective study. Pediatrics \& Neonatology, 2018; 59(6): 573-80. 


\title{
SINOVITE VILONODULAR PIGMENTADA: RELATO DE CASO
}

\author{
PIGMENTED VILLONODULAR SYNOVITIS: CASE REPORT
}

\author{
JORGE GARCIA, ANA CLAUDIA PEREIRA LIMA, PROCÓPIO DE FREITAS, AUGUSTO CESAR SAAB BENEDETI, \\ FERNANDO MARUM MAUAD, FRANCISCO MAUAD FILHO
}

\section{RESUMO}

A sinovite vilonodular pigmentada é uma doença sinovial proliferativa, benigna, caracterizada por nódulo, séssil, pedunculada de etiologia desconhecida. Sua incidência anual é de 1.8 / 100.000 acomete a 3a e 4a década. Na maioria dos casos os sintomas são inespecíficos, é monoarticular sendo o joelho o segmento mais acometido. Conclui-se que a ultrassonografia mostrou ser uma técnica de imagem eficaz na detecção da lesão vilonodular.

PALAVRAS-CHAVE: SINOVIA, INTRA-ARTICULAR, ÓSSEO, VILONODULAR, HOFFA.

\begin{abstract}
Pigmented villonodular synovitis is a benign, proliferative synovial disease characterized by a nodule, sessile, pedunculated disease of unknown etiology. Its annual incidence is 1.8/100,000 affects the 3rd and 4th decade. In most cases the symptoms are non-specific, it is monoarticular and the knee is the most affected segment. It was concluded that ultrasonography showed to be an effective imaging technique in the detection of villous lesion.
\end{abstract}

KEYWORDS: SYNOVIA, INTRA-ARTICULAR, BONE, VILLONODULAR, HOFFA.

\section{INTRODUÇÃO}

A sinovite vilonodular pigmentada (SVNP) é uma enfermidade clínica benigna e incomum de etiologia desconhecida, caracterizada por uma proliferação excessiva da membrana sinovial de articulações, bainhas sinoviais e bursas ${ }^{1-4}$. Em 1852, Chassaignac relatou o primeiro caso de lesão nodular na bainha dos tendões flexores do segundo e terceiro quirodáctilo1. Recentemente, a Organização Mundial de Saúde definiu que SVNP e o tumor de células gigantes são termos equivalentes ${ }^{2,4}$.

\section{RELATO DE CASO}

Paciente feminino, 26 anos, apresenta tumefação na região anterolateral do joelho direito há três meses (Figura1), sem queixas de dor ou bloqueio da articulação. Exame físico ortopédico com bom alinhamento dos membros inferiores, testes dos meniscos e ligamentos negativos e ausência de sinais de instabilidade articular.

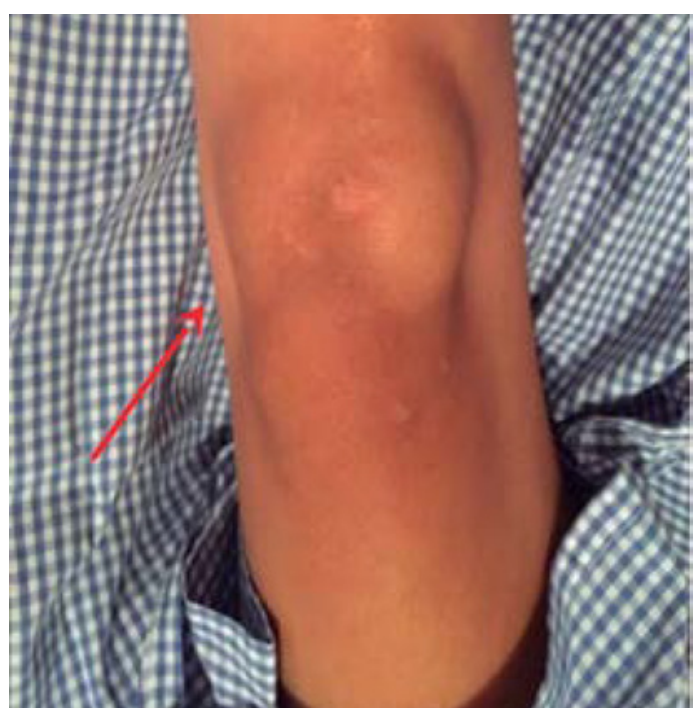

Figura. 1. Tumefação anterolateral joelho direito.
Faculdade de Tecnologia em Saúde. FATESA/ EURP. Ribeirão Preto. SP.

Faculdade de Medicina e Odontologia Mandic de Campinas.
Endereço para correspondência:

Augusto César Saab Benedeti

Email: augusto@fatesa.edu.br 
Realizou ultrassonografia que evidenciou em formação sólida intra-articular, hipoecogênico com dimensões de 3.5 x 1.6 x $3.8 \mathrm{~cm}$, expandindo para gordura de Hoffa (Figura 2 e 3) vascularizada ao estudo Doppler de amplitude e espectral. (Figura 4 e 5).

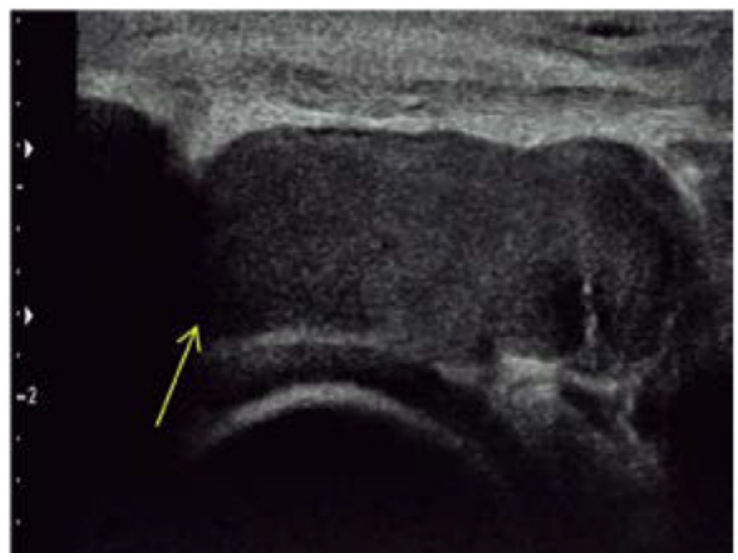

Figura2. Nódulo transversal hipoecogênico.

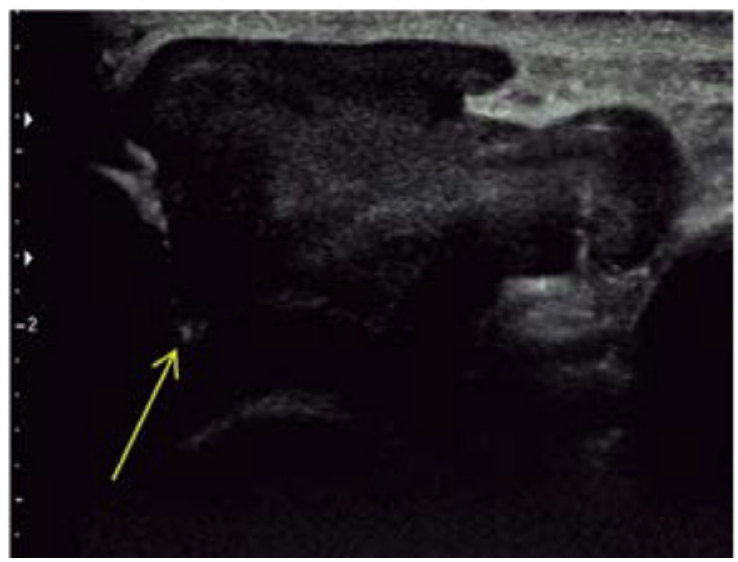

Figura3. Nódulo longitudinal hipoecogênico

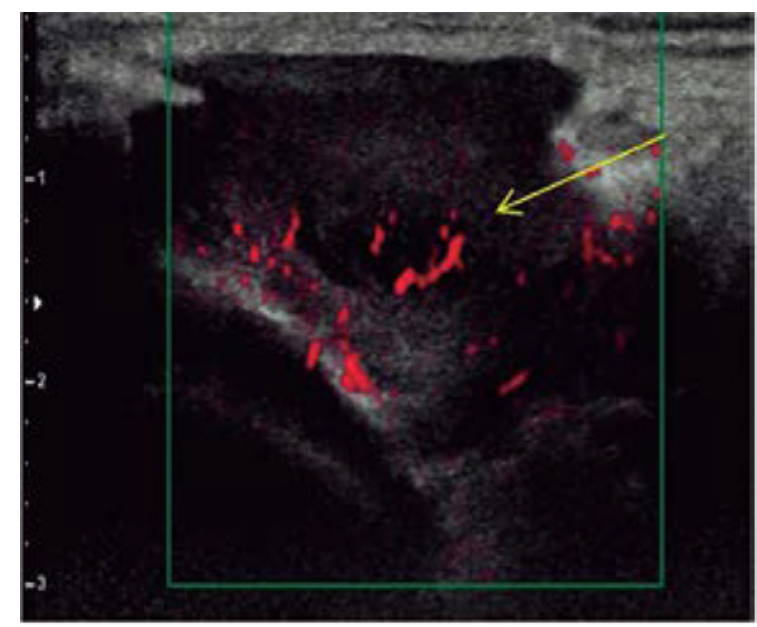

Figura4. Nódulo vascularizado com Doppler de amplitude.

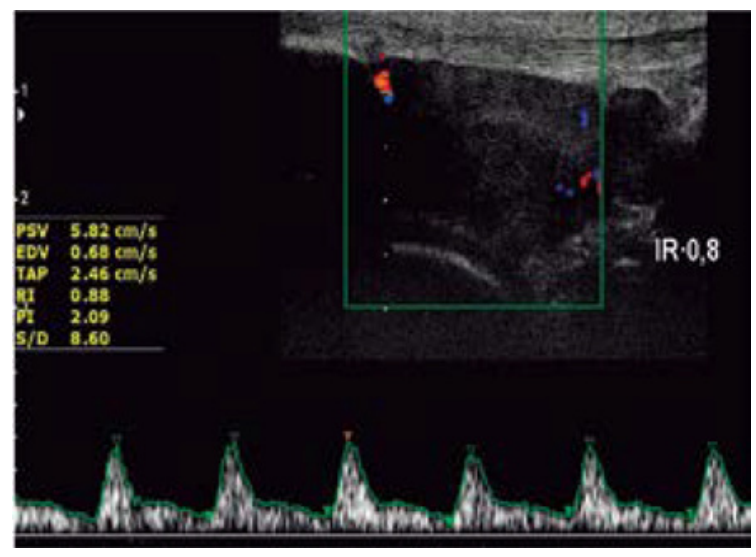

Figura5. Nódulo com pico de velocidade sistólico acentuado.

A ressonância magnética evidenciou massa heterogênea com baixa captação em T1 e T2. O resultado do anatomopatológico foi compatível com SVNP. O tratamento com a ressecção artroscópica foi um sucesso.

\section{DISCUSSÃO}

A SVNP é uma enfermidade rara, usualmente monoarticular, sendo o joelho a articulação mais acometida em $80 \%$ dos casos, seguido do quadril e tornozelo. Incidência de 1.8/100.000 de pessoas, na 3a e 4a década 1, 3,6.

A clínica mais frequente é o aparecimento lento insidioso de dor, edema e rigidez articular6. Tem duas apresentações: a) difusa: envolvendo inteiramente o revestimento sinovial das grandes articulações, como joelho e quadril; b) localiza- da: vilonodular, séssil acometendo pequenas articulações de mãos e pés 5,7 .

Faz diagnóstico diferencial com sarcoma sinovial, condromatose sinovial, hemangioma, lipoma arborescente da sinovial4.

O método de imagem mais adequado para o seu diagnóstico é a ressonância magnética, uma vez que a extensão intra-articular e o envolvimento ósseo não pode ser avaliado com precisão pela ultrassonografia. A ultrassonografia pode auxiliar no diagnóstico, porém não é especifica 4,7.

\section{CONCLUSÃO}

A sinovite vilonodular pigmentada mesmo incomum é benigna e seu diagnóstico é histopatológico, porém a ultras- sonografia demonstrou ser um método sensível na detecção do processo expansivo intra-articular.

\section{REFERÊNCIAS:}

1. Chassaignac EP. Câncer de lagainedestendons. Gaz Hop CivMilit. 1852; 25:185-6.

2. Rodriguez-Merchan EC. Review article: open versus arthroscopic synovectomy for pigmented villonodular synovitis of the knee. J OrthopSurg (Hong Kong), 2014; 22(3): 406-8.

3. Yang B, Liu D, Lin J, Jin J, Weng XS, Qian WW, et al. Surgical treat- ment of diffuse pigmented villonodular synovitis of the knee. Zhon- gguo Yi XueKeXue Yuan XueBao. 2015; 37(2):234-9.

4. Jendrissek KA, Hotfiel T, Swoboda B, Soder S, Janka R. Pigmented 
villonodular synovitis: a rare differential diagnosis of synovial joint swelling. Z Rheumatolog, 2016; 75 (2): 157-65.

5. Kramer DE, Frassic FJ, Cosgarea AJ. Total arthroscopic synovectomy for pigmented villonodular synovitis of the knee. Tech Knee Surg 2004, 3(1): 36-45

6. Myers B, Masi A. Pigmented villonodular synovitis and tenosynovitis: A clinical epidemiologic study of 166 cases and literature review. Medicine (Baltimore). 1980; 59: 223-38.

7. Kim SI, Shin SI, Choi NH, Choo ET. Arthroscopic treatment for lo- calized pigmented vilonodular synovitis of the knee. Clin Orthop. 2000. 379: 224-30. 


\title{
ULTRASSONOGRAFIA COM DOPPLER NA
}

AVALIAÇÃO DO REFLUXO GASTRESOFÁGICO

\author{
DOPPLER ULTRASONOGRAPHY IN THE EVALUATION OF \\ GASTROESOPHAGEAL REFLUX
}

\author{
THALITA BARBOSA DUTRA DE MIRANDA, ARIELA MAULLER VIEIRA PARENTE, LARISSA BARBOSA DUTRA DE MIRANDA, \\ MÔNICA SILVA CARNEIRO, AVELINO PEIXOTO NETO, HAYTHAM LOAIY IBRAHIM KARAJAH, \\ WALDEMAR NAVES DO AMARAL
}

\section{RESUMO:}

Orefluxo gastroesofágico (RGE) éa passagem involuntária do conteúdo gástrico para a luz do esôfago. Éuma condição comum nos lactentese crianças menores, sendo, na maioria das vezes, considerado fisiológico, no entanto, pode determinar manifestações clínicas e levar à doença do refluxo gastroesofágico. O objetivo geral deste trabalho foi analisar o papel da ultrassonografia no diagnóstico e acompanhamento do refluxo gastresofágico. A metodologia utilizada nesse trabalho foi de revisão de literatura. A metodologia utilizada foi revisão bibliográfica de artigos publicados em espanhol, inglês e português nos últimos 20 anos, a base de dados foram PubMed, SciElo, Bireme, Lilacs. O que se pode concluir que o refluxo gastroesofágico é um exame não invasivo, rápido, acessível e barato.

\section{KEYWORDS: GASTROESOPHAGEAL REFLUX, ULTRASONOGRAPHY, DIAGNOSTIC IMAGING}

\begin{abstract}
Gastroesophageal reflux (GERD) is the involuntary passage of gastric contents into the lumen of the esophagus. It is a common condition in infants and young children, and is often considered physiological; however, it can determine clinical manifestations and lead to gastroesophageal reflux disease. The general objective of this study was to analyze the role of ultrasonography in the diagnosis and follow-up of gastroesophageal reflux. The methodology used in this work was a literature review. The methodology used was a bibliographic review of articles published in Spanish, English and Portuguese in the last 20 years, the database was PubMed, SciElo, Bireme, Lilacs. What can be concluded is that the ultrasonography in the evaluation of gastroesophageal reflux is a non-invasive, fast, affordable and cheap exam.
\end{abstract}

KEYWORDS: GASTROESOPHAGEAL REFLUX, ULTRASONOGRAPHY, DIAGNOSTIC IMAGING

\section{INTRODUÇÃO}

O refluxo gastroesofágico (RGE) é a situação que mais agride o esôfago, uma das reclamações mais habituais em consultórios ${ }^{1}$.

A expressão doença do refluxo gastroesofágico sintomática diz respeito àqueles pacientes que se manifestam com os sinais pépticos (pirose e regurgitação), com ou sem indícios endoscópicos de esofagite. Os pacientes mais complexos de entender são aqueles que exibem ampla sintomatologia, mas sem indícios de lesão tecidual do esôfago (doença do refluxo gastroesofágico não erosiva) ${ }^{2}$.

$\mathrm{O}$ número de hospitalizações associadas à doença do refluxo gastresofágico (DRGE) nos EUA aumentou de
710.000 para 3.100.000 de 2002 a 2004. Um episódio de RGE ocorre quando o esfíncter esofágico inferior (EEI) se abre espontaneamente e o conteúdo gástrico repercute no esôfago ${ }^{3}$.

A DRGE é um dos distúrbios mais comuns na prática médica. Dados da América do Norte indicam que a azia, o sintoma mais predominante do transtorno, ocorre pelo menos uma vez por semana em $20 \%$ da população estudada. Dados semelhantes foram relatados na Inglaterra e na Escócia . No Brasil, um estudo de base populacional mostrou uma prevalência de pelo menos $12 \%$ na população geral ${ }^{4}$.

É uma das condições mais comuns que afeta o trato gastrointestinal e geralmente é considerada a causa de uma va-
FAMP - Faculdade Morgana Potrich ScholaFértile
Endereço para correspondência:

Waldemar Naves do Amaral

Alameda Cel. Joaquim de Bastos, 243 - St. Marista

Goiânia - CEP 74175-150

Email: waldemar@sbus.org.br 
riedade de sintomas esofágicos. Em um indivíduo que sofre de DRGE, sintomas como azia ou sensação de queimação no peito podem estar presentes. A DRGE não tratada pode levar a outras consequências tais como o esôfago de Barrett, que tem sido considerado um precursor do câncer de esôfago ${ }^{5}$.

A DRGE tem etiologia multifatorial, sendo que tanto as lesões teciduais quanto os sintomas resultam do contato da mucosa com o conteúdo refluxado. Tal contato é decorrente da falha das defesas do esôfago. A barreira antirrefluxo, considerada como sendo a principal proteção contra o refluxo gastroesofágico, é formada pelo esfíncter interno (ou esfíncter esofágico inferior) e esfíncter externo (formado pela porção crural do diafragma). O principal mecanismo dessa falha é o relaxamento transitório do esfíncter esofágico inferior, não relacionado à deglutição, sendo responsável por cerca de $70 \%$ dos episódios de RGE ${ }^{6}$.

O diagnóstico do RGE deve iniciar pela identificação da história clínica completa. A abordagem diagnóstica deve variar conforme a apresentação clínica. As manifestações clínicas do RGE são variáveis e referentes não somente ao trato digestivo. Assim sendo, o diagnóstico diferencial é amplo, abrangendo causas clínicas e cirúrgicas de vômitos e regurgitações, causas de broncoespasmo e de sintomas atípicos, como asma, otites, laringites e sinusites. Outro fator significativo é a idade do paciente, pois as doenças variam de acordo com a idade ${ }^{7}$.

A doença do refluxo gastroesofágico pode ser diagnosticada por suas manifestações clínicas subjetivas. Azia (ou pirose), regurgitação e disfagia representam os sintomas comuns da DRGE. A endoscopia é indicada em pacientes nos quais o tratamento clínico comum não é eficiente e apresenta sintomas de DRGE, disfagia, odinofagia, sangramento gastrointestinal (GI) microscópico ou macroscópico ou em pacientes com anemia por deficiência de ferro detectada ${ }^{6}$.

Considerando a característica não invasiva e não oncogênica da ultrassonografia transabdominal (US), este método pode anular as principais desvantagens da endoscopia digestiva alta. Diversos estudos sugeriram a utilidade da US transabdominal na detecção de DRGE em pacientes pediátricos. Porém, parece haver poucos estudos que invetigam a utilidade da US na detecção de esofagite induzida pela DRGE na população adulta ${ }^{6}$.

Recentemente, Savino et al. ${ }^{8}$ publicaram um artigo sobre US para o diagnóstico de DRGE em pediatria. Os autores analisaram outras causas de sintomas, como vômitos, que não a DRGE; e mensuraram o comprimento do esôfago abdominal, o diâmetro do esôfago, a espessura da parede esofágica e o ângulo de Hiss para levantar dados anatômicos e funcionais. Os autores destacaram, ainda, a necessidade de se definir critérios diagnósticos, de uniformização dos exames e das medidas referidas. A análise tradicional para o estudo do RGE é a seriografia do esôfago, estômago e duodeno (SEED) com bário e, mais recentemente, a ultrassonografia do esôfago intra-abdominal (USEI) - figura 1.

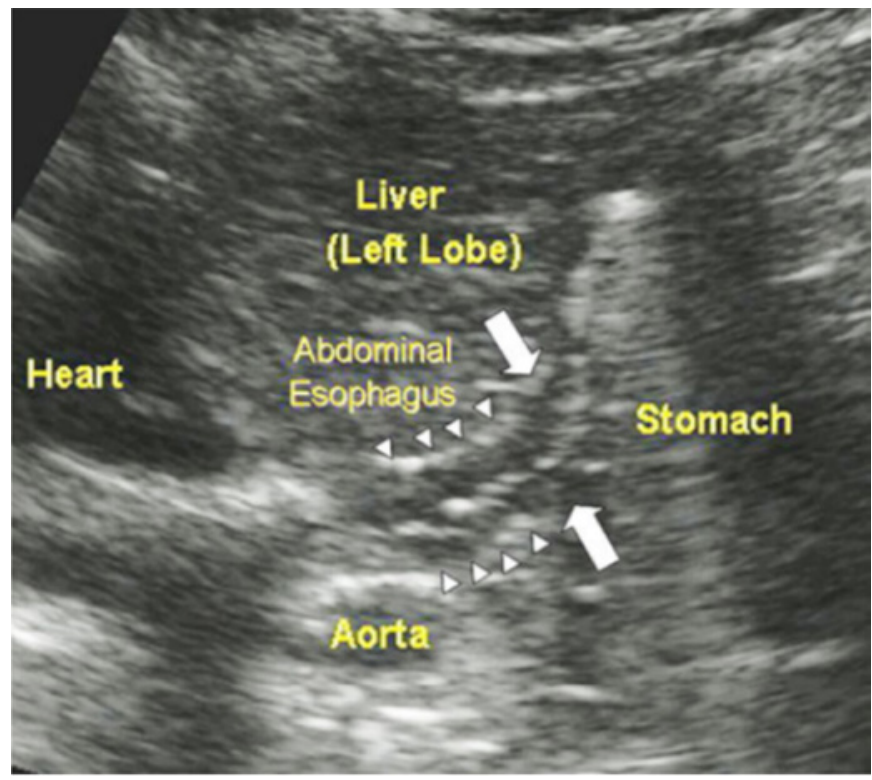

Figura 1. Ultrassonografia transversa obliqua da junção gastroesofágica (setas). O esôfago é visto como uma estrutura tubular (pontas de setas) com uma parede hipoecogênica (camada muscular) e um centro hiperecogênico (mucosa e lumen)

Hoje em dia, já se encontram vários métodos que permite a análise de perturbações esofágicos, como radiografias contrastadas com fluoroscopia, cintilografia, ma- nometria, endoscopia digestiva alta e pHmetria esofágica prolongada (24 horas). Entretanto, são essenciais exames simples, rápidos, de baixo custo e não invasivos e que não utilizem radiação ionizante. O US transabdominal para analisar o esôfago intra-abdominal, dentro desse contex- to, representam-se como um bom recurso e incorpora as vantagens imediatas, tais como distinguir-se como um estudo inicial, dirigir melhor o exame complementar, e apresentar a balanço do efeito do tratamento de indivíduos com disfagias 9 .

A USEI proporciona de modo análogo à SEED, clas- sificar detalhes anatômicos estruturais, e pode constatar diversos métodos patológicos, até mesmo o RGE, em tempo real. É um método não invasivo, seguro e não usa a radiação ionizante ${ }^{10}$.

Pensando nisso, o presente artigo teve como objetivo descrever o papel da ultrassonografia no diagnóstico e acompanhamento do refluxo gastresofágico.

\section{METODOLOGIA}

Trata-se de um estudo de revisão de literatura. Após a definição do tema foi realizada busca de artigos científicos nas seguintes bases de dados científicos: Pubmed, Scielo, Lilacs e Bireme.

A busca foi realizada por meio das seguintes palavras chaves: refluxo gastroesofágico/ gastroesophagealreflux, 
ultrassonografia / ultrasonography, refluxo gastroesofágico /diagnóstico por imagem / gastroesophagealreflux / diagnosticimaging.

Foram incluídos nessa pesquisa: artigos publicados em espanhol, inglês e português nos últimos 20 anos.

Foram excluídos dessa pesquisa artigos de revisão, sistemática ou não, e os que utilizaram modelos animais.

\section{RESULTADOS}

Conceito refluxo gastroesofágico - RGE

O termo doença do refluxo gastroesofágico sintomá- tica refere-se àqueles pacientes que se apresentam com os sintomas pépticos (pirose e regurgitação), com ou sem evidência endoscópica de esofagite. Os pacientes mais difíceis de entender são aqueles que apresentam grande sintomatologia, mas sem evidência de lesão tecidual do esôfago (doença do refluxo gastroesofágico não erosiva) e também aqueles com sintomas ditos extra digestivo refluxo oculto e com mínimas alterações da motilidade esofágica ${ }^{11}$. Refluxo gastroesofágico (RGE) refere-se à passagem involuntária do conteúdo gástrico para o esôfago. Em crianças, muitas vezes representa um fenômeno fisiológico, especialmente em crianças com regurgitação inocente. Por outro lado, a doença do RGE (DRGE) ocorre quando o refluxo do conteúdo gástrico causa sintomas incômodos e / ou complicações. É uma das causas mais comuns de sintomas de intestino em todas as faixas etá- rias pediátricas ${ }^{12}$.

Embora a fisiopatologia e os sintomas, especialmente em crianças mais velhas, da DRGE pediátrica sejam seme- lhantes em adultos, as crianças podem apresentar-se com uma diferença entre sintomas gastroesofágicos e extra esofágicos distintos e possíveis complicações ${ }^{13}$.

A doença do refluxo gastroesofágico (DRGE) é o distúrbio esofágico mais comum em lactentes e crianças, causando regurgitação intermitente ou vômitos. Embora seja um evento fisiológico na maioria dos adultos e crianças, torna-se patológico quando a intensidade e / ou fre- quência aumentam ${ }^{14}$.

Ao fluxo retrógado de conteúdo gástrico para o esôfago denomina-se refluxo gastroesofágico (RGE). Essa condição clínica, resultante da imaturidade dos mecanismos naturais de defesa antirrefluxo, é frequente em lactentes, sendo autolimitada e isenta de complicações. Quando acompa- nhada de repercussões clínicas como anemia, hemorragia digestiva, dificuldade em ganhar peso ou perda ponderal, manifestações respiratórias e otorrinolaringológicas, atraso do desenvolvimento, entre outras, passa a ser caracterizada como doença do refluxo gastroesofágico (DRGE) ${ }^{15}$.

O refluxo do conteúdo gástrico pode ocorrer em grau maior ou menor e com frequência variável. Na maioria dos casos é passageiro, em pequeno volume e sem ne- nhuma consequência em particular. Porém, se for persistente, configura-se o refluxo patológico ${ }^{16}$.

\section{EPIDEMIOLOGIA}

O RGE é, seguramente, uma das principais condições gastroenterológicas entre as crianças. Apesar de predominar no sexo masculino, a diferença entre os sexos não tem significância estatística. Estudo recente envolvendo amostra de 1.447 mães nos Estados Unidos, tendo como critérios aqueles definidos pelo Consenso Roma III, evidenciou prevalência de regurgitações entre lactentes de 26\%. Estima-se, ainda, que as regurgitações ocorram mais de uma vez ao dia em 41 a $67 \%$ dos lactentes saudáveis de quatro meses de idade. Felizmente, apenas a minoria dessas crianças regurgitadoras necessitará de alguma investigação clínica e/ou intervenção terapêutica ${ }^{17}$

Outra associação alarmante foi proposta por um estudo epidemiológico recente que sugere que a ocorrência de DRGE, em RNPT ou pequenos para a idade gestacional, pode ser o fator responsável pela maior frequência de adenocarcinoma esofágico em adultos que nasceram prematuramente ${ }^{18}$.

As taxas de prevalência de DRGE, caracterizada por presença de sintomas de pirose e regurgitação ácida, são bastante variáveis, mas, principalmente em países ocidentais, quase sempre elevadas. Na Espanha, estudo transversal publicado em 2004, identificou prevalência de 31,6\% de DRGE ao ano. Na Bélgica também é elevada, tendo sido de 28\% em 2002. Em estudo realizado na Austrália em 1996, $56 \%$ dos indivíduos relataram ter tido sintomas de DRGE pelo menos alguma vez em suas vidas, sendo que $37 \%$ os têm pelo menos uma vez a cada quatro meses. Na Dinamarca, em 1994, a prevalência foi de 38\% entre os homens e 30\% entre as mulheres. No Brasil, em 2001 foi de 48,2\%. Em estudo de revisão publicado em 1997, a variação da prevalência fica na faixa de $10 \%$ a $48 \%$ para pirose, $9 \%$ a $45 \%$ para regurgitação ácida e $21 \%$ a $59 \%$ para ambos os sintomas ${ }^{19}$.

A prevalência da doença do refluxo gastroesofágico (DRGE) está aumentando no Japão, assim como nos países ocidentais, o que pode estar relacionado ao estilo de vida ocidentalizado e à alimentação, aumento da idade, a prevalência diminuída de infecção por Helicobacterpylori, e assim por diante. DRGE afeta as atividades da vida diária e reduz qualidade de vida do paciente, para que o diagnóstico e o manejo dessa condição sejam clinicamente cruciais ${ }^{20}$.

Exames diagnósticos: ultrassonografia com Doppler

O diagnóstico do RGE precisa iniciar pela elaboração da história clínica completa. O enfoque diagnóstico do RGE deve mudar segundo a apresentação clínica. Os testes diagnósticos são úteis para documentar o refluxo patológico ou suas dificuldades, constituir relação causal entre refluxo e sintomas, analisar a terapia e excluir outras espécies patológicas. Como nenhum teste pondera todas essas questões, eles devem ser cuidadosamente escolhidos segundo com a história obtida, e suas limitações precisam ser reconhecidas 7 . 
O refluxo gastroesofágico (RGE) é uma condição co- $^{-}$ mum na primeira infância, caracterizada pelo fluxo retrógrado do conteúdo gástrico para o esôfago. Devido a se- quelas potencialmente graves, o diagnóstico e tratamento precoces nesses pacientes são extremamente importantes. Embora a monitorização contínua do $\mathrm{pH}$, a cintilografia e os exames de contraste do trato gastrointestinal superior tenham sido os métodos primários para avaliar o RGE, a ultrassonografia também tem sido usada para diagnosticar essa condição, especialmente em crianças e bebês a ter- mo. A sensibilidade e especificidade da ultrassonografia no diagnóstico de refluxo em crianças são de cerca de 95 e 60\%, respectivamente e recentemente foi demonstrado que a sensibilidade pode ser aumentada pelo uso de ima- gem com Doppler colorido. Vários estudos compararam a monitorização do $\mathrm{pH}$ com exames de ultrassonografia no diagnóstico de DRGE em crianças, dando resultados diferentes ${ }^{21}$.

Um estudo feito por Manabe et al. ${ }^{22}$, tem sido especulado que o fluxo salivar prejudicado contribui para o clearance anormal de ácido em pacientes com esofagite erosiva (EE). Para uma avaliação fácil e objetiva da função salivar, desenvolvemos uma técnica de medição de fluxo sanguíneo nas glândulas salivares usando a sonografia com Doppler de ondas contínuas. No presente estudo, avaliamos a função secretora salivar em pacientes com EE e aqueles com doença do refluxo não erosivo (NERD) usando este método. Foi feito uma análise da forma de onda Doppler foi realizada na artéria facial para avaliar o fluxo sanguíneo para a glândula submandibular de 30 indivíduos saudáveis (HS). O fluxo sanguíneo foi comparado antes e após a estimulação secretória com $1 \mathrm{~mL}$ de suco de limão. A saliva foi simultaneamente coletada e pesada antes e após a estimulação. A sonografia com Doppler de onda contínua também foi realizada em pacientes com EE e NERD. O tamanho da glândula submandibular foi comparado em 26 pacientes com EE, 41 pacientes com NERD e 86. O fluxo sanguíneo da glândula submandibular aumentou após a estimulação em todos os HS. Tanto a reprodutibilidade no dia como no dia a dia foi boa. Houve uma correlação significativa entre o aumento percentual na velocidade máxima e o aumento percentual na secreção salivar. Embora o tamanho da glândula submandibular não tenha sido significativamente diferente entre os três grupos, o aumento percentual na velocidade máxima em pacientes com EE foi significativamente menor do que na HS. O que este estudo revelou que uma diminuição na função secretora salivar está envolvida na patologia do EE. Manabe et al. ${ }^{22}$, desenvolveram um novo método para medir o fluxo sanguíneo da glândula submandibular por sonografia com Doppler cefalométrico para avaliar a secreção salivar. Usando este método, demonstramos que pacientes com EE tiveram significativamente menor reatividade à secreção salivar após a estimulação do que HS.
Sakuno 23, em dissertação apresentada à Universidade Federal de Santa Catarina, 76 comparou a US com a SEED. Examinaram 102 crianças com suspeita clínica de DRGE por meio da SEED, US e US com Doppler. A US mostrou-se mais sensível que a SEED na detecção do RGE (83,3\% da US contra $62,7 \%$ da SEED), com valor preditivo negativo alto, próximo de $100 \%$, sendo que a adição do Doppler à US não aumentou a sua sensibilidade.

Riccabona et al. ${ }^{24}$ comparando US com pHmetria encontraram $100 \%$ sensibilidade de $87,5 \%$ de especificidade, porém a sua população era exclusivamente de $\mathrm{RN}$ e latentes. Jang et al. ${ }^{25}$ utilizando o US com Doppler também encontraram uma sensibilidade de 95,5\%, porém uma baixa especificidade, de 11,0\%, quando comparada à $\mathrm{pHmetria}$ (figura 2).
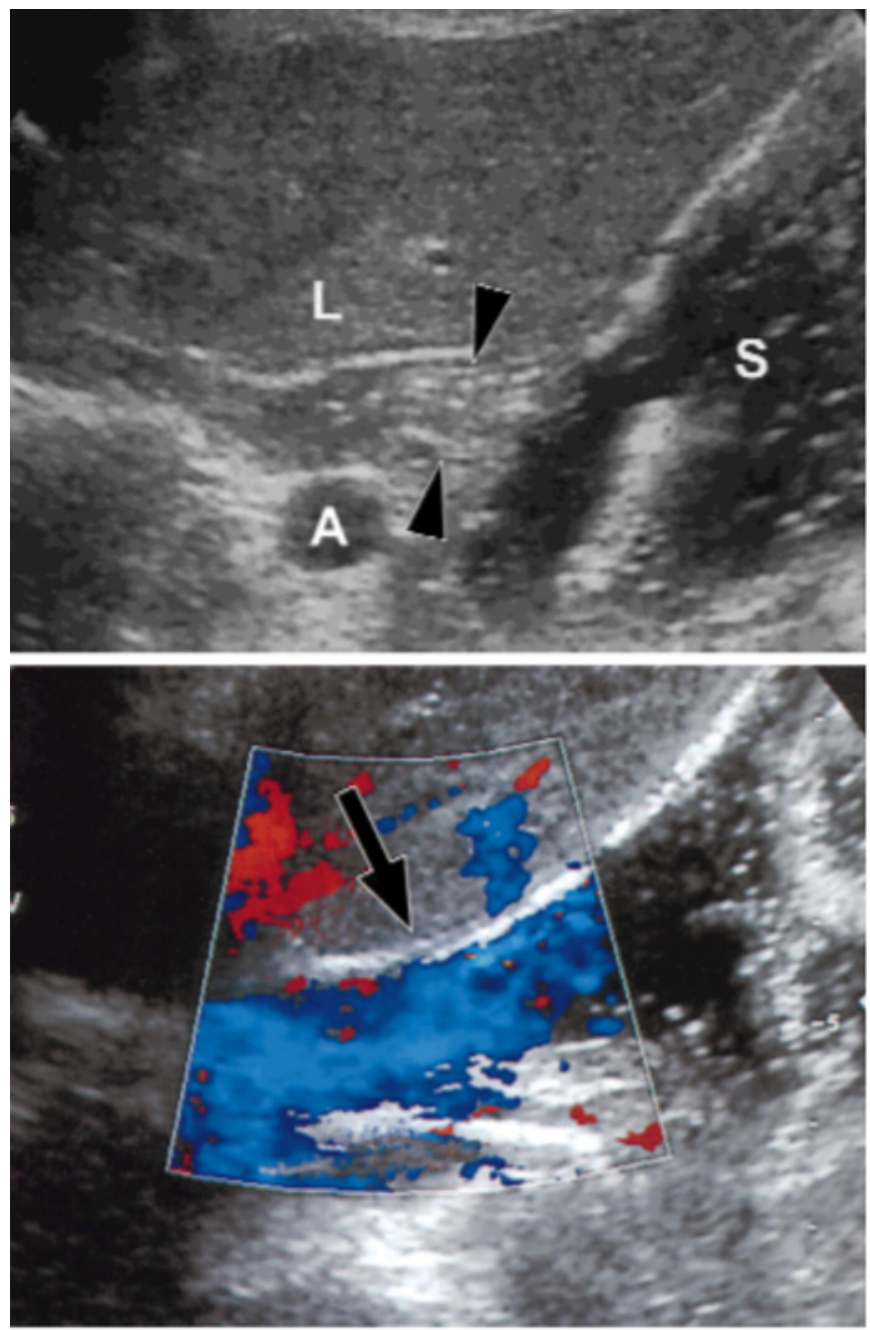

Figura 2. A - Ultrassonografia longitudinal obliqua do epigástrio exibe a junção gastroesofágica (pontas de setas). B - A cor azul no estudo Doppler ilustra um episódio de refluxo (seta) na junção gastroesofágica. $\mathrm{A}=$ aorta, $\mathrm{S}=$ estômago, $\mathrm{L}=$ fígado $^{25}$. 
Foi realizada uma análise de comparação de alguns artigos que falam da sensibilidade e especificidade, conforme tabela abaixo:

\begin{tabular}{lll}
\hline Autor & Sensibilidade & Especificidade \\
\hline Pezzati et al., 2005 & $38 \%$ & $100 \%$ \\
Sakuno T, 2002 & $87,5 \%$ & $97,4 \%$ \\
& & \\
Riccabona et al., 1992 & $100 \%$ & $87,5 \% \mathrm{p}<0,001$.
\end{tabular}

Um estudo feito por Pezzati et al. ${ }^{21}$ (2005), mostrou que a ultrassonografia tem baixa sensibilidade na detecção de RGE em prematuros e não deve substitua o monitoramento do $\mathrm{pH}$ em 24 horas pela ferramenta de diagnóstico definitivo. No entanto, a ultrassonografia tem uma especificidade muito alta e um valor preditivo positivo de 100\%. Já um estudo feito por Sakuno ${ }^{23}$, a ultrassonografia é capaz de diagnosticar o refluxo gastroesofágico, o seu número e duração, avaliando, de forma adequada, a anatomia da junção esofagogástrica e determinando, com precisão, o comprimento do esôfago intra-abdominal e o ângulo de His. Quando comparada à seriografia esofagogástrica duodenal, apresenta maior sensibilidade e valor preditivo negativo alto.

Já outro estudo feito por Riccabona et al. ${ }^{24}$ (1992) verificou que a ultrassonografia foi comparada à pHmetria e / ou esofagomanometria para avaliar a acurácia ultrassonografia no diagnóstico precoce de refluxo gastroesofágico. Trinta crianças com média de idade de 72 dias (21- 252 dias) foram estudados. Os resultados mostraram que a especificidade do diagnóstico ultrassonográfico foi de $87,5 \%$ e sensibilidade foi de $100 \%$ (com $\mathrm{P}<0,001$ ). A ultrassonografia provou ser útil no fornecimento tanto funcional como morfológico dados, além de resultados métricos de $\mathrm{pH}$.

\section{CONSIDERAÇÕES}

A ultrassonografia com Doppler pode ser usada como procedimento de escolha na investigação e controle da DRGE.

Ela é capaz de diagnosticar o refluxo gastroesofágico, o seu número e duração, avaliar de forma adequada, a anatomia da junção esofagogástrica e determinar com precisão o comprimento do esôfago intra-abdominal e o ângulo de Hiss.

\section{REFERÊNCIAS}

1. Lightdale JR; Gremse DA. Gastroesophageal reflux: management guidance for the pediatrician. Pediatrics, 2013; 131(5): 1684-95.

2. Junqueira JCF. Doença do refluxo gastroesofágico: diagnóstico e trata- mento. Rev Pediatria SOPERJ, 2007; 8(2).

3. Everhart JE. Gastroesophageal reflux disease. In: Everhart JE, editor. The burden of digestive diseases in the United States.US Department of Health and Human Services, Public Health Service, National Institutes of Health, National Institute of Diabetes and Digestive and Kidney Diseases. Washington, DC: US Government Printing Office. NIH Publication 2008; 09-6443: 96-72.

4. Moraes-Filho JPP et al. Guidelines for the diagnosis and management of gastroesophageal reflux disease: an evidence-based consensus. Arq. Gastroenterol., 2010; 47(1): 99-115.

5. Barlow WJ, Orlando RC. The pathogenesis of heartburn in nonerosive reflux disease: a unifying hypothesis. Gastroenterol, 2005; 128(3): 771-8. 6. Mohammadi A et al. Lack of utility of transabdominal ultrasound in the detection of gastroesophageal reflux disease-induced esophagitis in comparison with endoscopy. Ultrasound Q., 2011; 27 (2): 121-5.

7. Pimenta JR et al. Refluxo gastroesofágico. Rev Med Minas Gerais, 2016; 26(6): S76-S81.

8. Savino A et al. US in the diagnosis of gastroesophageal reflux in children. Pediatr Radiol., 2012; 42 (5): 515-24.

9. Sakate $\mathrm{M}$ et al. Avaliação do tempo de trânsito esofágico pelo ultrassom: influência do gênero e índice de massa corpórea. Radiol Bras, 2011; 44(6): 360-62.

10. Sakate $M$ et al. Refluxo gastroesofágico: estudo comparativo da receptividade e sensibilidade entre seriografia e ultrassonografia. Radiol Bras, 2009; 42(4): 245-8.

11. Fass $\mathrm{R}$ et al. Review article: supra-oesophageal manifestations of gastrooesophageal reflux disease and the role of night-time gastro-oesophageal reflux. Aliment Pharmacol Ther. 2004; 20(9): 26-38.

12. Gold BD. Review article: epidemiology and management of gastro-oesophageal reflux in children. Aliment Pharmacol Ther, 2004; 19(1):22 7.

13. Nelson SP et al. Prevalence of symptoms of gastroesophageal reflux during childhood: a pediatricpractice-based survey. Pediatric Practice Research Group. Arch Pediatr Adolesc Med, 2000. 15(2): 150-4.

14. Matrunola $\mathrm{M}$ et Al. Role of radiography and ultrasonography In: The diagnosis of the pediatric gastro-esophageal reflux disease. Eur Rev Med Pharmacol Sci, 2003; 7(5): 147-9.

15. Rosen R. Gastroesophageal reflux in infants: more than just a phenomenon. JAMA Pediatr, 2014; 168(1): 83-9.

16. Sakate $M$ et al. Um novo método de avaliação do "tempo esofágico" com ultrassonografia por abordagem externa. Radiol Bras, 2008; 41 (5): 309-12.

17. Benninga MA et al. Childhood functional gastrointestinal disorders: neonate / toddler. Gastroenterol., 2016; 15 pii: S0016-5085(16)00182-7.

18. Kaijser $\mathrm{M}$ et al. Preterm birth, low birth weight, and risk for esophageal adenocarcinoma. Gastroenterol. 2005; 128(3): 607-9.

19. Diaz-Rubio M et al. Symptoms of gastro-oesophageal reflux: prevalence, severity, duration and associated factors in a Spanish population. Aliment Pharmacol Ther., 2004; 19(1): 95-105.

20. Moki $\mathrm{F}$ et al. Association between reflux oesophagitis and features of the metabolic syndrome in Japan. Aliment Pharmacol Ther., 2007; 26(7): 1069-75

21. Pezzati $M$ et al. Diagnosis of gastro-oesophageal reflux in preterm in fants: sonography vs.pH-monitoring. Neonatology, 2007; 91 (3): 162-6. 22. Manabe $\mathrm{N}$ et al. Differences in salivary secretory function between pa- tients with erosive esophagitis and those with nonerosive reflux disease. J Gastroenterol Hepatol., 2018; 33(4): 807-13.

23. Sakuno T. A Ultrassonografia no diagnóstico do refluxo gastroesofágico em crianças [Mestrado]. Florianópolis: Universidade Federal de Santa Catarina; 2002.

24. Riccabona $\mathrm{M}$ et al. The role of sonography in the evaluation of gas tro-oesophageal reflux--correlation to pH-metry. Eur J Pediatr., 1992; 151 (9): 655-7.

25. Jang HS et al. Correlation of color Doppler sonographic findings with $\mathrm{pH}$ measurements in gastroesophageal reflux in children. J Clin Ultrasound . 2001; 29(4): 212-7. 


\title{
TERMO DE CONSENTIMENTO INFORMADO: CONCEITOS QUE O ULTRASSONOGRAFISTA DEVE SABER
}

\author{
INFORMED CONSENT FORM: CONCEPTS THAT THE \\ ULTRASONOGRAPHIST SHOULD KNOW
}

\author{
LEONARDO DE SOUZA PIBER ${ }^{1}$, MARCELO IVANDER ANDRADE WANDERLEY ${ }^{1}$, CARLA MICAELE DE FREITAS ${ }^{2}$, \\ ARTHUR SOUSA BEZERRA ${ }^{2}$, RONALDO SOUZA PIBER ${ }^{3}$
}

\section{RESUMO}

OBJETIVO: Apresentar conceitos sobre o termo de consentimento informado que são importantes à prática cotidiana médica.

MÉTODO: Trata-se revisão narrativa de literatura a respeito do termo de consentimento informado. Os conceitos discutidos foram selecionados de artigos disponíveis para acesso gratuito online, livros de doutrina jurídica, a legislação brasileira, bem como orientações e resoluções do Conselho Federal de Medicina.

RESULTADOS: A prática ou a obtenção do consentimento informado no exercício da medicina são próprias das últimas décadas e caracterizamo aperfeiçoamento da ética biomédica. Deve-se seguir a legislação, as orientações e as resoluções brasileiras que regem a relação médico-paciente e o consentimento informado. Contudo, não há regras estabelecidas que definam a forma deste termo.

CONCLUSÕES: A validade do termo de consentimento informado dependerá do profissional informar e esclarecer, além da vontade do paciente.

\author{
PALAVRAS-CHAVE: TERMO DE CONSENTIMENTO INFORMADO, LEGISLAÇÃO BRASILEIRA, \\ ÉTICA MÉDICA, BIOÉTICA, DIREITO MÉDICO.
}

\begin{abstract}
OBJECTIVE: The goal is to present concepts about the informed consent form that are important to the medical daily practice. online, legal doctrine books, Brazilian law, as well as guidelines and resolutions of the Federal Council of Medicine. be followed. However, there are no established rules that define the form of this term. the patient.

KEYWORDS: INFORMED CONSENT FORM; BRAZILIAN LEGISLATION; MEDICAL

ETHICS; BIOETHICS; MEDICAL LAW
\end{abstract}

METHOD: This is a narrative literature review about the informed consent form. The concepts discussed were selected from articles available freely

RESULTS: The practice or obtention of informed consent in the practice of medicine is typical of the last decades and characterizes the improvement of biomedical ethics. Brazilian legislation, guidelines and resolutions governing the doctor-patient relationship and informed consent form should

CONCLUSION: The validity of the informed consent form will depend on the professional to inform and clarify it, in addition to the willingness of

\section{INTRODUÇÃO}

Desde a Antiguidade, observam-se poucos e esparsos relatos e referências de situações nas quais o paciente era informado e esclarecido sobre procedimentos médicos que lhe eram indicados. Também pouco consta sobre a consideração e a importância dadas, pelo médico, à manifestação de vontade do paciente de anuir ao procedimento recomendado ou de recusá-lo.

\footnotetext{
1. CDB Inteligência Diagnóstica.

2. Universidade Santo Amaro, São Paulo, Brasil.

3. Faculdade de Direito, da Universidade de

São Paulo, Brasil.
}

Endereço para correspondência:

Leonardo Piber

Rua Marechal Deodoro, 135 apto 62B Santo Amaro

São Paulo - CEP 04738-000

Email:1piber@prof.unisa.br 
Nos anos 1950, alguns eventos jurídicos de grande repercussão sucederam nos Estados Unidos, resultando em mudanças comportamentais na relação médico-paciente. A expressão informed consent surgiu da decisão judicial do caso Salgo v. Leland Stanford Jr. University Board of Trustees, em 1957. ${ }^{1}$

Também se observa que os documentos éticos e legais mais expressivos foram concretizados a partir da década de 1970, coincidindo com a queda dos regimes ditatoriais na Europa, entre estes documentos destacam-se: o Código de Nuremberg (1947), o Relatório de Belmont (1978), a Declaração de Helsinki (1964), e a Declaração Universal dos Direitos Humanos (1948).

$\mathrm{Na}$ atual realidade, os profissionais da saúde baseiam-se tanto no Código de Ética Médica, quanto na legislação pátria para melhor assegurar a autonomia do paciente.

O Código de Ética Médica refere-se ao consentimento informado do paciente, em diversas oportunidades: qualifica a autonomia do paciente, nas escolhas referentes à assistência médica, como um princípio deontológico fundamental da ética médica, e veda, ao médico, deixar de obter consentimento do paciente, ou de seu representante legal, após esclarecê-lo sobre o procedimento a ser realizado, salvo em caso de risco iminente de morte. ${ }^{2}$

Dessa forma, é importante mencionar que a principal causa do litígio rotulado de erro do médico advém da insatisfatória relação médico-paciente, fruto da inabilidade do profissional de prover adequada comunicação interpessoal e primar pelo atendimento de boa qualidade. Nos dias de hoje, essa relação tende a ser impessoal, de desconfiança, mútua e recíproca. ${ }^{3}$

A elaboração do termo de consentimento informado (TCI) é uma obrigação do profissional da saúde que prestará o serviço, sendo um ato médico próprio e não do hospital, clínica ou laboratório, onde irá se esclarecer ao pa- ciente acerca dos benefícios, riscos dos procedimentos e tratamentos médicos aos quais será submetido, o que fortalece a sua confiança. ${ }^{3}$

Certo é que, não fazê-lo, pode o profissional ser caracterizado como agente de má-fé, culposa ou dolosamente, pois somente a partir do conhecimento exato do que the é oferecido, bem como dos riscos e benefícios a que será submetido - é que o paciente concorda ou não com a realização do procedimento, contemplando, assim, o princípio bioético da autonomia. ${ }^{4}$

Vale dizer que, a falha ou no dever de informar ou na obtenção do consentimento, tornam-se hoje, o ponto focal dos processos contra médicos em muitos países. ${ }^{5}$

Quando se tratar de procedimento invasivo, em especial os realizados através da imaginologia intervencionista, os quais podem causar ao paciente, além de ansiedade e desconforto, é de extrema necessidade que os efeitos colaterais elencados na literatura médica sejam muito bem esclarecidos $^{5}$, motivando, assim, a importância da aprendizagem e reciclagem da classe médica através deste artigo.

\section{OBJETIVO}

Apresentar conceitos sobre o termo de consentimento informado que são importantes à prática cotidiana dos médicos ultrassonografistas.

\section{MÉTODO}

Trata-se revisão narrativa de literatura a respeito do termo de consentimento informado. Foram selecionados artigos disponíveis para acesso gratuito online, livros de doutrina jurídica, a legislação brasileira, bem como orientações e resoluções do Conselho Federal de Medicina.

\section{RESULTADOS E DISCUSSÃO}

O Conselho Federal de Medicina dispôs à classe médica a Recomendação $n^{\circ} 1 / 2016$, que trata sobre a obtenção do consentimento na assistência médica, justificando a iniciativa de elaborar orientações aos médicos sobre o tema, pelos seguintes fatos:

a) A evolução, o desenvolvimento e a ampliação do catálogo de direitos humanos, refeito a partir do conhecimento das atrocidades perpetradas durante a Segunda Guerra Mundial, inclusive experimentos em seres humanos; ${ }^{6}$

b) Os documentos que amparam e estipulam garantias, direitos, deveres e referenciais éticos em relação aos seres humanos; ${ }^{6}$

C) Os quatro referenciais básicos da bioética: os princípios da (i) autonomia, da (ii) não maleficência, da (iii) beneficência e da (iv) justiça; ${ }^{6}$

d) A garantia da dignidade da pessoa humana; ${ }^{6}$

e) O Código de Ética Médica e a necessidade de complementar as orientações nele contidas; ${ }^{6}$

f) A necessidade de firmar, para todos os profissionais e instituições de saúde, o fato de que o paciente é titular de direitos, inclusive de decidir, de forma livre e autônoma, após ser suficientemente informado e esclarecido, sobre sua submissão a qualquer terapêutica, procedimento clínico ou cirúrgico que lhe seja recomendado. ${ }^{7}$

Dessa forma, o consentimento informado tornou-se prática médica obrigatória, equiparando-se ao status jurídico da liberdade, igualdade e dignidade humana, por se tratar de direito fundamental do paciente. ${ }^{8}$

O termo de consentimento informado é mais que uma simples faculdade do paciente de recusar ou não o médico ou um tratamento. É um processo de diálogo, de recíprocas trocas de informações entre médico e paciente para, assim, iniciar o tratamento. ${ }^{9}$

No diálogo médico-paciente, o médico elucidará todas as informações sobre o tratamento a que o paciente será submetido, informando todos os riscos, os efeitos colaterais e as consequências do tratamento. Além disso, é necessário que o médico não informe apenas um tratamento, mas que forneça informações sobre outros procedimentos possíveis, ou que o paciente receba até mesmo uma segunda opinião. ${ }^{10}$

Para que o termo de consentimento informado seja completo, faz-se necessário que o paciente obtenha o direito de 
escolher a forma de intervenção com base nas informações recebidas no decorrer do diálogo. ${ }^{10}$

A sentença do Tribunal de Nuremberg do ano de 1947 resume especificamente o que vem a ser o termo de consentimento informado e voluntário, demonstrando que este é essencial, uma vez que é o meio pelo qual o paciente exerce o seu direito de escolha após receber todas as informações do procedimento a que se submeterá. ${ }^{10}$

Logo, o termo de consentimento informado constitui o direito do paciente de participar das decisões pertinentes ao seu tratamento, devendo o médico alertá-lo sobre os benefícios e riscos do procedimento. ${ }^{11}$

Diante da subjetividade dessa relação, a forma se torna secundária ao objetivo real do instituto. Porém, tendo em vista a necessidade de defesa documental em processo judicial, a prática habitual de se exigir formulários escritos em instituições de saúde deve ser levada em consideração. ${ }^{12}$

Dessa forma, levando-se em consideração a necessidade de prova documental, as principais características são 13: a) Escrito - contendo todos os riscos e todos os benefícios escritos, não bastando conter a informação "o paciente ficou ciente de todos os riscos e benefícios";

b) Compreensível - compreensível para o paciente (ser claro, pelo princípio da informação - sem termos puramente técnicos);

c) Informativo - com riscos e benefícios de alcance às diversas culturas e classes sociais dos pacientes;

d) Ausência de vícios - livre de qualquer tipo de dolo, coação, intimidação, ameaça, lesão, simulação, erro, etc.

O termo de consentimento informado tem como objetivo a proteção da: (i) dignidade da pessoa humana, (ii) autonomia privada, (iii) beneficência, (iv) não maleficência e (v) justiça; esses princípios devem ser utilizados como moldes na atuação do médico. ${ }^{14}$

O princípio da autonomia é a essência do termo de consentimento informado, uma vez que prescreve o respeito pela legítima autonomia das pessoas, pelas suas escolhas e decisões; estas devem ser verdadeiramente autônomas ou livres. Sendo assim, para que haja a autonomia, é necessária a vontade livre da pessoa, sem defeitos ou vícios que possam macular o seu querer. ${ }^{14}$

Já o princípio da beneficência descreve que o médico deve buscar o melhor tratamento sem considerar as manifestações pessoais dos pacientes e o princípio da não maleficência, corresponde ao fazer somente o bem ao paciente. ${ }^{15}$

O termo de consentimento informado, na ótica dos princípios da dignidade da pessoa humana e da justiça, tem como finalidade o exercício do direito fundamental à integridade física e moral da pessoa/paciente. ${ }^{15}$

É discutível, quando o paciente não pode falar por si ou é incapaz de entender o ato que se vai executar, estando o médico obrigado a conseguir o consentimento de seus responsáveis legais, cujo nome é o consentimento substituto.

A capacidade civil definida como aptidão para exercera- tos da vida civil está delimitada nos artigos $3^{\circ}$ e $4^{\circ}$ do Código Civil Brasileiro, que exclui de forma absoluta os me- nores de 16 anos e os portadores de doenças mentais e de forma relativa os maiores de 16 e menores de 18 anos. Na ausência da capacidade civil é necessária a obtenção do consentimento substituto para a execução de procedimentos médicos. O titular desse direito varia conforme a situação fática apresentada e nem todo tipo de parentesco confere tal prerrogativa. ${ }^{16}$

Caso o menor tenha sido emancipado pelos pais, mediante instrumento público ou sentença do juiz, ele não dependerá mais de responsáveis para consentir.

A participação do menor na obtenção do assentimento deve ser incentivada. Sugere-se, inclusive, seja obtido o assentimento de forma lúdica, com figuras e quadrinhos, para exercício da melhor compreensão do paciente. ${ }^{17}$

Nos demais casos de incapacidade, a participação dos envolvidos também deverá ser estimulada, a partir da avaliação do grau de comprometimento da capacidade de entendimento dos pacientes.

Pacientes que, por qualquer razão, apresentam maior dificuldade em entender a informação devem receber explicações mais detalhadas e adequadas a seu grau de compreensão.

O critério para a determinação da capacidade para consentir, ou mesmo para recusar, compreende a avaliação da habilidade do indivíduo para, ao receber informações, processá-las de modo a compreender as questões postas e avaliar racionalmente as possibilidades apresentadas, ou seja, avaliar valores, entender riscos, consequências e benefícios do tratamento cirúrgico ou terapêutico a que será submetido. $^{18}$

Podem ocorrer situações em que o paciente negue seu consentimento para a realização de determinado procedimento médico, com graves consequências para sua saúde. Nesses casos, havendo dúvidas sobre sua capacidade de decisão, convém que o médico solicite avaliação especializada. Se o paciente é capaz e negar seu consentimento, o médico deve registrar sua decisão por escrito; propor alternativas, se existentes; dar-lhe tempo para reflexão; explicar o prognóstico e as consequências; e, finalmente, preencher um termo de recusa.

Em relação à legislação, destacam-se os seguintes artigos:

a) Artigo 1o da Constituição Federal: A República Federativa do Brasil, formada pela união indissolúvel dos Estados e Municípios e do Distrito Federal, constitui-se em Estado Democrático de Direito e tem como fundamentos: (...) III - a dignidade da pessoa humana. ${ }^{19}$

b) Artigo 5, inciso X, da Constituição Federal: Todos são iguais perante a lei, sem distinção de qualquer natureza, garantindo-se aos brasileiros e aos estrangeiros residentes no País a inviolabilidade do direito à vida, à liberdade, à igualda- de, à segurança e à propriedade, nos termos seguintes: (...) X - são invioláveis a intimidade, a vida privada, a honra e a imagem das pessoas, assegurado o direito a 
indenização pelo dano material ou moral decorrente de sua violação. ${ }^{19}$

c) Artigo 15 do Código Civil: Ninguém pode ser constrangido a submeter-se, com risco de vida, a tratamento mé- dico ou a intervenção cirúrgica. ${ }^{20}$

d) Artigo $6^{\circ}$ do Código de Defesa do Consumidor: São direitos básicos do consumidor: (...) III - a informação adequada e clara sobre os diferentes produtos e serviços, com especificação correta de quantidade, características, compo- sição, qualidade, tributos incidentes e preço, bem como so- bre os riscos que apresentem. ${ }^{21}$

e) Artigo. 22 da Resolução CFM n. 2.217/2018: É vedado ao médico: Deixar de obter consentimento do paciente ou de seu representante legal após esclarecê-lo sobre o procedimento a ser realizado, salvo em caso de risco iminente de morte. ${ }^{22}$

f) Artigo. 24 da Resolução CFM n. 2.217/2018: É vedado ao médico: Deixar de garantir ao paciente o exercício do direito de decidir livremente sobre sua pessoa ou seu bem-estar, bem como exercer sua autoridade para limitálo. ${ }^{22}$

g) Artigo. 31 da Resolução CFM n. 2.217/2018: É vedado ao médico: Desrespeitar o direito do paciente ou de seu representante legal de decidir livremente sobre a execução de práticas diagnósticas ou terapêuticas, salvo em caso de iminente risco de morte. ${ }^{22}$

\section{CONCLUSÕES}

Portanto, o consentimento para o ato médico é a anuência dada pelo paciente ao profissional que observa os requisitos supracitados. Assim, sua validade dependerá do cumprimento do dever de informação do profissional e do esclarecimento e vontade do paciente.

Não existe, em lei específica ou no Código de Ética Médica, forma definida para o consentimento informado de uma maneira geral. Isso se baseia na ideia de propiciar o contato entre o profissional e o paciente, fortalecendo, as- sim, a relação.

\section{REFERÊNCIAS}

1. Beauchamp TL, Faden RR. History of informed consent. In: Reich WT, editor. Encyclopedia of Bioethics. New York: Simon \& Shuster MacMillan; 1995.

2. Vaz W, Reis C. Consentimento informado na relação médico-pacien- te. Revista Jurídica Cesumar - Mestrado. 2008; 7(2): 489-514.

3. Pereira AGD. O dever de esclarecimento e a responsabilidade médi- ca. Revista dos Tribunais, São Paulo. 2005; 94(839):69-109.

4. Kfouri Neto M. Responsabilidade Civil do Médico. 8 ed. São Paulo: Ed. Revista dos Tribunais, 2013.

5. Tsuji FH. Grau de satisfação e intensidade da dor dos pacientes submetidos à biópsia prostática transretal guiada por ultrassom com uso de sedação e analgesia endovenosa com midazolam e citrato de fentanila. 2012. Disponível em: https://repositorio.unesp.br/handle/11449/97710, acessado 20 de Março 2020.

6. Brasil. Conselho Federal de Medicina - Recomendação n¹/2016 - Disponível em: https://sistemas.cfm.org.br/normas/visualizar/reco- mendacoes/BR/2016/1, acessado 20 de Março de 2020.

7. Junges, JR. Exigências éticas do consentimento informado. Revista bioética. 2007; 15(1):77-82.

8. Oliveira V, Pimentel D, Vieira M. O uso do termo de consentimento livre e esclarecido na prática médica. Revista Bioética. 2010; 18(3):

705-24.

9. Fernandes CF, Pithan LH. O consentimento informado na assistência médica e o contrato de adesão: uma perspectiva jurídica e bioética. Revista HCPA. 2007; 27(2): 78-82.

10. Clotet J - O Consentimento informado nos comitês de ética em pesquisa e na prática médica: conceituação, origens e atualidade. Bioética, 1995

11. Albuquerque A. Violação aos direitos dos pacientes: análise da jurisprudência no Brasil. Revista Direitos Fundamentais e Alteridade. 2019; 3(1): 7-33.

12. Duarte R. Consentimento informado: um conceito incompreendi-

do breve ensaio sobre a judicialização da medicina e suas conse- quências na relação médico-paciente. Revista de Estudos Jurídicos UNESP. 2015; 19(29): 1-10.

13. Pereira AG - A capacidade para consentir: um novo ramo da capa- cidade jurídica, em: Pereira AG. Comemorações dos 35 anos do Código Civil e dos 25 anos da Reforma de 1977, 1a Ed, Coimbra, Coimbra Ed, 2004.

14. Nunes LNBT. O consentimento informado na relação médico-pa- ciente: respeitando a dignidade da pessoa. Ed. Padma LTDA, RTDC, 2007.

15. Rodrigues JV. O consentimento informado para o acto médico no ordenamento jurídico português (elementos para o estudo da mani- festação da vontade do paciente). Coimbra Ed., 2001.

16. França GV. Direito Médico. 12 ed. Rio de Janeiro: Forense, 2014: 277.

17. Aguiar M, Barboza AS. Autonomia bioética de crianças e adolescen- tes e o processo de assentimento livre e esclarecido. Revista Brasilei- ro de Direito Animal. 2017; 12(2): 17-42.

18. Sampaio CV, Menezes JB. Autonomia da pessoa com deficiência e os atos de disposição do próprio corpo. Revista Jurídica Cesumar - Mestrado. 2018; 18(1): 133-157.

19. Brasil. Constituição Federal. Constituição da República Federativa do Brasil de 1988. Disponível em: http://www.planalto.gov.br/cci- vil_03/ constituicao/constituicaocompilado.htm, acessado dia 20 de Março de 2020.

20. Brasil. Código Civil. Disponível em: https://www.jusbrasil.com. br/topi$\cos / 10729769 /$ artigo-15-da-lei-n-10406-de-10-de-janeiro- -de-2002

21. Brasil. Código de Defesa do Consumidor. Disponível em: https:// www. jusbrasil.com.br/topicos/10607666/artigo-6-da-lei-n-8078-de- -11-desetembro-de- 1990

22. Brasil. Conselho Federal de Medicina - Art. 22 da Resolução CFM n. 2.217/2018. Disponível em: https://portal.cfm.org.br/images/PDF/ cem2019.pdf, acessado dia 20 de Março de 2020.

23. Brasil. Conselho Federal de Medicina - Art. 24 da Resolução CFM n. 2.217/2018. Disponível em: https://portal.cfm.org.br/images/PDF/ cem2019.pdf, acessado dia 20 de Março de 2020.

24. Brasil. Conselho Federal de Medicina - Art. 31 da Resolução CFM n. 2.217/2018. Disponível em: https://portal.cfm.org.br/images/PDF/ cem2019.pdf, acessado dia 20 de Março de 2020. 

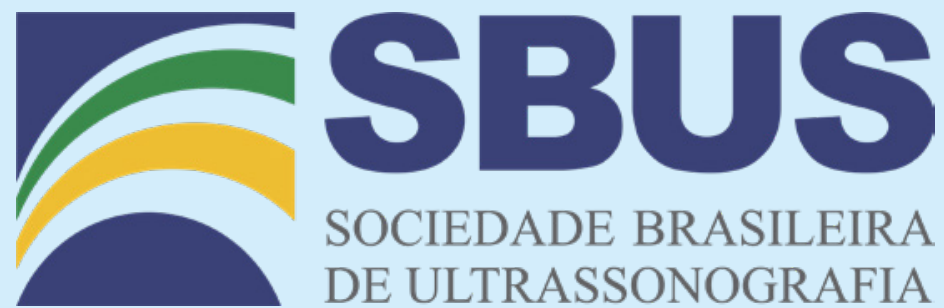

SOCIEDADE BRASILEIRA DE ULTRASSONOGRAFIA 

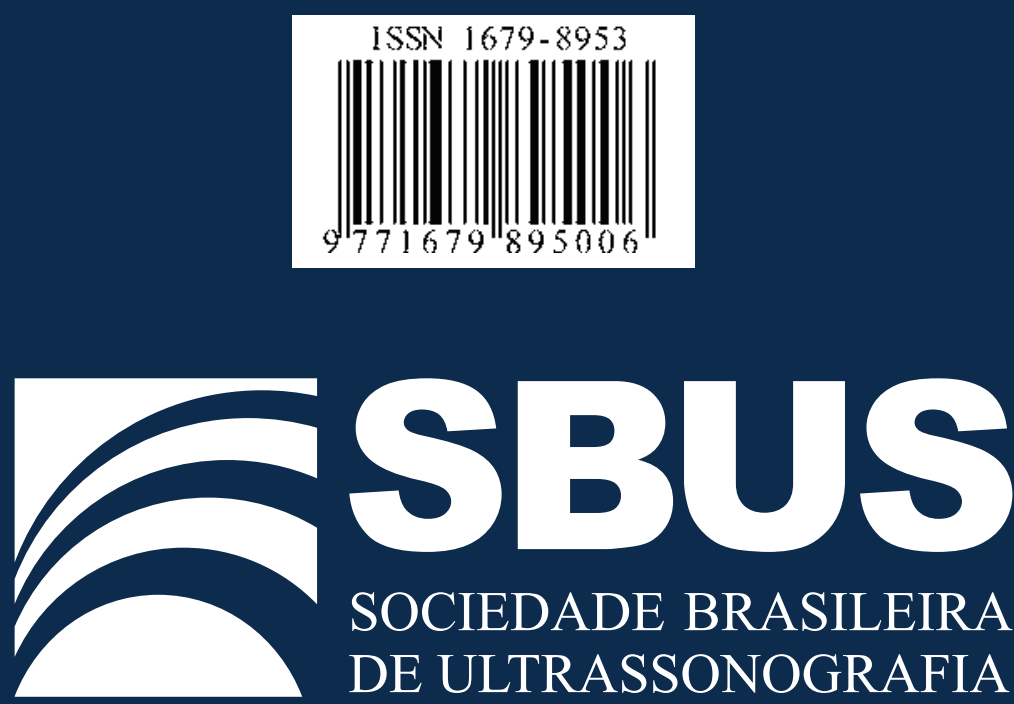